University of Louisville

ThinkIR: The University of Louisville's Institutional Repository

$12-2013$

\title{
Alignment study of Kentucky's mathematics placement examinations and entry level credit-bearing mathematics course examinations.
}

Lisa Conn

University of Louisville

Follow this and additional works at: https://ir.library.louisville.edu/etd

\section{Recommended Citation}

Conn, Lisa, "Alignment study of Kentucky's mathematics placement examinations and entry level creditbearing mathematics course examinations." (2013). Electronic Theses and Dissertations. Paper 269. https://doi.org/10.18297/etd/269

This Doctoral Dissertation is brought to you for free and open access by ThinkIR: The University of Louisville's Institutional Repository. It has been accepted for inclusion in Electronic Theses and Dissertations by an authorized administrator of ThinkIR: The University of Louisville's Institutional Repository. This title appears here courtesy of the author, who has retained all other copyrights. For more information, please contact thinkir@louisville.edu. 


\title{
ALIGNMENT STUDY OF KENTUCKY'S MATHEMATICS PLACEMENT EXAMINATIONS AND ENTRY LEVEL CREDIT-BEARING MATHEMATICS COURSE EXAMINATIONS
}

By

\section{Lisa Conn}

B.A., Morehead State University, 1993

M.A., Morehead State University, 1998

\begin{abstract}
A Dissertation
Submitted to the Faculty of the

College of the Education and Human Development of the University of Louisville in Partial Fulfillment of the Requirements

for the Degree of
\end{abstract}

Doctor of Philosophy

Department of Middle and Secondary Education

College of Education and Human Development

University of Louisville

December 2013 



\title{
ALIGNMENT STUDY OF KENTUCKY'S MATHEMATICS PLACEMENT EXAMINATIONS AND ENTRY LEVEL CREDIT-BEARING MATHEMATICS COURSE EXAMINATIONS
}

\author{
By \\ Lisa Conn \\ B.A., Morehead State University, 1993 \\ M.A., Morehead State University, 1998
}

A Dissertation Approved on

May 29, 2013

By the following Dissertation Committee

Dissertation Director: William S. Bush

Dr. Jennifer Bay-Williams

Dr. Thomas Tretter

Dr. Michael Mays

Dr. Susan Peters 


\section{DEDICATION}

This dissertation is dedicated to my late father, Charles F. Stansbury, who always supported my educational endeavors. 


\section{ACKNOWLEDGEMENTS}

I would like to thank my dissertation chairman, William S. Bush, for his guidance and feedback throughout this process, always helping me improve my writing and giving me clear direction. I would also like to thank the other members of my committee: Dr. Jennifer Bay-Williams, Dr. Thomas Tretter, Dr. Michael Mays, and Dr. Susan Peters. Their patience and hours of reading were greatly appreciated. Additionally, I would like to thank my husband Mike, daughters Taylor and Faith, and my mother Bernadette for all

of the time they allowed me to spend away from home during the summer months and long work nights. Without their support, I would not be able to complete this educational journey. 


\begin{abstract}
ALIGNMENT STUDY OF KENTUCKY'S MATHEMATICS PLACEMENT EXAMINATIONS AND ENTRY LEVEL CREDIT-BEARING MATHEMATICS COURSE EXAMINATIONS
\end{abstract}

\title{
Lisa Conn
}

May 29, 2013

This research alignment study compares content assessed on course finals from Kentucky public universities in highest level remedial mathematics courses and content assessed on college placement examinations. These assessments are used to determine if a student is ready for credit-bearing courses at a university. The study addressed the following four research questions: (1) What mathematical prerequisite knowledge do state universities consider necessary to be college ready? Specifically 1a) What content domains do the state universities emphasize in their remediation courses?; 1b) Is there consistency across the state public universities with regard to the content domains?; and (2) How well do Kentucky's mathematics placement assessments (ACT, COMPASS, and KYOTE) align in both content and cognitive demand with four-year universities' Kentucky Mathematics College Readiness Expectations (KM-CRE)?

The study was implemented in two phases. In Phase 1, course finals in the highest mathematics remediation class offered at five Kentucky universities were analyzed using Common Core State Standards (CCSS). Phase 2 of the study involved an alignment analysis between the universities' identified KM-CRE and Kentucky's approved college 
placement examinations: ACT, KYOTE, and COMPASS. The study is framed using Webb's alignment modeling the areas of (1) categorical concurrence, (2) balance of representation, (3) range of knowledge, and (4) depth of knowledge. Findings suggested that consistency across universities in content emphasis exists. Examinations were heavily weighted in Algebra readiness (Expressions and Equations, Functions, and Algebra). Findings in the alignment study suggested some content alignment existed but more alignment is needed through intentional assessment of college ready content. Additionally, all placement examinations revealed a strong cognitive complexity alignment to KM-CRE. Implications of this study suggest the redesign of the placement examinations to assess the content knowledge necessary for college success. 


\section{TABLE OF CONTENTS}

PAGE

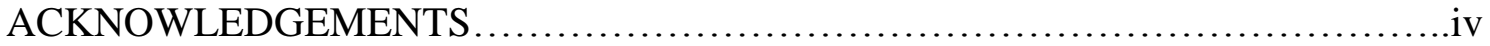

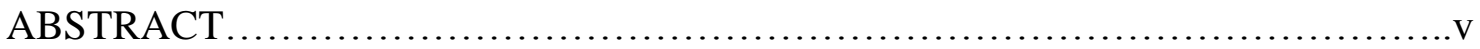

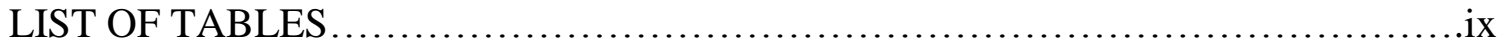

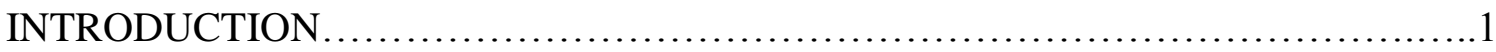

Aligning Standards and Assessments....................................2

Norman Webb's Alignment Model..........................................2

College Readiness..................................................4

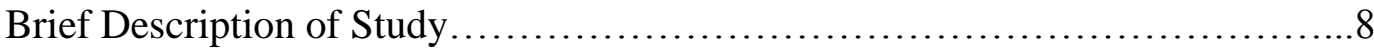

Purposes of the Study and Research Questions...............................

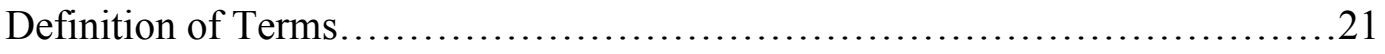

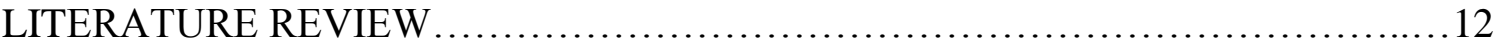

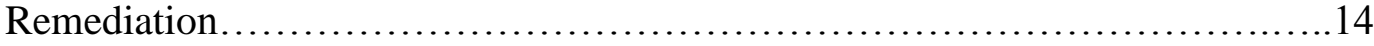

Examinations......................................................... 18

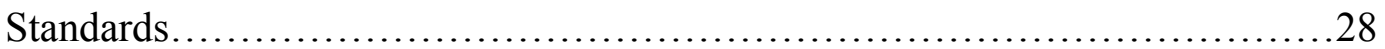

Alignment......................................................... 31

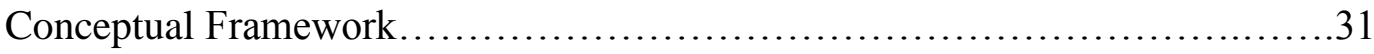

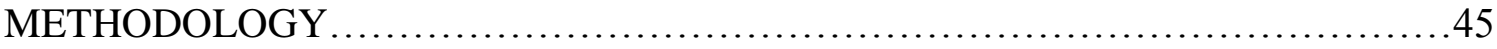

Placement Examination Data Collection Procedures.........................47

Instrumentation.......................................................... 49 
Accurate Coding of Test Items......................................52

Data Analysis....................................................53

Limitations.......................................................... 57

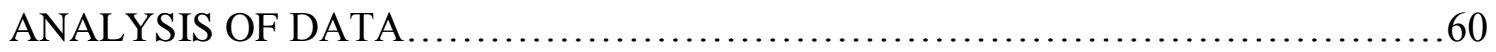

Part I - Comparison of Expectations among Kentucky Universities............60

Part II - Alignment Study........................................ 80

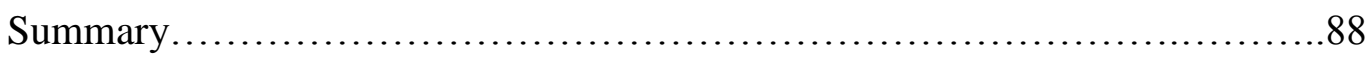

FINDINGS, IMPLICATIONS AND LIMITATIONS ..........................90

Research Findings............................................... 91

Implications on Future Assessments .................................99

Limitations...................................................... 100

Future Studies..................................................101

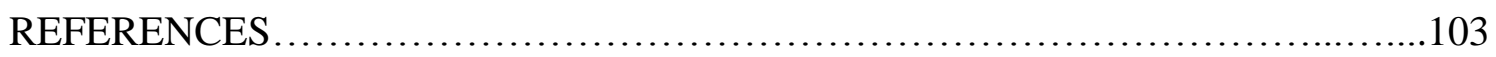

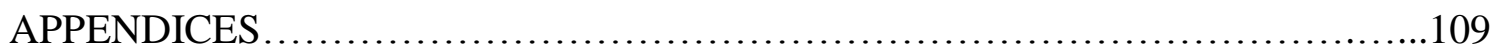

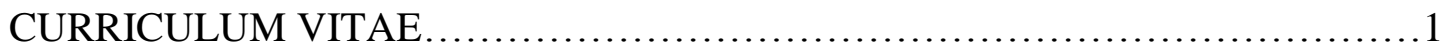




\section{LIST OF TABLES}

TABLE

PAGE

1. Minimal Competency Mathematics Scores on Placement Examinations..14

2. COMPASS Pre-Algebra Scores to ACT Math Concordance 24

3. Percent of Emphasis on CCSS Domains............................50

4. Categorical Concurrence Analysis Table.............................51

5. CCSSM Coding Instrument Hit Counts for Universities.................53

6. University 1-CCSS Matrix of Percent of Emphasis.....................62

7. University 2-CCSS Matrix of Percent of Emphasis....................63

8. University 3-CCSS Matrix of Percent of Emphasis.....................63

9. University 4-CCSS Matrix of Percent of Emphasis.....................61

10. University 5-CCSS Matrix of Percent of Emphasis.....................64

11. Percent of Emphasis of CCSS Mathematics Content for 5 Public Universities..................................................65

12. Kentucky Mathematics College Readiness Expectations...............70

13. Categorical Concurrence Analysis Table.............................81

14. Range of Knowledge Analysis Table...............................82

15. Balance of Representation Index Values ..........................84

16. Percent of DOK levels that meet or exceed KM-CRE DOK Level........86

17. CCSS Consistency Table across 5 Universities..................... 92

18. Percent of Emphasis Table across Grade Bands........................ 92 
19. Percent of Emphasis of CCSS Domains.............................93 


\section{CHAPTER I INTRODUCTION}

"The likelihood that students will make a successful transition to the college environment is often a function of their readiness - the degree to which previous educational and personal experiences have equipped them for the expectations and demands they will encounter in college" (D. T. Conley, 2008, p. 3). Each year an increasing number of students enter college lacking readiness and are underprepared (Attewell, Lavin, Domina, \& Levey, 2006). More and more occupations require a fouryear degree and mathematics is often the gatekeeper to higher education. As a response to this trend, college administrators and faculty have implemented more mathematics remediation courses to provide students a chance to obtain the necessary content knowledge and college preparedness. The determining factor for placement of students in remedial coursework is often a placement examination.

In Kentucky, the placement examinations used are American College Test (ACT), COMputer-adapted Placement ASSssessment (COMPASS), and KentuckY Online Testing Examination (KYOTE). State legislation requires minimum competency scores for each of these examinations to enter a credit bearing college course at a state university. Although Kentucky legislators have established minimum competency scores, faculty at each university specifically plan and design their remediation courses to prepare students for the university's credit-bearing coursework. What is unclear is whether the prerequisite knowledge determined by faculty at each university matches the 
knowledge assessed on placement examinations. Since either passing a remedial course at a university or meeting minimal competency scores on a placement examination allows students to enroll in college credit bearing courses, these examinations should all measure the same core prerequisite knowledge that is essential to being successful in nonremedial, credit-bearing college mathematics courses.

\section{Aligning Standards and Assessments}

The mathematical content knowledge expectations or standards of college success determined by universities in Kentucky should be aligned with the state mandated placement examinations. Zucker, Shileds, Adelmand and Powell (1995) define alignment in the following terms:

Alignment is the degree to which expectations and assessments are in agreement and serve in conjunction with one another to guide the system toward students learning what they are expected to know and do (p. 2).

The success of standards-based reform relies on alignment among standards and standards-based assessments (Rothman, 2003). For reliable evaluation of student knowledge to occur, standards must align with the assessments administered to students. If standards and assessments do not align, then the results may indicate a misleading representation of student abilities.

\section{Norman Webb’s Alignment Model}

\section{Criteria and Alignment Definitions}

Norman Webb (1997) in his publication of Criteria for Alignment of Expectations and Assessments in Mathematics and Science Education defined criteria for evaluating the alignment between assessments and expectations. The criteria were developed by an 
expert panel in a collaborative effort of the Council of Chief School Officers and the National Institute for Science Education. Webb (1997) indicated that "two or more systems are aligned if they are in agreement or match each other. Alignment not only refers to a comparison between an assessment instrument and a curriculum, but also extends to a set of assessment instruments or the assessment system" (p. 4). Webb (1997) defined expectations as "what student should know about mathematics and science and what they should be able to do with that knowledge" (p. 4).

\section{Alignment Study Descriptors}

When students enter a credit-bearing college mathematics course, they are expected to know and be able to perform the prerequisites and meet established criteria or standards. This judgment is often made based on a placement examination score. Webb (1997) encouraged educational systems to create a formal process for evaluating the alignment between expectations (standards) and assessments and provided various document analyses that focus on descriptors of content. He recommended descriptors such as categorical concurrence, balance of representation, range of knowledge, and depth of knowledge. Categorical concurrence indicates that the same content occurs in both expectations and assessments. Balance of representation indicates that the degree of importance for each expectation and assessment is the same. All expectations should be assessed at the level in which they are emphasized. Range of knowledge correspondence indicates that a standard with multiple objectives occurs consistently across all objectives. Further, Webb states that all objectives within a standard should be assessed. Depth of knowledge indicates that the application and reasoning levels are consistent across assessments and expectations. 


\section{College Readiness}

In the past, approximately 40 percent of all undergraduate students have enrolled in a remedial course at some point in their college career (Attewell et al., 2006; Bettinger \& Long, 2005; Horn, McCoy, Campbell, \& Brock, 2009; Illich, Hagan, \& MeCallister, 2004; Waycaster, 2001). According to the Kentucky Council on Postsecondary Education, fifty percent of all students enrolled in Kentucky public universities in 2006 needed one or more remedial courses ("Developmental Education Needs in the 2006 Entering Cohort," 2008). Furthermore, approximately 41 percent of students need remediation in mathematics.

Prior to 2010, most universities in Kentucky classified students as underprepared if they scored below 18 on any component of the ACT and required those students to enroll in appropriate remediation courses. In an effort to reduce the increasing number of students enrolling in remedial courses, the Kentucky legislature passed Senate Bill 1 in 2009 to address student college and career readiness (Patterson, 2011). Senate Bill 1, entitled 'Unbridled Learning' and passed in 2009, “....mandated for the Kentucky Council on Postsecondary Education (CPE), the Kentucky Board of Education (KBE), and the Kentucky Department of Education (KDE) to develop a unified strategy to reduce the high college remediation rates of recent high school graduates by at least fifty percent before 2014" ("Senate Bill 1 (2009) College and Career Readiness," 2011). The Kentucky Department of Education passed two administrative regulations in support of Senate Bill 1 ("Minimum requirements for high school graduation," 2011; "Next generation learners," 2011). Administrative regulation 703 KAR 5: 200 required the implementation of a new statewide assessment to measure student achievement. In 
addition, administrative regulation 704 KAR 3:305 described minimum requirements for high school graduation and high school remediation and testing for underprepared students.

Together these regulations required all students in Kentucky public schools to take the American College Test (ACT) in the spring of their junior year. As mandated by Unbridle Learning, the Kentucky Council on Postsecondary Education determined minimal competency scores for the ACT placement examination to determine college readiness ("Senate Bill 1 (2009) College and Career Readiness," 2011). Minimal competency scores on norm-referenced examinations are now the determinant of college readiness and are considered essential scores for enrolling in credit-bearing college courses (D. T. Conley, 2008). All Kentucky public postsecondary institutions have adopted the mandated minimal competency score of 19 for mathematics on the ACT. ("Guidelines for admission to the state-supported postsecondary education institutions in Kentucky," 2011). When high school juniors do not obtain this score in mathematics on the ACT , they are required to enroll in a transition mathematics course their senior year ("Minimum requirements for high school graduation," 2011). As a part of Senate Bill 1, a group of secondary and postsecondary mathematics instructors were asked to develop a transitional mathematics course framework in the summer of 2010. This framework embedded Kentucky Core Academic State Standards and college and career readiness standards into a transitional mathematics course. High schools were encouraged to implement the developed framework, but they were allowed to use others with permission. The format, duration, and content of the transitional course were left up to each school to implement. 
When students complete the mathematics transition course, students are reassessed using ACT, COMputer-adapted Placement Assessment and Support Services (COMPASS), or KentuckY Online TEsting (KYOTE) placement examinations. The second administration of ACT and any administration of COMPASS are additional expenses to school districts, while KYOTE is free. The Kentucky Council on Postsecondary Education also determined minimum placement scores on COMPASS and KYOTE as mandated by Unbridled Learning ("Guidelines for admission to the statesupported postsecondary education institutions in Kentucky," 2011) . If students meet the minimum competency score on any one of the examinations, then they are deemed "college ready" and can enroll in a college credit-bearing mathematics course.

Students not meeting the minimum competency score in high school can still be admitted to a postsecondary institution, but they must enroll in a non-credit-bearing college course to develop necessary mathematical skills and understanding. These noncredit-bearing courses were established to meet the needs of underprepared college students and are often referred to as remedial. Although students enrolling in these courses do not receive credit toward graduation, their successful completion is a requirement for enrolling in required credit-bearing courses. Grubb and others (1999) defined remediation as " a class or activity intended to meet the needs of students who initially do not have the skills, experiences or orientation necessary to perform at a level that the institutions or instructors recognize as 'regular' for those students" (p. 174). Remedial courses are also often referred to as developmental, basic skills, or preparatory courses (Attewell et al., 2006; Bahr, 2008; Levin \& Calcagno, 2008; Schachter, 2008). 
Parallel to what high schools are doing through transition courses and placement examinations to prepare students to be ready for credit-bearing courses, colleges have been redesigning remedial courses. In a concentrated effort to make college success more obtainable for larger numbers of students, each Kentucky college and university has determined specific content knowledge necessary for success in coursework and placed that content into a remedial courses (D. T. Conley, 2008). According to the Knowledge and Skills for University Success (KSUS) developed by the Standards for Success project, students entering college are expected to have conceptual understanding and hands-on skills in mathematics (D. Conley, 2003). Conley states, "Entering [college] students should know basic mathematical concepts-computation, algebra, trigonometry, geometry-so that they have the tools to work with increasingly complex conceptual mathematical and quantitative procedures and analyses in the college courses" (2003, p. 29). Conley and his research team, in a study of research universities, developed a list of prerequisite mathematics college standards that drive university remediation courses. These mathematical standards were intended to be the criteria for measuring the quantity and quality of student mathematical knowledge. The inability to meet prerequisite mathematical standards often required students to be placed in a remedial course.

Although Conley found consistencies among institutions in remediation course content, the institutions were free to choose their own curricula for remediation courses. Norman Webb (1997) reported that state educational testing systems often rely on the premise that student knowledge will be improved if alignment between assessments and student expectations is clear. If alignment between assessments and expectations does not occur, then students may appear to be "college prepared" in mathematics but not have the 
necessary prerequisite content knowledge or depth of understanding. This deficiency has the potential for adverse effects on student success and retention rates.

Several factors contribute to increasing retention rates. In a longitudinal study, Ishitani and DesJardins (2002) found that the higher a student's GPA was at the end of his/her freshman year, the less likely the student was to drop out of college. Waycaster (2011) found that if a student entered college underprepared and had success in a remediation course, he/she was more likely to complete college. Therefore, proper placement of students into remediation classes is an important topic of research. Theoretically, students receiving a minimum placement examination score should have the same knowledge base as those students receiving a passing score on their final examination in a remediation course. Therefore, an analysis of alignment between placement examinations for credit-bearing courses and knowledge expectations as displayed on remedial course final examinations can provide insights into what is considered readiness for credit-bearing mathematics courses. This can have implications for both K-12 and college settings. . This need for alignment on what it means to be college-ready in mathematics serves as a basis for my study.

\section{Brief Description of Study}

This study used collected and analyzed content and cognitive complexity data from placement examinations (KYOTE, COMPASS, and ACT) and the highest remediation college course comprehensive final examinations from five Kentucky state universities in the spring of 2013. Mathematics content was described and categorized using Common Core State Standards (CCSS, 2011), and cognitive complexity was 
categorized by Depth of Knowledge levels 1 to 4 developed by Norman Webb ("WAT Web Alignment Tool," 2012).

\section{Purposes of the Study and Research Questions}

The purposes of this research study were to: 1) complete a within-university comparison of Kentucky Mathematics College Readiness Expectations (KM-CRE), and

2) determine if an alignment between university mathematics college readiness expectations and college placement examinations existed. This study was completed in two phases: In Phase 1, course finals in the highest mathematics remediation class offered at five universities were analyzed using Common Core State Standards (CCSS). Each final examination item was coded to match one or more Common Core State Standards, along with a Depth-of-Knowledge level. (See Appendix A for coding instrument.) A comparison analysis of each university's percent of content strand emphasis on the final examination was conducted. Phase 2 of the study involved an alignment analysis between each university's identified Kentucky Mathematics College Readiness Expectations (KM-CRE) with Kentucky's regulated college placement examinations: ACT, KYOTE, and COMPASS. Using Webb's alignment model to compare the identified KM-CRE to each placement examination, I analyzed four categories of alignment: Categorical Concurrence; Range of Knowledge; Depth of Knowledge Consistency; and Balance of Representation (Webb, 2007). Together, these two phases attempted to answer the research questions: (1) What mathematical prerequisite knowledge do state universities consider necessary to be college ready. Specifically 1a) What content domains do the state universities emphasize in their remediation courses?;

1b) Does consistency across the state public universities with regard to the content 
domains exist?; and 2) How well do Kentucky's mathematics placement assessments (ACT, COMPASS, and KYOTE) align in both content and cognitive demand with fouryear universities' Kentucky Mathematics College Readiness Expectations (KM-CRE)?

This dissertation is organized into five chapters. Chapter 1 provides a description of the problem, issues on which the study is based, and the purpose of the study. Chapter 2 provides a review of the literature pertaining to previous and similar studies and background data intended to reinforce the proposed study. Additionally, Chapter 2 describes the conceptual framework, defines constructs, and the relationships among them. Chapter 3 describes the research methodology and design and provides a rationale for sampling techniques, data collection, and analysis procedures. Chapter 4 presents an analysis of the data and the results of the study. Chapter 5 summarizes and reflects on the results of the study, its findings, and implications.

\section{Definition of Terms}

Consistency - shared expectations across 3 of 5 institutions measured by a range value of $3 \%$.

College ready - evidence of knowledge of mathematics content needed to be successful in the first credit bearing college mathematics course

Alignment - the degree to which expectations and assessments are in agreement and serve in conjunction with one another to guide the system toward what students need to learn and what they are expected to know and do Domain - mathematical categories of related standards $\underline{\text { Standards }}$ - the individual descriptors or objectives of mathematical content CCSSM- Common Core State Standards for Mathematics 


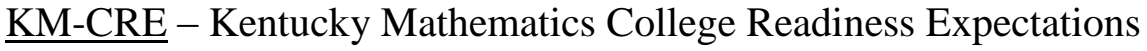




\section{CHAPTER II}

\section{LITERATURE REVIEW}

In 2001, President George Bush reauthorized the 1994 Elementary and Secondary Education Act to its current version known as No Child Left Behind (NCLB) ("Reinventing the federal role in education: Supporting the goal of college and career readiness for all students," 2009). NCLB legislation established a goal that all students should be proficient in mathematics and reading by 2014. It required each state to develop assessments and performance goals that aligned with its state standards (Bhola, Impara, \& Buckendahl, 2003). Each state independently determined performance proficiencies, and every school, district, and state-funded educational system were evaluated to determine if Adequately Yearly Progress (AYP) was met ("Reinventing the federal role in education: Supporting the goal of college and career readiness for all students," 2009). AYP was a state-set yearly benchmark of the percentage of students meeting or exceeding proficiency levels and graduating from high school. This information is readily available to the public and displayed in all schools. Any school or

district not meeting AYP for two consecutive years must implement a school improvement plan.

Unfortunately, the Adequate Yearly Progress mandated system did not address the goal of graduating students who were college and career ready. The annual report cards publicly displayed by each school reported only the percent of students meeting 
proficiency. Since states developed their own standards and determined proficiency levels, meeting AYP did not necessarily equate with college and career readiness. The Education Digest ("Reinventing the federal role in education: Supporting the goal of college and career readiness for all students," 2009) published by the Alliance for Excellent Education emphasized the importance of graduating students college and career ready. The Education Digest offered the following first goal for the federal government: "College and career-ready graduation must be established as the common goal for all students and the education system" ("Reinventing the federal role in education: Supporting the goal of college and career readiness for all students," 2009).

Kentucky's most recent response to the federal mandate of No Child Left Behind was Senate Bill 1(later named Unbridled Learning) in 2009. This bill aligned with the recommendation of The Education Digest to graduate college and career ready individuals. Unbridled Learning was a consolidated effort among the Kentucky General Assembly, Kentucky Department of Education, Kentucky Council on Postsecondary Education, and the Kentucky Educational Professional Standards Board to ensure that Kentucky's public school students were college and career ready upon graduation from high school. This initiative served as an important precursor for the adoption of the Common Core State Standards in February 2010 in mathematics and reading (Gross, 2010). Legislative measures also required: (1) the development of new assessments; (2) mandates for existing assessments; (3) and remediation strategies based on these assessments. One requirement was that all students take the ACT during the spring of their junior year ("Minimum requirements for high school graduation," 2011). To improve college and career readiness, the state established minimum baseline scores on a 
set of assessments that all Kentucky four-year postsecondary institutions would use to determine eligibility for taking a college credit-bearing course. Students who did not meet baseline scores in mathematics and reading were required to enroll in a transition course during their senior year. At the end of the transition course, students could retest using ACT, COMPASS, or KYOTE. Those students still not meeting baseline scores would be required to take a remediation course upon entering a Kentucky college.

Success in a freshman-level remedial or credit-bearing college course directly affects college retention rates (Ishitani et. al., 2002). Kentucky ranks 40 out of 50 states in retention rates $(72 \%)$ for freshmen entering their sophomore year at public four-year colleges/universities ("The college completion agenda," 2011). Furthermore, Kentucky ranks only slightly better (38 out of 50 states) for four-year private colleges/universities, but with a lower retention rate of $70.5 \%$. Unbridled Learning legislation addressed these low retention rates through one of its two main goals: "to increase the college completion rates of students enrolled in one or more remedial classes by three percent annually from 2009 to 2014" ("Senate Bill 1 (2009) College and Career Readiness," 2012). This goal not only highlighted a goal of students enrolling in remediation classes to be successful in those classes, but also targeted a goal for them to complete college.

\section{Remediation}

Grubb and others (1999) defined remediation as " a class or activity intended to meet the needs of students who initially do not have the skills, experiences, or orientation necessary to perform at a level that the institutions or instructors recognize as 'regular' for those students" (p. 174). Remedial courses are also often referred to as developmental, basic skills, and preparatory courses (Attewell et al., 2006; Bahr, 2008; 
Levin \& Calcagno, 2008; Schachter, 2008). Prior to the Unbridled Learning legislation, Kentucky colleges and universities used a variety of assessment methods to determine college mathematics readiness (Levin \& Calcagno, 2008; Oudenhoven, 2002). Many state universities and community college systems in the United States determined their own minimal placement scores on various assessments (Levin \& Calcagno, 2008). Based on Council on Postsecondary Education's recommendation, Kentucky established a minimal competency score for each of the state mandated placement examinations: ACT, COMPASS and KYOTE. ("College Readiness Indicators," 2010). These minimum scores were implemented in the fall of 2012 for all Kentucky state colleges and universities. Those students not meeting the minimal scores were required to take remedial or transitional courses. The minimal competency scores are shown in Table 1 and are indicators to enroll in the lowest credit-bearing mathematics course, not college algebra.

\section{Table 1}

Minimal Competency Mathematics Scores on Placement Examinations

\begin{tabular}{|c|c|c|c|}
\hline $\begin{array}{l}\text { Readiness } \\
\text { Score Area }\end{array}$ & ACT Score & COMPASS & KYOTE \\
\hline $\begin{array}{c}\text { Mathematics } \\
\text { (General } \\
\text { Education, } \\
\text { Liberal Arts } \\
\text { Courses) } \\
\end{array}$ & $\begin{array}{l}\text { Mathematics } \\
19 \text { or higher }\end{array}$ & $\begin{array}{c}\text { Algebra Domain } \\
36 \text { or higher }\end{array}$ & $\begin{array}{c}\text { College } \\
\text { Readiness } \\
\text { Mathematics } \\
22 \text { or higher }\end{array}$ \\
\hline $\begin{array}{c}\text { Mathematics } \\
\text { (College } \\
\text { Algebra) }\end{array}$ & $\begin{array}{l}\text { Mathematics } \\
22 \text { or higher }\end{array}$ & $\begin{array}{c}\text { Algebra Domain } \\
50 \text { or higher }\end{array}$ & $\begin{array}{l}\text { College Algebra } \\
\text { (2011-12) } \\
27 \text { or higher } \\
\text { (2012 and } \\
\text { beyond) } \\
\text { KYOTE College } \\
\text { Algebra } \\
\text { placement test of } \\
14 \text { or higher }\end{array}$ \\
\hline
\end{tabular}


("College Readiness Indicators," 2010)

\section{Cost of Remediation}

Currently, approximately 40 percent of all undergraduate students across the country enroll in a remedial course at some point in their college career (Attewell et al., 2006; Bettinger \& Long, 2005; Horn et al., 2009; Illich et al., 2004; Waycaster, 2001). With a large number of students enrolled in remedial classes, the price tag required of this extra education is large. Saxon and Boylan (2001) reported that remedial programs have a direct cost of 1 to 2 billion dollars annually and combined indirect, direct, and public costs are near $\$ 17$ billion annually. Opponents to these high expendatures indicate that the government is paying twice for the same body of knowledge to be taught to the same students--once as high school students and then again as college students (Bahr, 2008). Besides the financial loss, Bahr emphasized that tax dollars are wasted to provide services that diminish academic standards and demoralize college faculty (2008).

Although remediation comes at a cost, advocates of remedial programs often respond to critics by pointing out that the alternatives to remediation are unemployment, low-paying jobs, underemployment or incareration (Levin \& Calcagno, 2008; McCabe, 1998; Schachter, 2008; Waycaster, 2001). These outcomes are considerably more expensive than providing remedial classes. At least with tuition costs, some of the expenses of these programs are offset with student payments. McCabe (1998) noted that for less than $\$ 1000$, underprepared students can obtain the basic skills and knowledge necessary to be college ready and eventually highly employable.

\section{Reasons for Remediation}


In support of appropriate placement of students into remediation, Waycaster (2001) conducted a study using data collected from five different univerisities. In addition, Hefound that retention rates for developmental students ranged from $61.9 \%$ to $80.6 \%$ while students enrolled in non-remedial courses had a retention rate that ranged from $42.1 \%$ to $61.9 \%$. The rationale for his findings was the extra attention given to students in remedial courses through counseling, advising, and smaller class sizes. In fact, he found that 40 percent of the students graduating from college had enrolled in remedial classes. This finding revealed that, with academic help, students who enter college underprepared can obtain the skills necessary to become successful college graduates. Bettinger and Long (2005) supported her claim in their research of Ohio students who entered community colleges in the fall of 1998. Their study indicated that students who attended two-year colleges or transferred to 4-year colleges and enrolled in remedial courses performed as well as students not enrolled in remedial courses. In fact students attending community colleges and completing remedial courses had the same or a better chance of completing their degree than those students that never enrolled in remedial courses.

Several reasons for the academic deficiencies that force students to enroll in remedial classes exist. Many students enter college with poor study skills or low academic motivation. (Illich et al., 2004). Approximately 60 percent of the students enrolled in remedial classes were traditional students straight from high school (Attewell et al., 2006; Schachter, 2008). Other underprepared students entered college after military assignments, child rearing, or employment loss. Schachter (2008) reported that underprepared students were not placed in remedial classes because of their lack of 
intellectual ability. Rather, "It is often the fact that they are not required to think at higher levels during high school and therefore are underprepared" (p. 54). Additionally, he reported that eighty percent of the students that required remediation maintained a 3.0 or better GPA in high school. The data also indicated that the percentage of students that needed remediation was the same regardless of ethnicity, race, or socioeconomic background. Using data collected from the National Educational Longitudinal Study, Attewell and others (2006) corroborated this finding by reporting that enrollment in remedial courses was not determined by socioeconomic status, gender, ethnicity and to some extent college preparedness. Students taking and successfully completing remedial courses did not have lower academic success or college graduation rates. In fact, for students enrolled in two-year colleges, students taking remedial classes were more likely to graduate than those who did not enroll in them.

Ishitani and DesJardins (2002) further supported this finding in their longitudinal study of college student drop out indicators in the United States. They found that the higher students' first-year GPA, the less likely they were to drop out. This finding implied that if students were placed in a course where they can be successful, they were much more likely to continue to be successful. This finding indicates the importance of placing first-year students in the most academic appropriate courses.

\section{Placement Examinations}

In Kentucky, placement into remediation college courses is based on performance on placement examinations. Mathematics college readiness expecations are communicated through end-of-course finals for remedial mathematics at colleges and universities. The Kentucky legislature equated mathematics college readiness expecations 
to knowledge assessed on ACT, COMPASS, and KYOTE by allowing acceptable scores on both as a gateway into credit bearing college courses. For this assumption to hold, knowledge assessed on college remedial mathematics finals must align with knowledge assessed on Kentucky's three placement examinations. ACT, COMPASS, and KYOTE. ACT

The American College Test (ACT) is offered six times a year and has five components: reading, science, mathematics, English and writing (Troseth, 2008). The first five components have a score range of 1 to 36 with 36 being a perfect score. ACT assigns a score to each component and then an average composite score for the test. Writing is scored separately with a score range of 2 to 12 . The ACT offers benchmark scores in each academic area ("ACT," 2010). A benchmark score indicates the likelihood of a student receiving a passing grade in an entry level credit-bearing college course.

The mathematics portion of the ACT is a 60 multiple-choice question test ("ACT," 2010). According to the ACT website, it measures content knowledge in prealgebra (23\%), elementary algebra (17\%), intermediate algebra (15\%), coordinate geometry (15\%), plane geometry (23\%), and trigonometry (7\%). The ACT has multiple versions with the 60 questions taken from a large question pool. It is often administered in pencil/paper format, but it is also available at parametric testing centers via computer. ACT suggests that 22 is the mathematics benchmark for college readiness. According to ACT, if students score a 22 or better on the mathematics portion, then in their College Algebra course they “... have approximately a fifty percent chance of earning a B or better and approximately a seventy-five percent chance of earning a C or better" (ACT, 2010c). Following the ACT recommendation, a 22 is the Kentucky benchmark for 
admission into College Algebra. Credit-bearing mathematics courses below College Algebra have a benchmark score of 19 in Kentucky.

\section{COMPASS}

COMPASS, COMputer-adapted Placement ASSessment, is a placement examination also developed by ACT. It evaluates students' levels of performance in reading, mathematics, writing skills and essays (ACT, 2010a). The mathematics placement test evaluates basic skills in a multiple-choice format and measures student performance in content areas of pre-algebra, algebra, college algebra, geometry, and trigonometry. It is a computer adaptive test with no pre-determined number of questions. The questions are adjusted to match students' academic ability based on their previous answers. As students answer questions correctly or incorrectly, the difficulty of the next question is adjusted to fit the students' knowledge level. The assessment is intended to quickly and efficiently assess a student's mathematical knowledge by not focusing valuable time on test items that are too difficult or too easy for the student. The COMPASS individual report summarizes results for the placement measure(s) and recommends course placement based on institutionally determined cut scores. ACT works with each individual institution to develop the cut scores for COMPASS based on course grade data. For the state of Kentucky, minimum scores are determined by the Council on Postsecondary Education for course placement into credit-bearing or noncredit-bearing courses. The individual reports also provide detailed information about the students' algebraic skills in a variety of subdomains ("COMPASS Tests," 2010). Its purpose is to place students in the most appropriate entry-level courses and to provide resources and recommendations for areas of specific weaknesses for underprepared 
students. COMPASS's design is considered an effective placement examination according to Conley (2008). He states that effective placement tests need to be diagnostic tests in order to tailor remedial courses to fit the needs of students.

\section{KYOTE}

KentuckY Online Testing Examination (KYOTE) is a college placement test developed at Northern Kentucky University and is unique to the state of Kentucky. The KYOTE placement examination is a thirty-one question test measuring content knowledge in pre-algebra, algebra and geometry. According to the Kentucky School Board Association (2010), KYOTE is intended to help more students transition from high school to college without needing a remediation course in college. The KYOTE mathematics' placement examination is administered upon the completion of a high school transition (remediation) course and is intended to quickly identify mathematical competencies after course completion. Additionally, KYOTE is easily administered and free of cost. These combined attributes contribute to the anticipated lowering of the number of students enrolling in a college remediation course. KYOTE can be administered online by high school personnel after obtaining administrative rights through the University of Kentucky. The KYOTE examination can be administered multiple times to the same student until a minimal competency score is obtained. If a minimal score is not reached by a student, then the university chosen by a student can use the score to place him/her in the most appropriate remediation mathematics course. If students score above the cut score on the KYOTE examination, then they will be placed in a college credit-bearing course regardless of their ACT score. 


\section{Research Related to KYOTE Placement Examination. Because KYOTE is}

relatively new as a mathematics placement examination, little research has been conducted on its reliability and validity. The few studies that have been located are described in the following paragraphs.

The University of Cincinnati Evaluation Services Center (2008) conducted a reliability and validity study on the Kentucky Online Testing Examination. For KYOTE's internal consistency reliability, the Center determined the test to have Cronbach Alpha score of .809 . This score is considered to be an acceptable value scoring above .7. In the item analysis, p-values ranged between .17 and .94 . The optimal value of .5 indicates that the item difficulty was appropriate. Since some questions in a placement examination should be easier or more difficult than others some higher and lower values were considered to be acceptable. The Center recommended that items scoring below 0.30 or higher than 0.90 should be removed from the test. The discrimination index (dindex) indicates how well students perform on a particular item with relation to how well they performed on the overall test. The d-index ranged from .09 to .7 , indicating that items ranged from satisfactory (.4 or higher) to problem items. Corrected item-total correlation scores ranged from .057 to .696 . Items scoring lower than .3 indicate that the questions are not measuring the same knowledge as the rest of the test and should therefore be removed. In summary, items 5, 6, 8 and 22 should be removed and 12 other items should be revised. Since these questions are static in nature, item analysis occurred for each item on the test. In the factor analysis to determine construct validity, KYOTE assesses two mathematical constructs. The Center also completed a correlational and regression analysis of student class placement and KYOTE scores and found it to be 
highly correlated but no details of how this analysis was completed were given. This data was given to me Dr. Newman at Northern Kentucky University with the statement that changes have been made since this research. It is unclear to me what exactly what changes have occurred.

Besides the evaluation conducted by the University of Cincinnati Evaluation Service Center, a few studies have been implemented by post-secondary institutions implementing KYOTE as a placement examination. Eastern Kentucky University reported information pertaining to the number of students placed in Math 095 (developmental math), Math 105 and Math 107 using KYOTE as a placement examination and some other means of placing students in those classes. Successful completion of the course is measured by receiving a "C" or higher. In 2008, 79\% of students placed by KYOTE in Math 095 were successful compared to $32 \%$ placed by other means. In 2009, 49\% of the students placed in Math 095 using KYOTE were successful compared to $43 \%$ placed by other means. Seventy-four percent of students placed in Math 105 received a "C" or better, while $71 \%$ of those placed using alternative means received similar grades. And 42\% of students placed using KYOTE in Math 107 were successful compared to $51 \%$ of those placed by other criteria. The paper does not indicate how the other students are placed in these courses. However, according to phone conversation with the testing center coordinator, students are placed in courses using ACT mathematical test scores. From the 2009 data, KYOTE placement testing did not appear to significantly change course placement and student success. It is important to note that the number of students being placed by KYOTE is very small compared to the 
number of students enrolled in these courses (34 out of 1,949 students). With this small number of students, more research is warranted in this area.

In a study completed by Riggs (2007) at Ashland Community and Technical College, student mathematical course success rates were compared between students placed using KYOTE and those placed by Kentucky Community and Technical College System (KCTCS) proposed scores. The study involved 368 students placed in Math 122, Math 065 and Math 055. The researcher did not state how many of the 368 students were placed by each method: KYOTE or KCTCS criteria. An overall success rate was determined for each class and then the students enrolled in each course were then subdivided into two groups. One group was placed into the course based upon their cut scores using KYOTE and the other group was placed by their cut scores using the KCTCS proposed criteria. The researchers divided KYOTE's thirty questions into 3 groups of 10 questions. If the test taker scored less than 7 correct in each group he/she was placed in Math 055. If the test taker answered 7 out of the first 10 questions correctly but fewer than 7 correctly in the next two sections, then that student was placed in Math 65. If the student scored a 7 or better on the first two sections but not in the $3^{\text {rd }}$ section then the student would be placed in Math 122. The researcher did not describe any of the details of the placement using KCTCS scores. In Math 122, 54\% of the students were successful and the two subgroups, KYOTE and not KYOTE, had $88 \%$ and $46 \%$ success rate respectively. In Math 065, 49\% were successful with the two subgroups having $71 \%$ and 36\% success respectively. In Math 055, 53\% percent of the students were successful with the subgroups having 53\% and 58\% success rate. Only the Math O55 course data did not have a significant difference in success rate of students placed using KYOTE 
verses those that did not. This study, although informative, contained little detail with no levels of significance given.

\section{Compatibility of Placement Examinations}

ACT and COMPASS, although very similar, were designed to measure different mathematical content areas and difficulty levels and are therefore limited in their compatibility. ACT is a college readiness examination that assesses content knowledge in pre-algebra, intermediate algebra, college algebra, coordinate and plane geometry, and trigonometry. COMPASS is intended to measure aptitude in pre-algebra, intermediate algebra and college algebra. For this reason these two tests cannot be completely equated (ACT, 2010b). However using thousands of test scores from 2001 to 2009 of students taking both the ACT and the COMPASS examinations, ACT created a concordance table to best compare examination scores. (See table 2)

\section{Table 2}

\section{COMPASS Pre-Algebra Scores to ACT Math Concordance}

$\mathrm{N}=152,675$

\begin{tabular}{|c|c|c|c|}
\hline $\begin{array}{c}\text { COMPASS Pre- } \\
\text { Algebra scale score }\end{array}$ & $\begin{array}{c}\text { Concorded ACT } \\
\text { Math Score }\end{array}$ & $\begin{array}{c}\text { COMPASS Pre- } \\
\text { Algebra scale score }\end{array}$ & $\begin{array}{c}\text { Concorded ACT } \\
\text { Math Score }\end{array}$ \\
\hline $17-20$ & 13 & $78-81$ & 23 \\
\hline $21-26$ & 14 & $82-86$ & 24 \\
\hline $27-33$ & 15 & $87-90$ & 25 \\
\hline $34-41$ & 16 & $91-92$ & 26 \\
\hline $42-49$ & 17 & $93-94$ & 27 \\
\hline $50-56$ & 18 & $95-96$ & 28 \\
\hline $57-63$ & 19 & 97 & 29 \\
\hline $64-69$ & 20 & 98 & 31 \\
\hline $70-73$ & 21 & 99 & 33 \\
\hline $74-77$ & 22 & & \\
\hline
\end{tabular}


COMPASS Algebra to ACT Math Concordance

$\mathrm{N}=175,039$

\begin{tabular}{|c|c|c|c|}
\hline $\begin{array}{c}\text { COMPASS Algebra } \\
\text { scale score }\end{array}$ & $\begin{array}{c}\text { Concorded ACT } \\
\text { Math Score }\end{array}$ & $\begin{array}{c}\text { COMPASS } \\
\text { Algebra scale score }\end{array}$ & $\begin{array}{c}\text { Concorded ACT } \\
\text { Math Score }\end{array}$ \\
\hline $16-17$ & 14 & $55-60$ & 23 \\
\hline $18-20$ & 15 & $61-67$ & 24 \\
\hline $21-25$ & 16 & $68-75$ & 25 \\
\hline $26-30$ & 17 & $76-82$ & 26 \\
\hline $31-35$ & 18 & $83-89$ & 27 \\
\hline $36-40$ & 19 & $90-93$ & 28 \\
\hline $41-44$ & 20 & $94-95$ & 29 \\
\hline $45-49$ & 21 & $96-97$ & 30 \\
\hline $50-54$ & 22 & 98 & 31 \\
\hline
\end{tabular}

COMPASS College Algebra to ACT Math Concordance

$\mathrm{N}=42,478$

\begin{tabular}{|c|c|c|c|}
\hline $\begin{array}{c}\text { COMPASS Algebra } \\
\text { scale score }\end{array}$ & $\begin{array}{c}\text { Concorded ACT } \\
\text { Math Score }\end{array}$ & $\begin{array}{c}\text { COMPASS } \\
\text { Algebra scale score }\end{array}$ & $\begin{array}{c}\text { Concorded ACT } \\
\text { Math Score }\end{array}$ \\
\hline 15 & 13 & $60-62$ & 24 \\
\hline $16-17$ & 14 & $63-66$ & 25 \\
\hline $18-22$ & 15 & $67-71$ & 26 \\
\hline $23-26$ & 16 & $72-75$ & 27 \\
\hline $27-33$ & 17 & $76-79$ & 28 \\
\hline $34-39$ & 18 & $80-83$ & 29 \\
\hline $40-45$ & 19 & $84-85$ & 30 \\
\hline $46-49$ & 20 & $86-87$ & 31 \\
\hline $50-53$ & 21 & $88-89$ & 32 \\
\hline $54-55$ & 22 & $90-96$ & 33 \\
\hline $56-59$ & 23 & 97 & 34 \\
\hline
\end{tabular}

Besides the concordance tables, ACT provides college readiness benchmark scores to indicate a high probability of success in a credit-bearing college level course (ACT, 2010c). The benchmark score for College Algebra on the ACT is 22 in 
mathematics and the benchmark score for COMPASS is 50 in the Algebra Domain. This information would indicate that students receiving either one of these scores or higher on their respective test would have a high probability of successfully completing the College Algebra course successfully. Since COMPASS is often used as a placement examination for different levels of remediation mathematics, universities have different benchmark scores or cut scores for different levels of remediation. The Kentucky Community and Technical College System determined their cut scores for Math 055-pre-algebra to be between 17 and 40. The cut score for Math 065 -basic algebra with measurement is between 41 and 54. In order to be placed in Math 150-college algebra, students have to score above a 50 on their COMPASS examinations in the Algebra Domain or a 22 on their ACT.

Using the research conducted by Ashland Community and Technical College (ACTC), the researcher made comparisons of KYOTE and COMPASS scores that were given (Developmental math placement test results Ashland Community and Technical College 2007). The first ten questions of the KYOTE examination matched with content covered in Math 055; the second ten questions matched with content covered in Math 065; and the last ten questions matched with content covered in Math 122-Intermediate Algebra: A Functional Approach (an alternative to college algebra). Students receiving less than seven out of each group of questions would be placed in Math 055 compared to a cut score of 17 on COMPASS. Student getting at least seven of the first ten questions and less than seven on the subsequent groups of questions would be placed in Math 065 . This compares to a cut score of 41 on COMPASS. Furthermore, students receiving a seven out of ten in each section would be placed in College Algebra, which is comparable 
to scoring a 50 in the Algebra domain on COMPASS. Since Kentucky Community and Technical College system (KCTCS) is a part of the state funded college system, it follows the minimal competency scores established by Senate Bill 1 of 2009.

\section{Standards}

Placement examinations (ACT, COMPASS, and KYOTE) are used to determine if minimal competency standards of knowledge and skills have been mastered. Standards have been established for content and grade level proficiencies for elementary, middle, secondary, and now post-secondary readiness. These standards are assessed at multiple levels and for multiple purposes as students advance through their educational journey.

\section{Common Core State Standards Initiative}

On February 10, 2010, Kentucky made history by being the first state to adopt the Common Core State Standards (CCSS). The CCSS were designed to be more rigorous, focused, and applicable (Holiday, 2010) than previous standards. They are aligned across grade levels and are specific with regard to what content is taught at a particular grade level. Detailed learning objectives are stated within each Standard strand. The Standards have been internationally benchmarked and adopted by 45 out of the 50 states ("Common core state standards inititative," 2011; Holiday, 2010). Currently Common Core State Standards have been developed only for mathematics and English language arts. The Standards are intended to align across elementary, middle, and high school levels. The high school mathematics standards for content are divided into seven domains: Algebra, Geometry, Modeling, Function, Number and Quantity, and Statistics and Probability. Within each domain are specific concepts and skills that all high school students should 
know and be able to do to be ready for college and productive careers ("Common core state standards inititative," 2011).

Included in the Common Core State Standards Initiative are Standards for Mathematical Content and Standards for Mathematical Practices. The Standards for Mathematical Content describe the content knowledge students must obtain at three grade spans, the Standards for Mathematical Practices describe a variety of mathematical processes needed to be proficient and successful in today's world ("Common Core State Standards Intiative ", 2012). Below are listed the eight Standards for Mathematical Practice:

1. Make sense of problems and persevere in solving them.

2. Reason abstractly and quantitatively.

3. Construct viable arguments and critique the reasoning of others.

4. Model with mathematics.

5. Use appropriate tools strategically.

6. Attend to precision.

7. Look for and make use of structure.

8. Look for and express regularity in repeated reasoning (para 2).

The Standards for Mathematical Practices describe mathematical processes and thinking that students of mathematics should engage during their learning of mathematics. Students' ability to reason abstractly, display understanding, model mathematical situations and exhibit the other Mathematical Practices should continue to develop as their knowledge of mathematical content increases.

\section{Knowledge and Skills for University Success}

Understanding University Success, a 2003 report from Standards for Success, describes what students need to know and be able to do to be successful in entry-level college courses. These standards were developed over a two-year period by over 400 university professors and staff members from research institutions. They collaborated to 
determine the most essential student skills and knowledge necessary for success in an entry-level mathematics course. Through extensive research and meetings, they developed a list of standards for each content area.

The Standards for Success were used in an alignment study conducted by Brown and Conley (2007) who analyzed sixty mathematics examinations from twenty states including Kentucky. The purpose of the study was to determine alignment between assessment questions from state mandated examinations and college readiness expectations defined by the Knowledge and Skills for University Success (KSUS) (Brown \& Conley, 2007). The researchers reasoned that, due to the expanded use of high school examinations as a measure of college readiness, alignment between the assessments and expectations should be explored.

Using Webb’s (1997) model for curriculum alignment, Brown and Conley (2007) analyzed categorical concurrence, depth of knowledge, range of knowledge, and balance of representation in the state mandated examinations. Their results found that: (1) algebra standards met categorical alignment $63 \%$ of the time; (2) geometry standards met alignment $60 \%$ of the time; and trigonometry standards met alignment $3 \%$ of the time. For depth of knowledge, the researchers found that on average $70 \%$ of the mathematical assessment items met or exceeded the cognitive complexity of the KSUS standards. The lowest match in depth of knowledge occurred in the area of trigonometry. In the range of knowledge category, only $28 \%$ of the KSUS objectives were addressed. Less than $13 \%$ of the state mathematics assessments addressed at least half of the KSUS objectives. From this study, the researchers concluded that high school assessments aligned well only in areas of basic mathematics knowledge. However, standards requiring more complex 
cognitive understanding did not align well with high school assessments. As a result, researchers encouraged more alignment studies to be conducted as new state assessments were developed.

\begin{abstract}
Alignment
According to David Conley (2008) in "Rethinking College Readiness," understanding algebraic concepts is critical for success in college entry-level mathematics courses He added that the purpose of remedial courses is to develop this understanding for those who are underprepared. Additionally, Conley (2008) stated that students needed to apply conceptual knowledge beyond formulas to contextual application problems. Students also needed to depict important content, formulate a solution, and then interpret their answers. Furthermore, students needed to know how to estimate in order to determine the reasonableness of their answers. This content knowledge is not likely to be found in a course description but in objectives of a classroom syllabus. Furthermore, these objectives should be assessed in course examinations to show alignment between content knowledge and classroom objectives.
\end{abstract}

\title{
Conceptual Framework
}

This study based its analysis on the Common Core State Standards for Mathematics (CCSSM) document. This history-making document has created consistency of language in the identification of the expectations across states and with other nations. Using the CCSSM, Kentucky Mathematics College Readiness Expectations (KMCRE) was established across five universities. Each conceptual category of CCSS-M used in the KM-CRE was compared among the universities for percent of emphasis on content. Following Webb's alignment model, Kentucky 
Mathematics College Readiness Expectations were analyzed to determine alignment with ACT, COMPASS, and KYOTE placement examinations. The categories of content alignment analyzed were: Categorical Concurrence, Range of Knowledge, and Balance of Representation. The category for cognitive complexity alignment was Depth of Knowledge Consistency. This process followed the diagramed conceptual framework model in Figure 1.

Figure 1

\section{Conceptual Framework Model}

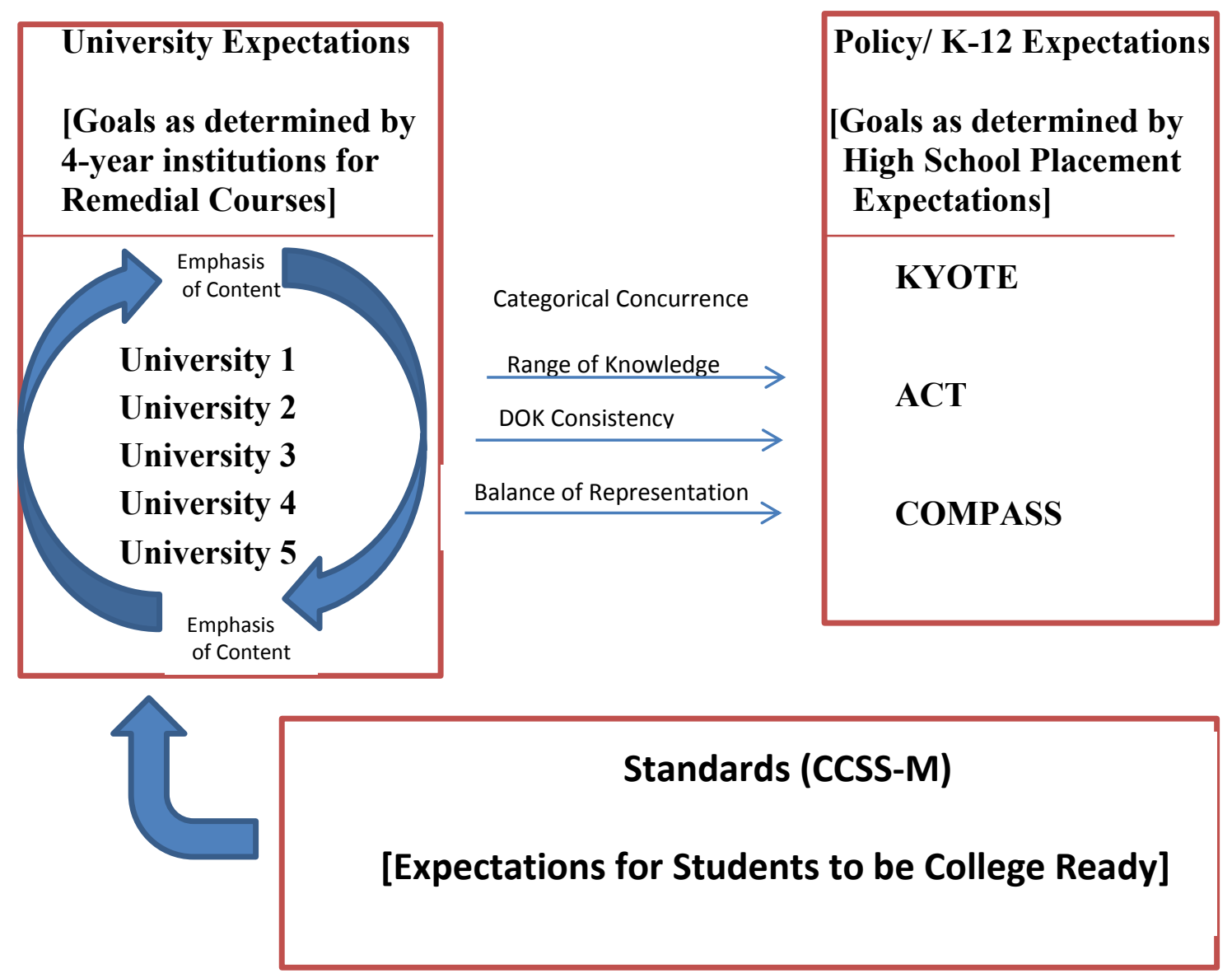




\section{Alignment Model and Criterion}

In State Standards and State Assessment Systems: A Guide to Alignment, a publication of the Council of Chief State School Officers, the authors stated, "Alignment of content standards, performance standards, and assessment is crucial, whether assessment data are used to make policy decisions, funding allocations, or recommendations for student learning “ (LaMarca, Redfield, \& Winter, 2000, p. 7). The document also offered assumptions made about an aligned system of standards and assessments. It indicated that: (a) standards and assessments should be visible and transparent; (b) alignment is viewed as an ongoing process and open to evaluation and improvement; and (c) valid and reliable data-making decisions depend on the close alignment between standards and assessments. The document also indicated that: (1) information about standards should be clear, understandable, and accessible to all stakeholders involved; (2) parents, students, and educators should have access to the expected educational goals and the assessment process; (3) a description of how the assessments will be used to measure students' academic achievement; and (4) a list of the judgments to be made according to the outcome of those assessments .

LaMarca and others (2000) stated that standards, assessments, and curricula should be viewed as a dynamic system working together to accurately measure student knowledge and proficiencies (LaMarca et al., 2000). Assessment systems need to be reviewed periodically to determine that clear alignment exists among the separate but highly related parts. Developers and implementers of the assessments and standards need to be open to research and revisions. The assessment system must provide accurate, 
reliable, and valid data to which assumptions based on results are made. The ultimate purpose of a standards-based assessment system is to ensure that students' knowledge and understanding are accurately displayed by the resulting score on the assessment. Additionally, LaMarca and others (2000) stated that if standards have been set and an assessment has been given as a measure to determine class placement, then:

1. the content standards must clearly and accurately represent the knowledge and skills, including cognitive skills, that students are expected to achieve as a function of schooling;

2. the performance standards must clearly, fairly, and accurately reflect multiple predetermined levels of performance relative to the content standards; and

3 . in a perfectly aligned system, the assessments would cover the breadth and depth of both content and performance standards (pg. 11).

In addition to these assumptions, it is ultimately imperative that an effective standardsassessment system is thoughtfully and purposely developed to ensure alignment. Standards, assessments, and alignment between the two must be clearly defined for the assumptions to hold true. Content standards are the knowledge, skills and concepts acquired through an educational experience. Assessments are the measuring tools used to determine the degree to which student learning has occurred. And, alignment shows the match between content standards and assessments. The match must occur in content, depth, and emphasis placement.

\section{Content Match}

Content match is the interrelatedness between standard content and assessment content (LaMarca et al., 2000). A high degree of alignment between what is being taught and what is being assessed must be present. The comprehensive assessment must evaluate a wide range of content from all areas of the established standards. It must cover a span of topics from different strands within each standard. Norman Webb described this 
alignment criteria as "categorical concurrence" and "range of knowledge correspondence" (N. L. Webb, 2007).

Categorical Concurrence. Categorical concurrence provides a general guide for determining if the assessment measures the same content covered in the standards. Using Webb's model, (2007), this criterion is met if similar areas or categories are present in both documents. In this alignment, each category of the standards or strand is determined to have a "hit" on the assessment. A "hit" is when the researcher maps a question on the assessment to a standard strand. The number of hits per standard is determined by averaging the number of hits each reviewer has on an objective within a standard. More than one hit per assessment item is possible. Webb (2007, p. 10) states that no more than three hits of objectives within a standard from one assessment item should occur. Multiple hits are to be used sparingly by assessment reviewers. Generally the number of hits should be equal to the number of assessment items, but the number can be more. An acceptable number of hits for the criterion to be met is six. This number is based on the prediction of the number of items that would result in a reasonably reliable subscale showing content mastery on that subscale. "Using a procedure by Subkoviak (1988) and assuming that the cutoff score is the mean and that the reliability of one item is 0.1 , it was estimated that six items would produce an agreement coefficient of at least .63" (N. L. Webb, 2007, p. 11). According to Subkoviak, " the agreement coefficient $\left(\mathrm{P}_{\mathrm{o}}\right)$ represents the proportion of examinees consistently classified on two administrations of a mastery test" (1988, p. 51). For the categorical concurrence criterion, Webb applied Subkoviak's agreement coefficient to the amount of agreement on two measurements--standards and 
assessment items. For Webb, "hits” were used to measure the agreement coefficient. Subkoviak's agreement coefficient $\left(\mathrm{P}_{\mathrm{o}}\right)$ formula was defined as:

$$
\mathrm{P}_{\mathrm{o}}=(\mathrm{a}+\mathrm{d}) / \mathrm{N} \text { or } \mathrm{P}_{\mathrm{o}}=\mathrm{h} / \mathrm{N}
$$

Where, $\mathrm{h}$ is the number of hits

$a$ and $d$ are the number of examinees classified as masters and non-masters on both administrations, and

$\mathrm{N}$ is the total number in the group.

Modifying Subkoviak's formula and using an agreement coefficient of .63, $(a+d)$ would be the "hit" of an objective within a standard on the assessment. $\mathrm{N}$ is the total number of objectives within a standard. Using the second formula and solving for $\mathrm{h}$ results in the number of hits required per standard needed to reach an agreement coefficient of .63. This strategy is a very general guideline for content match because it is assumed that all objectives equally measure the same standard.

Range of Knowledge. The other criterion used by Webb to measure content match is "range of knowledge correspondence." This criterion determines the alignment of breadth of knowledge between standards and assessment. It is used to judge whether the span of knowledge described in a standard is the same as what is applied to answer assessment items correctly. The range-of-knowledge correspondence uses the objectives within a standard to determine if all strands within a standard are assessed. Researchers rate this criterion by averaging the number of hits of each objective by individual reviewers. Some reviewers often mark objectives differently within the same standard. The value used is the average number of hits per standard on different objectives. It measures how many objectives are assessed, and the actual objectives hit may be 
different based on different reviewers. Having at least one item matched to at least half of the objectives in a standard provides sufficient content match within the criterion of range of knowledge correspondence. Webb stated that this match “...ensures the assessment is measuring some breadth in content knowledge and is at least sampling half of the most important partitions of content identified by the objectives" (2007, p. 13). At least fifty percent of the objectives for each standard must be assessed for this criterion to be judged acceptable. Webb indicated that this assumption is based on the idea that students should be knowledgeable and proficient on at least half of the domain of content within a standard. This criterion also assumes that all objectives have equal weight within a standard and that a student will have to demonstrate an acceptable level of knowledge on more than one objective per standard to achieve a minimal competency score on the examination. Webb further clarified that, if more than $50 \%$ of the objectives within a standard are assessed, then the range of knowledge correspondence has been met and if only $40 \%$ to $49 \%$ of the objectives were assessed. Otherwise it was said to be weakly met.

\section{Depth Match}

Depth-of-content match is an alignment criterion that shows a high correspondence in the similarity of the number of dimensions covered on both standards and assessments. Cognitive complexity is one measure for this criterion (LaMarca et al., 2000). The amount of knowledge, and how it is applied to non-routine problems, should match between the standards and assessment. Students should not simply recall information on an assessment if the standards require critical thinking for its application. Webb (2007), in his alignment model, calls the depth match "DOK Consistency." He 
describes this match as the consistency between what students are demanded to know and be able to do at multiple cognitive levels according to the standards and the cognitive level that is required to answer questions appropriately on an assessment. Webb applied the fifty percent rule to this category as well. The assessment must have at least $50 \%$ of the hits on test items to be at or above the cognitive level (DOK level) of the corresponding objective standard. If ten (10) questions are on the assessment, at least five (5) of those questions must require the same DOK level or higher as described in the standard objective in order to arrive at a correct response. If $40 \%$ to $49 \%$ of the DOK levels match then the assessment is deemed to weakly meet the criterion.

Cognitive Complexity. In order to determine alignment in Depth of Knowledge (DOK) Consistency, it is important to understand the levels of cognitive complexity (N. L. Webb, 2007). DOK describes the complexity of knowledge required to answer questions appropriately and accurately. A DOK level 1 question requires simple recall of a fact, term, definition or simple formula. It could also require the completion of a simple calculation one or more times. Words that often indicate a Level 1 question are recognize, measure, use, identify, and define.

DOK Level 2 requires a student to make a decision about how to approach a problem (N. L. Webb, 2007). It goes beyond applying a simple algorithm to determine the most appropriate path to get a correct response. Instead of following a recipe for the accurate answer, the student must use some mental processing to determine what information is important, decide how that information is best manipulated, and then apply the skill or concept necessary. Some activities often associated with Level 2 question are: 1) noticing and describing a pattern; 2) explaining the purpose and use of 
experimental patterns; 3) collecting data and discussing the findings; and 4) classifying and organizing data into charts, graphs, and tables.

DOK Level 3 questions require a student to use strategic thinking through planning, in-depth reasoning, and applying evidence to reach a conclusion (N. L. Webb, 2007). This level requires more abstract and complex thinking than Level 1 or 2 . It often requires students to justify their answer and explain their reasoning. More than one correct answer is possible, but students would have to provide a rationale for their choices. Some activities that are often associated with a Level 3 question are: 1) explaining phenomena in terms of concepts; 2) solving problems using conceptual understanding and reasoning; 3) using a scientific approach to draw conclusions based on observations; and 4) developing logical arguments based on given or developed evidence.

DOK Level 4 requires complex reasoning, planning, and developing logical conclusions over an extended period of time (N. L. Webb, 2007). An extended period of time to complete a task does not solely qualify a Level 4 question. It is the development of complex ideas, logical sequencing of events and critical analysis of data that lead to a conclusion that justifies the classification of a Level 4 question. If students are required to record the outside temperature every day for a month and then create a graph from the data it would be considered a Level 2 activity. No critical or complex reasoning occurred over the one-month time period. However, if the task required analysis of a number of other variables considered in the rise and fall of temperatures, then the task would be at a Level 4. Some activities that are often associated with a Level 4 tasks are: 1) developing and proving conjectures; 2) combining and synthesizing ideas into new concepts; 3) critiquing ideas and conjectures based on evidence; and 4) proving suppositions. 
Emphasis Match. Content and skill alignment of standards and assessments also includes emphasis alignment. Emphasis alignment is the degree to which the assessment's emphasis on question types and content matches the emphasis placed on instruction and teaching of the standards (LaMarca et al., 2000). If content standards emphasize problem-solving tasks with little weight placed on computational skills, then the assessment should ask more questions pertaining to problem-solving tasks and fewer problems involving computational skills. Webb (2007) uses "balance of representation" to measure emphasis alignment (N. L. Webb, 2007). Balance of representation criterion is used to determine the degree to which emphasis is placed on one objective over another on an assessment. An index number is determined to measure this criterion by using only objectives that receive at least one hit. The index is computed by determining the difference in the proportion of the objectives hit in each standard and the number of hits each objective receives. The index is found by applying the following formula:

$$
1-\frac{\left(\sum_{k=1}^{T}\left|\frac{1}{T}-\frac{h(k)}{H}\right|\right)}{2}
$$

Where $\mathrm{T}=$ total number of objectives hit for the standard

$h(k)=$ number of items hit corresponding to objective $h$

$\mathrm{H}=$ total number of items hit for the standard (N. L. Webb, 2007, p. 14).

If all objectives were equally balanced between assessment and standards, then the index would be 1 . Webb determined that an acceptable index would be .7 to 1 . Values between .6 and .7 indicate a weakly met balance of representation criterion.

\section{Call for Research}

Due to the federal mandate of No Child Left Behind, public high schools are beginning to implement end-of-year assessments to determine student proficiency in 
mathematics and reading. NCLB legislation further requires that the assessments be aligned with educational standards (Rothman, 2003; N. L. Webb, 2007). Many high schools are using results from mandated examinations to make college readiness decisions based on student scores (Brown \& Conley, 2007). In a research study by Brown and Conley (2007), sixty mathematics and English tests from twenty different states, including Kentucky, were analyzed to determine alignment between college entrance standards and examinations. From the assessments analyzed, results revealed that high school examinations and college readiness standards were poorly aligned. The researchers suggested that more alignment studies needed to be conducted where college entry decisions are based upon the scores of high school examinations. Result interpretation about college preparedness based on high school examinations scores may not be indicative of student readiness. The misalignment between college entry level standards and high school assessments makes the validity of the assessments questionable (Rothman, 2003).

According to Roach, Niebling, and Kurz (2008), although the educational testing system is federally mandated to have standards-based alignment, few research studies have been conducted to ensure that alignment occurs. Brown and Conley (2007) suggest, "If states do wish to employ their high school exams to generate information on college readiness or placement, they will likely need to revisit the content domains from which examination items are drawn, the number and difficulty of test items, and the format used for testing” (pg. 153).

\section{Alignment between Placement Assessments}


Brown and Niemi (2007) conducted a study to determine the alignment between high school assessments and community college placement examinations in California. The study intended to measure the alignment between what students were expected to know based on college placement examinations and specific content knowledge that was assessed on California Standards Test (CSTs). Brown and Niemi first identified the most widely used placement examinations by the California Community College system. Then they determined the degree of alignment between the corpus of community college placement objectives and those addressed on the CSTs. Applying Webb's alignment model, members of the research team cross-referenced depth of knowledge with content standards to determine 1) categorical concurrence, 2) depth of knowledge consistency, 3) range of knowledge, and 4) balance of representation. To ensure inter-rater reliability, the lead content analyst conducted a training session for all evaluators.

The results indicated sufficient categorical concurrence in the areas of algebraic expressions and operations, equations, inequalities, word problems, functions, geometry, and applications of algebraic concepts. Insufficient categorical concurrence was found in the areas of whole numbers and fractions, decimals and percent, applications and interpreting graphs and tables, integers and rational numbers, operations with exponents, trigonometry, and graphing. More of these items appeared on the placement examinations than on the California Standards Test (CST). The CST showed alignment in the area of range of knowledge in only four categories: algebraic expression and operations; equations, inequalities, and word problems; functions; and geometry. These findings indicated that, in only the standards listed above, all objectives were assessed at least once. With regard to depth of knowledge, the researchers found that Webb's $50 \%$ 
recommended match occurred, which indicated that the California high school examinations aligned with the college placement examinations in all categories that appeared in both assessments. Using the recommended threshold of 0.7 , the evaluators found good alignment in the balance of representation category. This finding indicated that where matches occurred in content, equal distribution of objectives within that content was also found.

The " modest but uneven alignment" in their evaluation of the assessment system in California, they argued, were likely consistent with other states with many states currently relying on high school assessments to predict college readiness (Brown \& Niemi, 2007). In a similar study comparing high school assessments to Standards for Success in university courses, Brown and Conley (2007) concluded :

"In those cases where high school exams are used for postsecondary purposes, state assessment programs should be studied carefully to determine whether their content does align with college readiness standards and whether that alignment is limited to less cognitively complex aspects of college readiness" (pg. 154).

These two studies are the only recent attempts to analyze the extent to which placement examinations address college readiness standards. Additional alignment studies need to occur and those studies must address more than the basic topic of alignment. They need to address alignment, including cognitive complexity, as well as the other components outlined by Norman Webb, more comprehensively.

\section{Summary}

Kentucky legislatures recently adopted new regulations governing school assessments and evaluations. These assessments have a direct impact on graduating 
seniors' college readiness indicators. Just as Brown and Conley suggest, it is important for Kentucky educators to study alignment between the adopted high school examinations ACT, COMPASS, and KYOTE and college readiness standards established by Kentucky universities in both content and cognitive complexity. Norman Webb offers an alignment study model that assesses four categories: Categorical Concurrence; Range of Knowledge; Depth of Knowledge Consistency; and Balance of Representation. Each of these categories is intended to measure how completely each content category or domain is assessed and how well the cognitive demand of the standards and assessment align. 


\section{CHAPTER III}

\section{METHODOLOGY}

The purposes of this research study were to: 1) complete a within Kentucky university comparison of Kentucky Mathematics College Readiness Expectations (KMCRE) and 2) determine if an alignment among university mathematics college readiness expectations and college placement examinations exists. This study was implemented in two phases: In Phase 1, five universities' course finals in the highest-level mathematics remediation class offered were analyzed using Common Core State Standards (CCSS). In phase 1, each university final examination test item was coded to match one or more CCSS item(s) (See Appendix A for coding instrument). Phase 2 of the research study was an alignment analysis between each university's identified Kentucky Mathematics College Readiness Expectation (KM-CRE) with Kentucky's regulated college placement examinations: ACT, KYOTE, and COMPASS. Webb's alignment model was used to compare the identified KM-CRE to each placement examination, and four categories of alignment were explored. Content alignment was analyzed using Categorical Concurrence; Range of Knowledge; and Balance of Representation categories. Cognitive demand alignment was analyzed using Webb's Depth of Knowledge Consistency category (Webb, 2007). Together these two phases were intended to answer the research questions: (1) What mathematical prerequisite knowledge do state universities consider 
necessary to be college ready? Specifically 1a) What content domains do the state universities emphasize in their remediation courses?; 1b) Does consistency across the state public universities exist with regard to the content domains?; and 2) How well do Kentucky's mathematics placement assessments (ACT, COMPASS, and KYOTE) align in both content and cognitive demand with four-year universities' Kentucky Mathematics College Readiness Expectations (KM-CRE)? Content alignment will be determined using Webb's categories.

\section{Population and Sample}

The population in this research study was the final examinations in the highest remediation course at each Kentucky's college or university and the placement examinations mandated by Kentucky legislation. A purposeful sample of university remedial course examinations was selected based on a number of factors. First, although minimal competency scores on placement examinations for remedial course placement are recommended for all postsecondary institutions, Unbridled Learning mandates only minimal requirements for public universities and community colleges ("Next generation learners," 2011). Second, public universities were selected only if their mathematics' faculty used comprehensive finals that were consistent across all sections in their highest non-credit bearing remedial course. Of the eight Kentucky public universities, five were selected for the study (Two of the public colleges did not give a shared comprehensive final across sections, and one university did not offer remedial mathematics' courses). Community colleges were not included in this study because of the variety in programs and nature of the institutions and because those pursuing a bachelor's degree often 
transfer to a public university, thus the expectations of that four-year public institution are the goal for community colleges as well.

The sample of university final examinations included one final examination from each of the five selected universities. The researcher reviewed each university's website to determine the highest remediation course prior to a credit-bearing course. For questionable courses, the registrar's office at the various universities was contacted to verify course listings. The universities listed these classes as either Intermediate or Developmental Algebra. Course descriptions included topics such as exponents, integers, fractions, decimals, square roots, percent with applications, basic geometry, the real number system, algebraic expressions, linear and quadratic equations, inequalities, polynomials, graphing linear and quadratic functions, graphing circles, factoring, systems of equations, and radical expressions. Once the appropriate course was identified, the instructor of the course was contacted, and a copy of the final examinations was requested.

The placement examinations used in the sample were ACT, KYOTE, and COMPASS. With permission granted, the researcher analyzed a released test from ACT. The researcher completed the online adaptive COMPASS examination multiple times to analyze test items to create one common list of what topics were tested on any given COMPASS. Additionally, the researcher analyzed a version of the KYOTE placement examination consisting of thirty-one items. The test items from all three placement examinations were analyzed with respect to mathematics content and cognitive demand using Webb's alignment model.

\section{Placement Examination Data Collection Procedures}


The research and development department of ACT provided a released ACT mathematics examination. Because ACT serves as a range of knowledge indicator rather than a minimal knowledge assessment, not all sixty questions on the examination were anticipated to match an item on KM-CRE, which is a condensed version of the CCSS. Since the KM-CRE coding instrument was developed using remedial mathematics final examinations, I anticipated that ACT test items would access knowledge beyond minimal competency. All ACT test items that did not match a standard on the KM-CRE coding instrument were removed from data analysis. Because this study was not intended to determine the alignment between placement examinations and CCSSM, the removal of items not appearing on KM-CRE did not affect the alignment analysis being completed. Since the intention of the established KM-CRE was to reflect college ready expectations, ACT should have minimally assessed those standards; however, by design they assess standards beyond those as well. The number of analyzed test items was 47 .

The research and development department of COMPASS granted me permission to take multiple online examinations to analyze mathematics content and DOK levels. Based on the design of COMPASS, I gave both correct and incorrect answers on the examination to view a multitude of questions covering different content and difficulty levels. In order to review a wide range of questions from challenging to basic understanding, I took the examination three times. The first time all questions were answered correctly. After 55 questions, the examination ended and scored me ready for trigonometry and bypassing algebra and college algebra. Very few of these questions matched a KM-CRE standard. Since these questions were beyond the scope of the study and placed me beyond an entry-level mathematics course, these questions were excluded 
from the final study. The second examination was completed using the method of answering one question correctly followed by one incorrect answer. This strategy was used to represent a mid-range student. This method allowed me to see 15 questions and deemed me ready for algebra. On the third examination, two questions were answered incorrectly and one question was answered correctly. This strategy intended to represent a struggling student. Using this method, I was given 35 questions and placed in prealgebra. For the purpose of the alignment study of COMPASS, only the last two sets of examination questions were used. This strategy gave me 50 questions to analyze and was a similar number of question items as ACT.

To analyze the KYOTE examination, I contacted Northern Kentucky University and was prompted to contact Paul Eakin at the University of Kentucky who now oversees KYOTE administration. I received permission from Dr. Eakin to become a test administrator in order to analyze test items. I was given access to a 31-item test. I analyzed each question for content and DOK.

\section{Instrumentation}

Faculty and instructors from five public universities in Kentucky submitted comprehensive final examinations for the highest non-credit-bearing mathematics course. Each final examination item was analyzed using the Common Core State Standards coding instrument (see Appendix A). This instrument was a matrix of Common Core State Standards in Mathematics (CCSSM) from $6^{\text {th }}$ grade through high school and Depth of Knowledge Levels. This format allowed analysis of both content and cognitive demand. I used the CCSSM because of its adoption in Kentucky as standards for mathematic content knowledge to be college ready (CCSSO, 2010) and to create 
consistency of terminology. The CCSSM for $6^{\text {th }}$ grade through high school are divided into eight content categories: Ratios and Proportional Relationships; The Number System; Number and Quantity; Expressions and Equations; Algebra; Functions; Geometry; and Statistics and Probability. Under each of these content categories, lists of standards identify and describe specific content knowledge. Using a "hit" system, I first identified the conceptual category and the standard or standards assessed on the course final examination. Once the standard was identified, a "hit" was recorded on the CCSS coding instrument (See table 3). For some questions, multiple "hits" were recorded if more than one standard was assessed. After matching the question content to standard(s), I then recorded a depth of knowledge level to the "hit." If a standard had more than one "hit" on the same examination, I assigned the highest level DOK to that standard. The rationale for this strategy was that, if an examination had two or more questions about the same standard, then the expectation from the university was to know the topic at the highest depth-of-knowledge level it was assessed. When two or more universities had "hits" on the same standard, then I applied Webb's 50\% rule for assigning a depth-ofknowledge level. For instance if three universities assigned a DOK level 2 to standard X and one university assigned that same standard a DOK level 3, then on the KM-CRE document, a DOK level 2 would be assigned. Likewise, if two universities assigned a DOK 2 and two universities assigned a DOK 3 , then a DOK of 3 would be given to the KM-CRE standard. This strategy was important to insure the depth-of-knowledge consistency criterion. 
Table 3

Percent of Emphasis on CCSS Domains on Final Examination by University

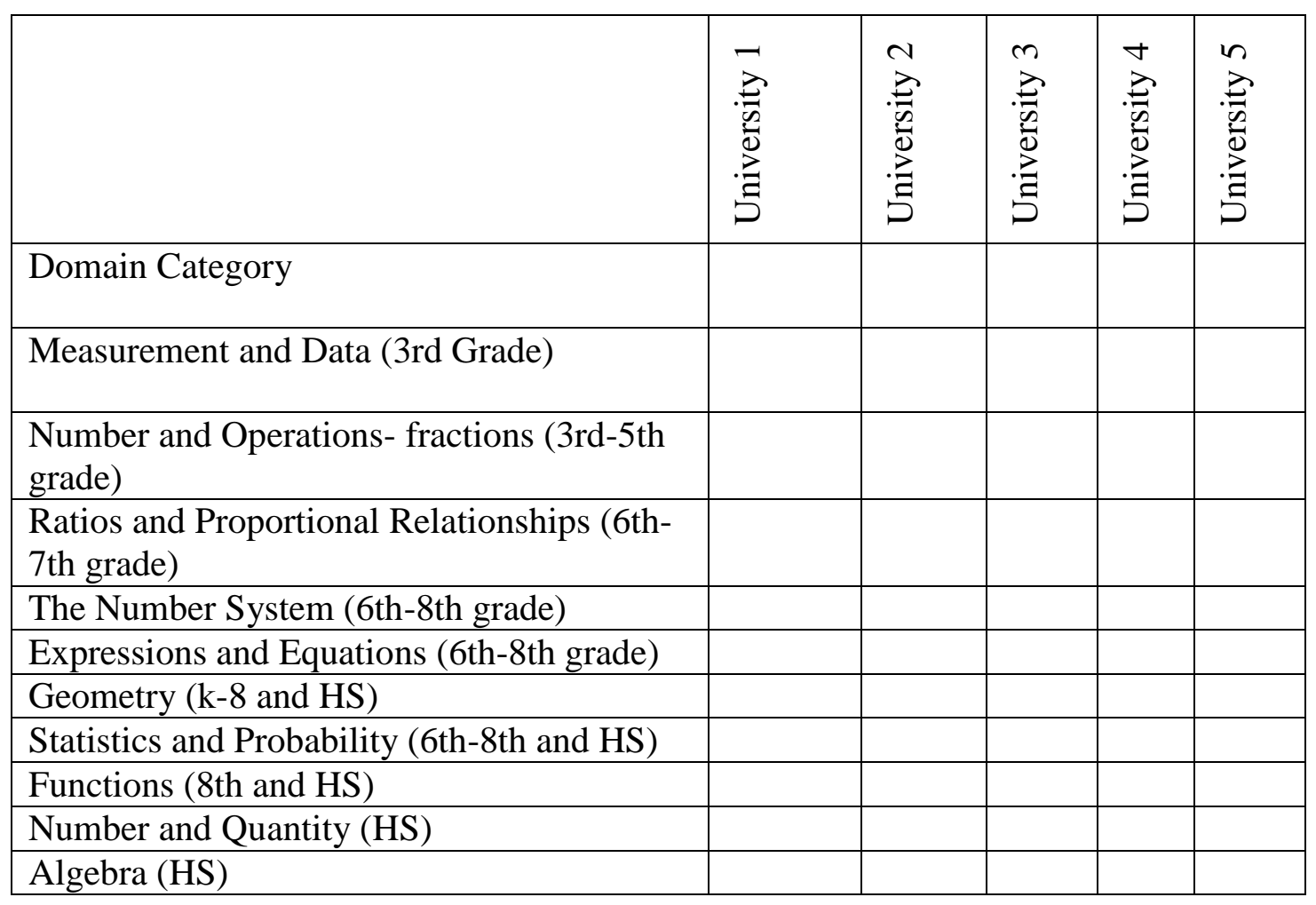

Once each remedial mathematics course final examination item was analyzed and recorded on the CCSS coding instrument, all conceptual categories and standards were removed from the coding instrument that were not assessed on at least one of the finals. The reason for the removal of the non-assessed CCSS was to create a list of college readiness expectations according to what Kentucky universities deemed important through their course final examinations. Matching final examination test items to CCSS was not performed to determine if colleges tested all of the CCSSM, but to determine exactly what was being assessed. These assessed standards were named Kentucky Mathematics College Readiness Expectations and will be referred from this point forward as KM-CRE. Using Webb's Alignment model between expectations and assessments, I 
placed KM-CRE in a matrix document to analyze the expectations with Kentucky's regulated placement examinations: ACT, COMPASS, and KYOTE (see table 4).

Table 4

\begin{tabular}{|c|c|c|c|c|c|}
\hline \multicolumn{6}{|c|}{ Alignment Analysis Table } \\
\hline Domains & $\begin{array}{l}\text { KM-CRE } \\
\text { Standard } \\
\text { Numbers }\end{array}$ & $\begin{array}{c}\text { Required } \\
\text { "Hit" } \\
\text { Count }\end{array}$ & $\begin{array}{c}\text { ACT "Hit" } \\
\text { Count }\end{array}$ & $\begin{array}{c}\text { KYOTE } \\
\text { "Hit" } \\
\text { Count }\end{array}$ & $\begin{array}{l}\text { COMPASS } \\
\text { "Hit" Count }\end{array}$ \\
\hline $\begin{array}{l}\text { Ratios and } \\
\text { Proportional } \\
\text { Relationships }\end{array}$ & & & & & \\
\hline Geometry & & & & & \\
\hline $\begin{array}{l}\text { Number and } \\
\text { Quantity }\end{array}$ & & & & & \\
\hline $\begin{array}{l}\text { The Number } \\
\text { System }\end{array}$ & & & & & \\
\hline $\begin{array}{l}\text { Expressions and } \\
\text { Equations }\end{array}$ & & & & & \\
\hline Functions & & & & & \\
\hline Algebra & & & & & \\
\hline
\end{tabular}

\section{Accurate Coding of Test Items}

To ensure correct matching of test items to the appropriate Common Core State Standards and accurately assigning a depth-of-knowledge level, I held a scoring session with two high school mathematics teachers. The selected teachers were familiar with the CCSSM and had experience and training in Depth of Knowledge. Each of us assessed 15 ACT practice test items from the ACT website. Each scorer's placement of test items on the coding instrument and DOK level assignment was compared to ensure consistency. Twenty "hits" were made to CCSS coding instrument within the 15 questions. All assigned DOK levels matched. Only one item matched to a different content standard, but 
it was located in the same domain. This coding resulted in a $95 \%$ level of agreement. With this high agreement level, I felt confident in continuing the test item analysis independently.

\section{Data Analysis}

For phase 1 of the study, data from the university final examinations of the highest level remedial course were examined to determine what mathematics content university faculty considered to be requirements for college-ready. The percent of emphasis on content was determined for each conceptual category: Ratios and Proportional Relationships: The Number System: Number and Quantity: Expressions and Equations: Algebra: Functions: Geometry: and Statistics and Probability. Each test item was analyzed using a "hit" system. When a test item matched a conceptual category standard, I recorded the problem number on the CCSS coding sheet. I determined the percent of emphasis on content by finding the number of "hits" each content standard received and dividing it by the total number of "hits" recorded in the CCSS coding instrument for each university's final examination. For instance, in the category of Algebra, if 10 hits were recorded and a total of 30 hits were recorded in all categories on the CCSS coding instrument, then the percent of emphasis for that university's final examination on Algebra was 33.3\% (10 out of 30). Each university's percent of content emphasis was compared to each of the other universities" percent of content emphasis.

Once each university's CCSSM coding instrument was completed, I analyzed them to determine the KM-CRE. Using the number of "hits" that each domain received by each university, I determined which domains in the CCSSM coding instrument would remain in the KM-CRE coding instrument. If more than half of the universities had at 
least one "hit" in a domain, then the domain was included in the KM-CRE. Using this process, the domain categories Measurement and Data, Number and Operations-fractions, and Statistics and Probability were all removed (See table 5). Once I selected the domains, all standards that appeared in that domain from each university were included in the final KM-CRE document to give a breadth of standards that met the content domain.

Table 5

\section{CCSSM Coding Instrument Hit Counts for Universities}

\begin{tabular}{|c|c|c|c|c|c|}
\hline Domain Category & 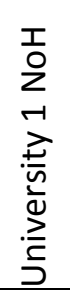 & 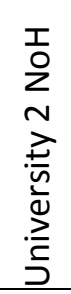 & 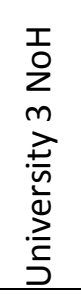 & 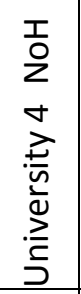 & 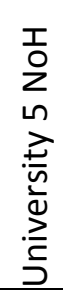 \\
\hline Measurement and Data (3rd Grade) & 0 & 1 & 0 & 0 & 2 \\
\hline Number and Operations- fractions (3rd-5th grade) & 2 & 0 & 0 & 0 & 0 \\
\hline $\begin{array}{l}\text { Ratios and Proportional Relationships (6th-7th } \\
\text { grade) }\end{array}$ & 4 & 3 & 4 & 0 & 1 \\
\hline The Number System (6th-8th grade) & 8 & 2 & 0 & 3 & 5 \\
\hline Expressions and Equations (6th-8th grade) & 29 & 23 & 22 & 3 & 20 \\
\hline $\begin{array}{l}\text { Geometry (k-8: HS) } \\
\text { Total }\end{array}$ & $\begin{array}{r}1: 2 \\
3\end{array}$ & $\begin{array}{r}1: 0 \\
1\end{array}$ & $\begin{array}{l}0 \\
0\end{array}$ & $\begin{array}{l}1 \\
1\end{array}$ & $\begin{array}{r}1: 8 \\
9\end{array}$ \\
\hline Statistics and Probability (6th-8th and HS) & 0 & 0 & 0 & 0 & 0 \\
\hline $\begin{array}{l}\text { Functions (8th :HS) } \\
\text { Total }\end{array}$ & $\begin{array}{r}7: 7 \\
14\end{array}$ & $\begin{array}{r}3: 5 \\
8\end{array}$ & $\begin{array}{r}2: 6 \\
8\end{array}$ & $\begin{array}{r}3: 4 \\
7\end{array}$ & $\begin{array}{r}3: 7 \\
10\end{array}$ \\
\hline Number and Quantity (HS) & 11 & 5 & 7 & 6 & 0 \\
\hline Algebra (HS) & 35 & 25 & 34 & 12 & 27 \\
\hline
\end{tabular}

The alignment portion of this study used Webb's (1997) model for alignment between expectations and assessments. The expectations analyzed in the study were those established by examining each university's final examination in the highest non-creditbearing remediation course and were identified as KM-CRE in phase 1 . The assessments 
in the study were the college placement examinations ACT, COMPASS, and KYOTE. These placement examinations are mandated and regulated by Kentucky legislation ("Minimum requirements for high school graduation," 2011). In preparation for the cognitive demand alignment portion, the KM-CRE standards assessed by each university were assigned a depth-of-knowledge level. This process was described previously. Using the KM-CRE coding matrix with DOK levels identified, I analyzed each test item on a released version of the examinations (ACT, COMPASS, and KYOTE). I conducted an analysis of both content and cognitive demand as described below. The examinations were analyzed for matches or "hits" with the possibility of a test item having multiple "hits" within the matrix.

The categories of Webb's model that were used for analyzing alignment in this study were categorical concurrence, depth of knowledge, range of knowledge correspondence, and balance of representation.

\section{Content Alignment}

Categorical Concurrence. Categorical concurrence was measured by determining the number of items that appeared in each assessment. According to Webb, if six or more items occur in each category or standard strand, then sufficient coverage of content is ensured. The Kentucky's College Mathematics Readiness Standards have seven strands with multiple objectives within each strand. The seven strands and number of objective per strand are: Ratios and Proportional Relationships (5); The Number System (17); Expressions and Equations (9); Geometry (7); Functions (14); Number and Quantity (7); and Algebra (21). 
Range of Knowledge. For range of knowledge correspondence to occur, Webb stated that all objectives within a standard should be assessed; however a match of at least $50 \%$ of each objective per strand is considered acceptable. Using the Kentucky College Mathematics Readiness Standards and the "hits" determined by the analysis of the placement examination questions, range of knowledge was considered met in each standard if at least $50 \%$ of the objectives within a standard strand matched to an examination question.

Balance of Representation. The balance of representation criterion is used to measure the degree to which emphasis is placed on one standard in a domain over another on an assessment (Webb, 2007). An index number is determined to measure this criterion by using only objectives that receive at least one hit. The index is computed by determining the difference in the proportion of the number of standards in each domain and the number of hits each standard receives. The index for each domain was found by applying the following formula:

$$
1-\frac{\left(\sum_{k=1}^{T}\left|\frac{1}{T}-\frac{h(k)}{H}\right|\right)}{2}
$$

Where $\mathrm{T}=$ total number of standards hit for the domain. $\mathrm{h}(\mathrm{k})=$ number of items hit corresponding to standard $\mathrm{h}$ $\mathrm{H}=$ total number of items hit for the domain (N. L. Webb, 2007, p. 14).

To illustrate the above formula, I will show the calculations for ACT in the Expressions and Equations domain. There are eight standards assessed with a total of 20 hits. $\mathrm{T}=8 \quad \mathrm{H}=20$ 


$$
\begin{aligned}
& 1-\frac{\left(\sum_{k=1}^{T}\left|\frac{1}{T}-\frac{h(k)}{H}\right|\right)}{2} \quad 1-\frac{\left(\frac{1}{3}-\frac{3}{20}\right)+\left(\frac{1}{3}-\frac{2}{20}\right)+\left(\frac{1}{3}-\frac{3}{20}\right)+\left(\frac{1}{8}-\frac{2}{20}\right)+\left(\frac{1}{8}-\frac{2}{20}\right)+\left(\frac{1}{8}-\frac{5}{20}\right)+\left(\frac{1}{8}-\frac{2}{20}\right)+\left(\frac{1}{8}-\frac{1}{20}\right)}{2} \\
& =1-\frac{\frac{1}{40}+\frac{1}{40}+\frac{1}{40}+\frac{1}{40}+\frac{1}{40}+\frac{1}{40}+\frac{5}{40}+\frac{1}{40}+\frac{1}{40}}{2}=1-\frac{\frac{13}{40}}{2}=1-\frac{13}{80}=.8375
\end{aligned}
$$

Therefore 0.8375 is the alignment value for balance of representation for ACT's Expressions and Equations domain.

\section{Cognitive Complexity Alignment}

Depth of Knowledge Consistency. Webb (2007), in his alignment model, labels the depth-of-knowledge match "DOK Consistency." He describes this trait as the consistency between what students are demanded to know and be able to do at multiple cognitive levels according to the standards and the cognitive level that is required to answer questions appropriately on an assessment. Webb applies the fifty percent rule to this category as well. For this category criterion to be met, the assessment must have at least $50 \%$ of the hits on test items to be at or above the cognitive level (DOK level) as the corresponding objective standard. For instance, if an expectation standard has a DOK level of 2 and it is assessed at a DOK level 1, then it would be said to below the cognitive level of the corresponding objective. If the expectation standard is assessed at a DOK level of 2 or 3 , then it would be said to be at or above the cognitive level of the corresponding objective. For this criterion to be met, at least half of the standards assessed must be at or above the cognitive level of the corresponding expectation objective

\section{Limitations}

The purpose of this study was first to determine what expectations are common across universities in terms of what faculty consider readiness for the first credit-bearing course. For this study this expectation was defined as the final examination for the 
highest level remedial course. Yet, the final examination may not be an accurate indication of all that universities consider to be important in readiness for a credit-bearing course, but could instead focus on the subset of those topics for which they anticipate students to struggle.

Second, this study reflected the assessments from only five public institutions, all within the same state. Without administering comprehensive finals or offering remediation classes, I was unable to include others in the study using the methodology. For the one university excluded based on the non-comprehensive final the course description matched the other included universities and therefore the content covered and assessed should be the same. By including these five universities, the absence of the other three should have a negligible effect on the overall results.

Another limitation of the study was the different designs and formats of the college placement examinations KYOTE, COMPASS and ACT. Different methods were used to determine what mathematics content each assessment measured. These placement examinations had multiple versions, with COMPASS having an added complexity that drew from a pool of questions that adjusted difficulty based on how previous questions were answered. With little consistency in the questions that were posed to students, this study relied on the high concurrent validity and parallel forms reliability of the assessments. Additionally, ACT was designed to measure a range of mathematical knowledge, rather than just minimal competency. For this reason, some test items were removed from the item analysis if they assessed content not represented on the coding instrument. 
Finally, the KM-CRE was based on the Common Core State Standards for mathematics. These standards emphasize important mathematical content and mathematical processes. The Mathematical Practices described how students might engage in mathematics content. For instance, in order for a student to display their knowledge of functions, students may be required to reason abstractly, model with mathematics, use an appropriate model, and/or make use of structure. For this reason, assessing Mathematical Practices and mathematical content separately is challenging. Although through inferring what the intended practice was to be used on an assessment question, coding of this would be very difficult and with no absolute assurance it was being coded correctly, mathematical practice will not be included in this study. Only content standard domains of the Common Core State Standards were used in the coding instrument. Although both types of knowledge are important in the development of mathematical understanding, this study is limited to measuring only the alignment of Standards for Mathematical Content. 


\section{CHAPTER IV}

\section{ANALYSIS OF DATA}

This research study was divided into two parts (1) a within comparison study focused on mathematics college readiness content and cognitive demand expectations in mathematics courses in Kentucky's universities and (2) an alignment study among Kentucky Mathematics College Readiness Expectations (called KM-CRE from this point forward in chapter 4) and Kentucky college placement examinations (ACT, COMPASS, and KYOTE).

\section{Part I - Comparison of Expectations among Kentucky Universities}

\section{Coding Procedures}

The first part of the study involved collecting final examinations from the highest level remediation mathematics courses in five Kentucky public universities to determine the emphasis of content and the consistency of this emphasis across universities (Research questions 1, part a and b). The five universities were selected because their

mathematics' faculty used comprehensive finals that were consistent across all sections in their highest non-credit bearing remedial course. The other three Kentucky universities were excluded from the study because they did not meet this criterion. One excluded university did not offer remedial mathematics courses, and the other two did not give consistent comprehensive finals across courses. 
Course finals were collected from each university, and all assessments on the finals were analyzed to determine which, if any, CCSSM were assessed and at what particular depth-of-knowledge level. Each item was matched to a CCSSM based on the "big picture" of what was assessed. Multiple concepts may have been assessed within a question; however, I matched the overarching idea or point of emphasis. For example, if a task required the student to write a ratio of boys to girls in simplest form, the "big picture" was for a student to write and simplify a fraction. These topics matched the fourth-grade CCSS domain Number and Operations-Fraction. But if a task simply required "Simplify the following: $\frac{3 x}{12 x^{2}}$." then the "big picture" was to simplify a rational expression. This topic matches the CCSS standard "Rewrite rational expressions in the Algebra domain.” Although $\frac{3}{12}$ is a fraction that should be simplified, this problem would not receive a hit in $4^{\text {th }}$-grade Number and Operations because simplifying was not the "big picture" for the problem. Conversely, some assessment items had a "hit" on more than one standard. An example would be in the following question:

The determinant of a matrix $\left[\begin{array}{ll}a & b \\ c & d\end{array}\right]$ equals ad-cb. What must be the value of $x$ for the matrix $\left[\begin{array}{ll}x & 8 \\ x & x\end{array}\right]$ to have a determinant of -16 ?

This question does not require a student to know anything about determinants or matrices but rather to follow a prescribed formula for creating an expression to describe a determinant, setting it equal to -16 (creating an equation), and then solving a quadratic equation for $x$. This question hits three different KM-CRE standards: (1) Expressions and Equations-Write, read, and evaluate expressions in which letters stand for numbers; (2) 
Algebra-Creating Equations; and (3) Algebra-Reasoning with Equations and Inequalities -Solve quadratic equations.

\section{CCSSM and KM-CRE Domain Selections}

Initially, I began with only high school CCSSM, but realized that assessment items were also addressing CCSSM middle school $\left(6^{\text {th }}-8^{\text {th }}\right.$ grade $)$ content, and in some

cases, CCSSM even elementary content (e.g. Measurement and Data ( $3^{\text {rd }}$ grade), and Number and Operations - fractions $\left(3^{\text {rd }}-5^{\text {th }}\right.$ grade $\left.)\right)$. Since only three hits from all universities landed in these elementary CCSSM, and these hits were not represented by more than half of the universities, they were not included in the final version of the KMCRE. Additionally, no hits were recorded in the CCSSM matrix from any university final in the domain of Statistics and Probability. Therefore, this domain was excluded from the Expectations as well. All university CCSSM matrices are located in Appendix B. The data from the matrices are summarized for each university in Tables 6-10 which display the CCSS Domain strands, number of examinations items, hit count, and percent of emphasis. 
Table 6

\section{University 1-CCSS Matrix of Percent of Emphasis}

\begin{tabular}{|l|l|l|}
\hline Domain Category & $\begin{array}{l}\text { Number } \\
\text { of Hits }\end{array}$ & $\begin{array}{l}\text { Percent of } \\
\text { Emphasis }\end{array}$ \\
\hline Measurement and Data (3rd grade) & 0 & $0 \%$ \\
\hline Number and Operations- fractions (3rd-5th grade) & 2 & $2 \%$ \\
\hline Ratios and Proportional Relationships (6th-7th grade) & 4 & $4 \%$ \\
\hline The Number System (6th-8th grade) & 8 & $8 \%$ \\
\hline Expressions and Equations (6th-8th grade) & 29 & $27 \%$ \\
\hline Geometry (k-8 :HS) & $1: 2$ & $3 \%$ \\
\hline Statistics and Probability (6th-8th and HS) & 0 & $0 \%$ \\
\hline Functions (k-8: HS) & $7: 7$ & $6.5 \%: 6.5 \%$ \\
\hline Functions (Total) & 14 & $13 \%$ \\
\hline Number and Quantity (HS) & 11 & $10 \%$ \\
\hline Algebra (HS) & 35 & $33 \%$ \\
\hline \hline Total & 106 & $100 \%$ \\
\hline 87 question test with some & & \\
\hline
\end{tabular}

87 question test with some items having multiple hits

Table 7

\section{University 2 - CCSS Matrix of Percent of Emphasis}

\begin{tabular}{|l|l|l|}
\hline Domain Category & $\begin{array}{l}\text { Number } \\
\text { of Hits }\end{array}$ & $\begin{array}{l}\text { Percent of } \\
\text { Emphasis }\end{array}$ \\
\hline Measurement and Data (3rd Grade) & 1 & $1 \%$ \\
\hline Number and Operations- fractions (3rd-5th grade) & 0 & $0 \%$ \\
\hline Ratios and Proportional Relationships (6th-7th grade) & 3 & $4 \%$ \\
\hline The Number System (6th-8th grade) & 2 & $3 \%$ \\
\hline Expressions and Equations (6th-8th grade) & 23 & $34 \%$ \\
\hline Geometry (k-8 / HS) & $1: 0$ & $1 \%: 0 \%$ \\
Geometry (Total) & 1 & $1 \%$ \\
\hline Statistics and Probability (6th-8th and HS) & 0 & $0 \%$ \\
\hline Functions (k-8 / HS) & $3: 5$ & $4.4 \%: 7.2 \%$ \\
Functions (Total) & 8 & $12 \%$ \\
\hline Number and Quantity (HS) & 5 & $7 \%$ \\
\hline Algebra (HS) & 25 & $37 \%$ \\
\hline \hline Total & 68 & $100 \%$ \\
\hline
\end{tabular}

40 question test with some items having multiple hits 
Table 8

\section{University 3 - CCSS Matrix of Percent of Emphasis}

\begin{tabular}{|l|l|l|}
\hline Domain Category & $\begin{array}{l}\text { Number } \\
\text { of Hits }\end{array}$ & $\begin{array}{l}\text { Percent of } \\
\text { Emphasis }\end{array}$ \\
\hline Measurement and Data (3rd Grade) & 0 & $0 \%$ \\
\hline Number and Operations- fractions (3rd-5th grade) & 0 & $0 \%$ \\
\hline Ratios and Proportional Relationships (6th-7th grade) & 4 & $5 \%$ \\
\hline The Number System (6th-8th grade) & 0 & $0 \%$ \\
\hline Expressions and Equations (6th-8th grade) & 22 & $29 \%$ \\
\hline Geometry (k-8 / HS) & 0 & $0 \%$ \\
\hline Statistics and Probability (6th-8th and HS) & 0 & $0 \%$ \\
\hline Functions (k-8 / HS) & $2: 6$ & $2.6 \%: 8 \%$ \\
\hline Functions (Total) & 8 & $11 \%$ \\
\hline Number and Quantity (HS) & 7 & $9 \%$ \\
\hline Algebra (HS) & 34 & $45 \%$ \\
\hline \hline Total & 75 & $100 \%$ \\
\hline
\end{tabular}

44 question test with some items having multiple hits

\section{Table 9}

\section{University 4 - CCSS Matrix of Percent of Emphasis}

\begin{tabular}{|l|l|l|}
\hline Domain Category & $\begin{array}{l}\text { Number } \\
\text { of Hits }\end{array}$ & $\begin{array}{l}\text { Percent of } \\
\text { Emphasis }\end{array}$ \\
\hline Measurement and Data (3rd Grade) & 0 & $0.0 \%$ \\
\hline Number and Operations- fractions (3rd-5th grade) & 0 & $0.0 \%$ \\
\hline Ratios and Proportional Relationships (6th-7th grade) & 0 & $0.0 \%$ \\
\hline The Number System (6th-8th grade) & 3 & $9.4 \%$ \\
\hline Expressions and Equations (6th-8th grade) & 3 & $9.4 \%$ \\
\hline Geometry (k-8 / HS) & $0: 1$ & $0 \%: 3.1 \%$ \\
Geometry (Total) & 1 & $3.1 \%$ \\
\hline Statistics and Probability (6th-8th and HS) & 0 & $0.0 \%$ \\
\hline Functions (8) / HS) & $3: 4$ & $9.3 \%: 12.5 \%$ \\
Functions (Total) & 7 & $21.9 \%$ \\
\hline Number and Quantity (HS) & 6 & $18.8 \%$ \\
\hline Algebra (HS) & 12 & $37.5 \%$ \\
\hline \hline Total & 32 & $100.0 \%$ \\
\hline
\end{tabular}

27 question test with some items having multiple hits 


\section{Table 10}

\section{University 5- CCSS Matrix of Percent of Emphasis}

\begin{tabular}{|l|l|l|}
\hline Domain Category & $\begin{array}{l}\text { Number } \\
\text { of Hits }\end{array}$ & $\begin{array}{l}\text { Percent of } \\
\text { Emphasis }\end{array}$ \\
\hline Measurement and Data (3rd grade) & 2 & $3 \%$ \\
\hline Number and Operations- fractions (3rd-5th grade) & 0 & $0 \%$ \\
\hline Ratios and Proportional Relationships (6th-7th grade) & 1 & $1 \%$ \\
\hline The Number System (6th-8th grade) & 5 & $7 \%$ \\
\hline Expressions and Equations (6th-8th grade) & 20 & $27 \%$ \\
\hline Geometry (k-8 / HS) & $1: 8$ & $1.3 \%: 10.8 \%$ \\
Geometry (Total) & 9 & $12 \%$ \\
\hline Statistics and Probability (6th-8th and HS) & 0 & $0 \%$ \\
\hline Functions (k-8 / HS) & $3: 7$ & $4.1 \%: 9.5 \%$ \\
Functions (Total) & 10 & $14 \%$ \\
\hline Number and Quantity (HS) & 0 & $0 \%$ \\
\hline Algebra (HS) & 27 & $36 \%$ \\
\hline \hline Total & 74 & $100 \%$ \\
\hline
\end{tabular}

52 question test with some items having multiple hits

Table 11 shows the percent of emphasis of the CCSS Content domains for all five universities in the study. 


\section{Table 11}

Percent of Emphasis of CCSS Mathematics Content for 5 Public Universities

\begin{tabular}{|c|c|c|c|c|c|}
\hline Domain Category & 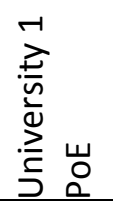 & 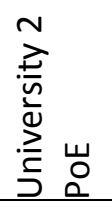 & 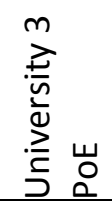 & 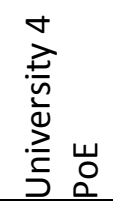 & 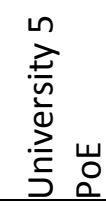 \\
\hline Measurement and Data (3rd Grade) & $0 \%$ & $1 \%$ & $0 \%$ & $0 \%$ & $3 \%$ \\
\hline $\begin{array}{l}\text { Number and Operations- fractions } \\
\text { (3rd-5th grade) }\end{array}$ & $2 \%$ & $0 \%$ & $0 \%$ & $0 \%$ & $0 \%$ \\
\hline $\begin{array}{l}\text { Ratios and Proportional } \\
\text { Relationships (6th-7th grade) }\end{array}$ & $4 \%$ & $4 \%$ & $5 \%$ & $0 \%$ & $1 \%$ \\
\hline The Number System (6th-8th grade) & $8 \%$ & $3 \%$ & $0 \%$ & $9 \%$ & $7 \%$ \\
\hline $\begin{array}{l}\text { Expressions and Equations (6th-8th } \\
\text { grade) }\end{array}$ & $27 \%$ & $34 \%$ & $29 \%$ & $9 \%$ & $27 \%$ \\
\hline Geometry (k-8 / HS) & $3 \%$ & $1 \%$ & $0 \%$ & $3 \%$ & $12 \%$ \\
\hline $\begin{array}{l}\text { Statistics and Probability (6th-8th } \\
\text { and HS) }\end{array}$ & $0 \%$ & $0 \%$ & $0 \%$ & $0 \%$ & $0 \%$ \\
\hline Functions (8th / HS) & $13 \%$ & $12 \%$ & $11 \%$ & $22 \%$ & $14 \%$ \\
\hline Number and Quantity (HS) & $10 \%$ & $7 \%$ & $9 \%$ & $19 \%$ & $0 \%$ \\
\hline Algebra (HS) & $33 \%$ & $37 \%$ & $45 \%$ & $38 \%$ & $36 \%$ \\
\hline Total & $100 \%$ & $100 \%$ & $100 \%$ & $100 \%$ & $100 \%$ \\
\hline
\end{tabular}

POE - Percent of Emphasis

Figure 2 shows a comparison of all universities in a bar graph format. 
Figure 2.

\section{Comparison of CCSS Domains for Each University Percent of Emphasis Chart}

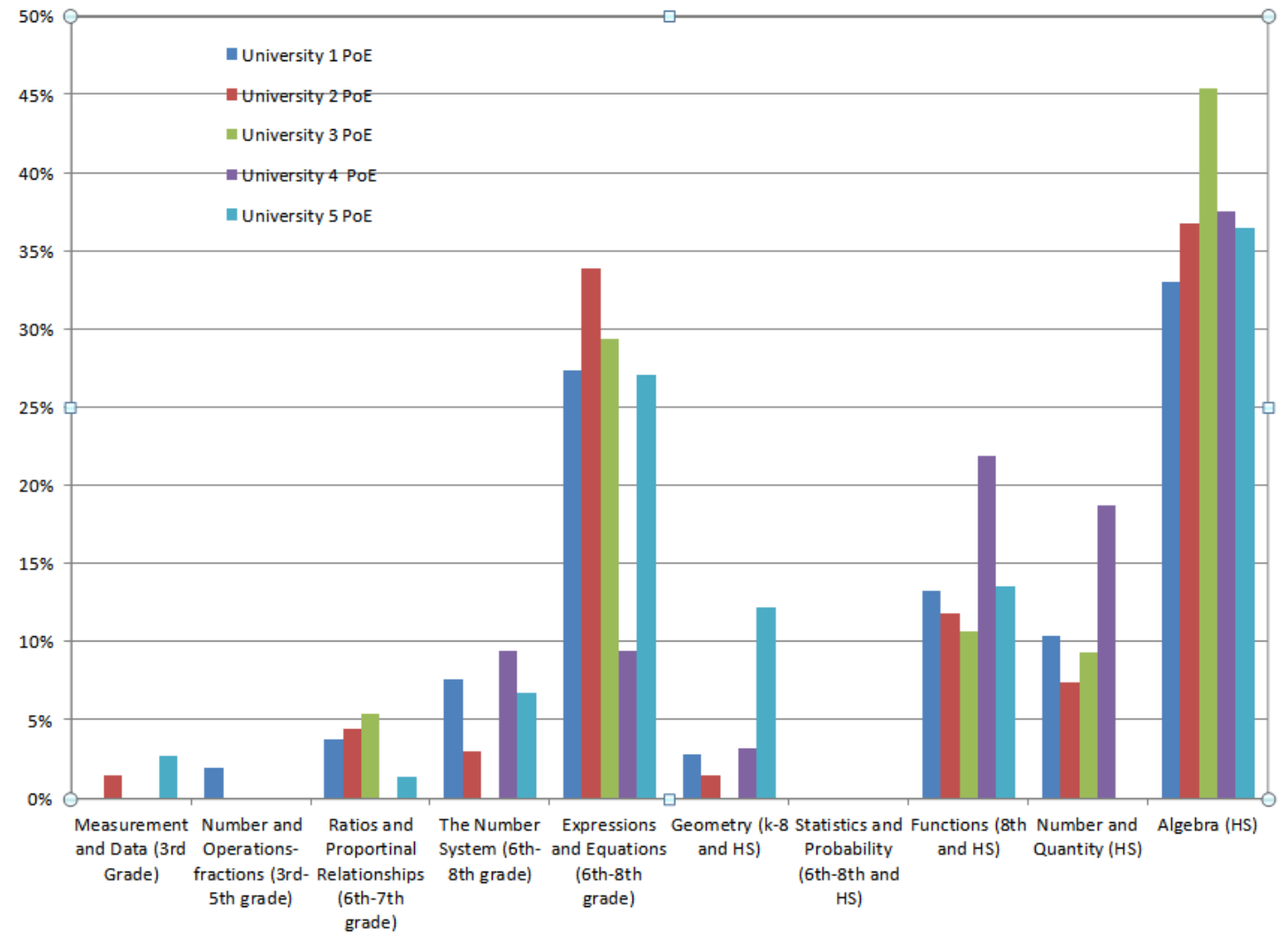

In order to answer the first research question, What prerequisite knowledge do state university students need to know to be considered college ready?, I needed to determine what content domains were assessed and did consistency exist across the five public universities. Using the "hit" tables 6-10, I looked for domains that received hits from at least three universities (more than half). Measurement and Data, Number and Operations-fractions, and Statistics and Probability did not meet this criterion. These content areas were consistently not assessed and removed from further analysis. From the remaining domains that were assessed by more than half of the institutions, the 
consistently least emphasized domains were Geometry, Number and Quantity, and Functions. The two consistently most emphasized domains were Expressions and Equations and Algebra. University 4 placed less emphasis on the Expressions and Equations domain while placing more emphasis on Functions and Number and Quantity compared to the other universities. University 5 placed a higher emphasis on Geometry compared to other universities and placed no emphasis on Number and Quantity. As the chart and data tables reveal, most of the universities placed similar emphasis on the same domains of the Common Core State Standards and consistency across universities was evident. No emphasis was placed on the domain of Statistics and Probability by any university. Less than 5\% emphasis was placed on Ratios and Proportional Relationships across all universities. Geometry had a very low percent of emphasis across universities with University 5 serving as an outlier. It had a $12 \%$ combined percent of emphasis across the middle and high school domains.

University 4 had the largest discrepancies of percent of emphasis across domains from the other universities. Expressions and Equations and Number and Quantity domains contained the largest portion of the differences. All universities placed the highest percent of emphasis on the domain Algebra. The percent of emphasis average on the Algebra domain was 38\%. Expressions and Equations was the second most emphasized by universities 1, 2, 3, and 5 with percent of emphasis of $27 \%, 34 \%, 29 \%$ and $27 \%$, respectively. University 4 had a percent of emphasis of $9 \%$ lowering the mean of Universities $1,2,3$, and 5 from $29.3 \%$ to $25.2 \%$ when including University 4 . The next most emphasized domain was Functions. Again Universities 1, 2, 3, and 5 were consistent, with University 4 serving as an outlier. Universities 1, 2, 3, and 5 had a 
percent of emphasis of $13 \%, 12 \%, 11 \%$, and $14 \%$, and University 4 had a percent of emphasis $22 \%$. The mean percent of emphasis with four universities is $12.5 \%$, and, with all 5 universities it was $14.4 \%$. Whereas the other universities placed emphasis on Expressions and Equations and Functions, University 4 emphasized Number and Quantity at a rate of $19 \%$, with the other universities having a percent of emphasis at $10 \%, 7 \%, 9 \%$, and $0 \%$. With the two outliers of the group, $19 \%$ and $0 \%$, off- setting each other the average percent of emphasis was $9 \%$. The remaining two domains The Number System and Geometry had an average percent of emphasis of $5.4 \%$ and $3.8 \%$, respectively.

There was consistency across all five universities in the least and most emphasized CCSSM domains for 6 -12 grade bands. The most emphasized domain was Algebra and the least emphasized domains were Statistics and Probability, Geometry, and Ratios and Proportional Relationships. All domains had 3 of the 5 universities with range of percent of emphasis of $3 \%$ or less. This meets the criteria for consistency.

\section{The Kentucky Mathematics College Readiness Expectations}

Using the data collected from the 5 universities in the study, I developed the Kentucky Mathematics College Readiness Expectations (KM-CRE). Based on the little emphasis placed on Measurement and Data ( $3^{\text {rd }}$ grade) and Number and Operationsfractions $\left(3^{\text {rd }}-5^{\text {th }}\right.$ grade $)$, these domains were excluded from KM-CRE. Additionally, since the CCSS domain Statistics and Probability did not receive any hits on any university final, that domain was removed. All other CCSSM domains that received "hits" from at least three of the universities were included in the KM-CRE. All standards within the included domains were included in the KM-CRE to provide a variety of standards to 
assess the overall domain. After selection of content, the cognitive complexity for each standard had to be determined. The following practice problem was released from ACT. Quadrilateral $A B C D$ is drawn on the standard $(x, y)$ coordinate plane as shown below, with points $E$ and $F$ on $A D$. Point $G$ is the center of rectangle $B C E F$. How many coordinate units long is $A G$ ?

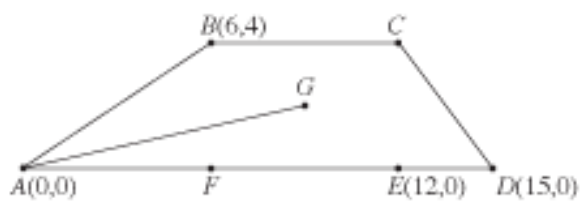
1. F. $\sqrt{10}$
2. G. $\sqrt{13}$
3. $\underline{\text { H. }} \sqrt{85}$
4. J. $\sqrt{97}$
5. $\underline{\text { K. }} 11$

This problem would be completed in 3 main steps.

$1^{\text {st }}$ - Determine the coordinates of point $\mathrm{G}$

$2^{\text {nd }}-$ Apply coordinates to lengths of triangle

$3^{\text {rd }}$ - Solve the for length of hypotenuse using the Pythagorean theorem

The first step requires strategic thinking realizing that if it is the midpoint of the rectangle then the coordinates can be found using the other points. This would be recorded as a DOK level of 3. Applying the Pythagorean theorem would be recorded as a DOK level 1 a straight algorithmic procedure. Once each question on the university finals was analyzed and assigned a DOK level and overall DOK level was determined for the KMCRE standard. If two different DOK levels were assigned to the same standard from the same university final, then the highest DOK level was assigned to that standard. The expectation from the university being that the student should understand the content at the highest level assessed on their examination. When determining the DOK level 
assigned to the KM-CRE standard, Webb's 50\% rule applied. The highest DOK level that was assigned by at least half of the universities assessing that standard was assigned to the KM-CRE standard (See table 12).

\section{Table 12}

\section{Kentucky Mathematics College Readiness Expectations}

\begin{tabular}{|l|l|}
\hline Ratios and Proportional Relationships & \\
\hline Ratios and Proportional relationships $6 . r P$ & \\
\hline Understand ratio concepts and use ratio reasoning to solve problems. & \\
\hline $\begin{array}{l}\text { 1. Understand the concept of a ratio and use ratio language to describe a ratio } \\
\text { relationship between two quantities. For example, "The ratio of wings to beaks in } \\
\text { the bird house at the zoo was } 2: 1 \text {, because for every } 2 \text { wings there was } 1 \text { beak." } \\
\text { "For every vote candidate A received, candidate C received nearly three votes." }\end{array}$ & 2 \\
\hline $\begin{array}{l}\text { 2. Understand the concept of a unit rate a/b associated with a ratio a:b with b } \neq 0, \\
\text { and use rate language in the context of a ratio relationship. For example, "This } \\
\text { recipe has a ratio of } 3 \text { cups of flour to } 4 \text { cups of sugar, so there is 3/4 cup of flour } \\
\text { for each cup of sugar." "We paid \$75 for } 15 \text { hamburgers, which is a rate of } \$ 5 \text { per } \\
\text { hamburger." }\end{array}$ & 2 \\
\hline $\begin{array}{l}\text { 3. Use ratio and rate reasoning to solve real-world and mathematical problems, } \\
\text { e.g., by reasoning about tables of equivalent ratios, tape diagrams, double number } \\
\text { line diagrams, or equations. }\end{array}$ & \\
\hline $\begin{array}{l}\text { c. Find a percent of a quantity as a rate per } 100 \text { (e.g., 30\% of a quantity means } \\
\text { 30/100 times the quantity); solve problems involving finding the whole, given a } \\
\text { part and the percent. }\end{array}$ & \\
\hline Ratios and Proportional Relationships $7 . r P$ & 2 \\
\hline 2. Recognize and represent proportional relationships between quantities. & \\
\hline $\begin{array}{l}\text { c. Represent proportional relationships by equations. For example, if total cost t is } \\
\text { proportional to the number } n \text { of items purchased at a constant price p, the } \\
\text { relationship between the total cost and the number of items can be expressed as t } \\
\text { = pn. }\end{array}$ & \\
\hline $\begin{array}{l}\text { 3. Use proportional relationships to solve multistep ratio and percent problems. } \\
\text { Examples: simple interest, tax, markups and markdowns, gratuities and } \\
\text { commissions, fees, percent increase and decrease, percent error. }\end{array}$ & \\
\hline The Number System & \\
\hline The number System $6 . n S$ & \\
\hline $\begin{array}{l}\text { Apply and extend previous understandings of multiplication and division to divide } \\
\text { fractions by fractions. }\end{array}$ & \\
\hline 1. Interpret and compute quotients of fractions & \\
\hline
\end{tabular}




\section{Compute fluently with multi-digit numbers and find common factors and}

multiples.

4. Find the greatest common factor of two whole numbers less than or equal to 100 and the least common multiple of two whole numbers less than or equal to 12. Use the distributive property to express a sum of two whole numbers 1-100 with a common factor as a multiple of a sum of two whole numbers with no common factor. For example, express $36+8$ as $4(9+2)$. Expectations for unit rates in this grade are limited to non-complex fractions.

Apply and extend previous understandings of numbers to the system of rational numbers.

5. Understand that positive and negative numbers are used together to describe quantities having opposite directions or values (e.g., temperature above/below zero, elevation above/below sea level, credits/debits, positive/negative electric charge); use positive and negative numbers to represent quantities in real-world contexts, explaining the meaning of 0 in each situation.

6. Understand a rational number as a point on the number line. Extend number line diagrams and coordinate axes familiar from previous grades to represent points on the line and in the plane with negative number coordinates.

b. Understand signs of numbers in ordered pairs as indicating locations in quadrants of the coordinate plane; recognize that when two ordered pairs differ only by signs, the locations of the points are related by reflections across one or both axes.

7.Understand ordering and absolute value of rational numbers.

c. Understand the absolute value of a rational number as its distance from 0 on the number line; interpret absolute value as magnitude for a positive or negative quantity in a real-world situation. For example, for an account balance of -30 dollars, write $|-30|=30$ to describe the size of the debt in dollars.

The Number System 7.nS

Apply and extend previous understandings of operations with fractions to add, subtract, multiply, and divide rational numbers.

1. Apply and extend previous understandings of addition and subtraction to add and subtract rational numbers; represent addition and subtraction on a horizontal or vertical number line diagram.

c. Understand subtraction of rational numbers as adding the additive inverse, $p-q$ $=p+(-q)$. Show that the distance between two rational numbers on the number line is the absolute value of their difference, and apply this principle in real-world contexts.

d. Apply properties of operations as strategies to add and subtract rational numbers.

2. Apply and extend previous understandings of multiplication and division and of fractions to multiply and divide rational numbers. 
a. Understand that multiplication is extended from fractions to rational numbers by requiring that operations continue to satisfy the properties of operations, particularly the distributive property, leading to products such as $(-1)(-1)=1$ and the rules for multiplying signed numbers. Interpret products of rational numbers by describing real-world contexts.

3. Solve problems involving the four operations with rational numbers.

\section{8th Grade Standards}

The Number System 8.nS

Know that there are numbers that are not rational, and approximate them by rational numbers.

2. Use rational approximations of irrational numbers to compare the size of irrational numbers, locate them approximately on a number line diagram, and estimate the value of expressions (e.g., $\pi$ ). For example, by truncating the decimal expansion of $\sqrt{ } 2$, show that $\sqrt{ } 2$ is between 1 and 2 , then between 1.4 and 1.5 , and explain how to continue on to get better approximations.

\section{Expressions and Equations \\ Expressions and Equations 6.ee}

Apply and extend previous understandings of arithmetic to algebraic expressions.

1. Write and evaluate numerical expressions involving whole-number exponents.

2. Write, read, and evaluate expressions in which letters stand for numbers.

a. Write expressions that record operations with numbers and with letters standing for numbers. For example, express the calculation "Subtract y from 5 " as $5-y$.

b. Identify parts of an expression using mathematical terms (sum, term, product, factor, quotient, coefficient); view one or more parts of an expression as a single entity. For example, describe the expression $2(8+7)$ as a product of two factors; view $(8+7)$ as both a single entity and a sum of two terms.

c. Evaluate expressions at specific values of their variables. Include expressions that arise from formulas used in real-world problems. Perform arithmetic operations, including those involving whole number exponents, in the conventional order when there are no parentheses to specify a particular order (Order of Operations). For example, use the formulas $V=s 3$ and $A=6 s 2$ to find the volume and surface area of a cube with sides of length $s=1 / 2$.

3. Apply the properties of operations to generate equivalent expressions. For example, apply the distributive property to the expression $3(2+x)$ to produce the equivalent expression $6+3 x$; apply the distributive property to the expression $24 x$ $+18 y$ to produce the equivalent expression $6(4 x+3 y)$; apply properties of operations to $y+y+y$ to produce the equivalent expression $3 y$. 


\begin{tabular}{|c|c|}
\hline Reason about and solve one-variable equ & \\
\hline $\begin{array}{l}\text { 5. Understand solving an equation or inequality as a process of answering a } \\
\text { question: which values from a specified set, if any, make the equation or } \\
\text { inequality true? Use substitution to determine whether a given number in a } \\
\text { specified set makes an equation or inequality true. }\end{array}$ & 2 \\
\hline $\begin{array}{l}\text { 7. Solve real-world and mathematical problems by writing and solving } \\
\text { equations of the form } x+p=q \text { and } p x=q \text { for cases in which } p \text {, } q \text { and } x \text { are all } \\
\text { nonnegative rational numbers. }\end{array}$ & 2 \\
\hline Expressions and Equations 7.ee & \\
\hline Use properties of operations to generate equivalent expressions. & \\
\hline $\begin{array}{l}\text { 1. Apply properties of operations as strategies to add, subtract, factor, and } \\
\text { expand linear expressions with rational coefficients. }\end{array}$ & 2 \\
\hline $\begin{array}{l}\text { 3. Solve multi-step real-life and mathematical problems posed with positive and } \\
\text { negative rational numbers in any form (whole numbers, fractions, and decimals), } \\
\text { using tools strategically. Apply properties of operations to calculate with numbers } \\
\text { in any form; convert between forms as appropriate; and assess the } \\
\text { reasonableness of answers using mental computation and estimation strategies. } \\
\text { For example: If a woman making } \$ 25 \text { an hour gets a } 10 \% \text { raise, she will make an } \\
\text { additional } 1 / 10 \text { of her salary an hour, or } \$ 2.50 \text {, for a new salary of } \$ 27.50 \text {. If you } \\
\text { want to place a towel bar } 93 / 4 \text { inches long in the center of a door that is } 271 / 2 \\
\text { inches wide, you will need to place the bar about } 9 \text { inches from each edge; this } \\
\text { estimate can be used as a check on the exact computation. }\end{array}$ & 2 \\
\hline $\begin{array}{l}\text { 4. Use variables to represent quantities in a real-world or mathematical problem, } \\
\text { and construct simple equations and inequalities to solve problems by reasoning } \\
\text { about the quantities. }\end{array}$ & \\
\hline $\begin{array}{l}\text { a. Solve word problems leading to equations of the form } p x+q=r \text { and } p(x+q)=r \text {, } \\
\text { where } p \text {, } q \text {, and } r \text { are specific rational numbers. Solve equations of these forms } \\
\text { fluently. Compare an algebraic solution to an arithmetic solution, identifying the } \\
\text { sequence of the operations used in each approach. For example, the perimeter of } \\
\text { a rectangle is } 54 \mathrm{~cm} \text {. Its length is } 6 \mathrm{~cm} \text {. What is its width? }\end{array}$ & 2 \\
\hline Expressions and Equations 8.ee & \\
\hline Work with radicals and integer exponents. & \\
\hline $\begin{array}{l}\text { 1. Know and apply the properties of integer exponents to generate equivalent } \\
\text { numerical expressions. }\end{array}$ & 2 \\
\hline $\begin{array}{l}\text { 2. Use square root and cube root symbols to represent solutions to equations of } \\
\text { the form } x=p \text { and } x=p \text {, where } p \text { is a positive rational number. Evaluate square } \\
\text { roots of small perfect squares and cube roots of small perfect cubes. Know that } \sqrt{ } 2 \\
\text { is irrational. }\end{array}$ & 2 \\
\hline $\begin{array}{l}\text { 4. Perform operations with numbers expressed in scientific notation, including } \\
\text { problems where both decimal and scientific notation are used. Use scientific } \\
\text { notation and choose units of appropriate size for measurements of very large or } \\
\text { very small quantities (e.g., use millimeters per year for seafloor preading). } \\
\text { Interpret scientific notation that has been generated by technology. }\end{array}$ & 2 \\
\hline 7. Solve linear equations in one variable. & \\
\hline
\end{tabular}


b. Solve linear equations with rational number coefficients, including equations whose solutions require expanding expressions using the distributive property and collecting like terms.

8. Analyze and solve pairs of simultaneous linear equations.

b. Solve systems of two linear equations in two variables algebraically, and estimate solutions by graphing the equations. Solve simple cases by inspection. For example, $3 x+2 y=5$ and $3 x+2 y=6$ have no solution because $3 x+2 y$ cannot simultaneously be 5 and 6 .

Geometry

Geometry 7.G

Draw, construct, and describe geometrical figures and describe the relationships between them.

4. Know the formulas for the area and circumference of a circle and use them to solve problems; give an informal derivation of the relationship between the circumference and area of a circle.

Geometry 8.G

Understand and apply the Pythagorean Theorem.

7.Apply the Pythagorean Theorem to determine unknown side lengths in right triangles in real-world and mathematical problems in two and three dimensions.

8. Apply the Pythagorean Theorem to find the distance between two points in a coordinate system.

\begin{tabular}{l} 
HS-Geometry \\
\hline Congruence G-CO \\
\hline Experiment with transformations in the plane
\end{tabular}

5. Given a geometric figure and a rotation, reflection, or translation, draw the transformed figure using, e.g., graph paper, tracing paper, or geometry software. Specify a sequence of transformations that will carry a given figure onto another. Understand congruence in terms of rigid motions Geometric Measurement and Dimension G-GMD Explain volume formulas and use them to solve problems

3. Use volume formulas for cylinders, pyramids, cones, and spheres to solve problems.

Expressing Geometric Properties with Equations G-GPE

Use coordinates to prove simple geometric theorems algebraically

5. Prove the slope criteria for parallel and perpendicular lines and use them to solve geometric problems (e.g., find the equation of a line parallel or perpendicular to a given line that passes through a given point).

6. Find the point on a directed line segment between two given points that partitions the segment in a given ratio. 


\begin{tabular}{|c|c|}
\hline \multicolumn{2}{|l|}{ Functions } \\
\hline \multicolumn{2}{|l|}{8 th grade } \\
\hline \multicolumn{2}{|l|}{ Functions 8.f } \\
\hline \multicolumn{2}{|l|}{ Define, evaluate, and compare functions. } \\
\hline $\begin{array}{l}\text { 1. Understand that a function is a rule that assigns to each input exactly one } \\
\text { output. The graph of a function is the set of ordered pairs consisting of an input } \\
\text { and the corresponding output. }\end{array}$ & 2 \\
\hline $\begin{array}{l}\text { 3. Interpret the equation } y=m x+b \text { as defining a linear function, whose graph is a } \\
\text { straight line; give examples of functions that are not linear. For example, the } \\
\text { function } A=s \text { giving the area of a square as a function of its side length is not } \\
\text { linear because its graph contains the points }(1,1),(2,4) \text { and }(3,9) \text {, which are not on } \\
\text { a straight line. }\end{array}$ & 2 \\
\hline \multicolumn{2}{|l|}{ Use functions to model relationships between quantities. } \\
\hline $\begin{array}{l}\text { 4. Construct a function to model a linear relationship between two quantities. } \\
\text { Determine the rate of change and initial value of the function from a description } \\
\text { of a relationship or from two }(x, y) \text { values, including reading these from a table or } \\
\text { from a graph. Interpret the rate of change and initial value of a linear function in } \\
\text { terms of the situation it models, and in terms of its graph or a table of values. }\end{array}$ & 2 \\
\hline \multicolumn{2}{|l|}{ HS-Functions } \\
\hline \multicolumn{2}{|l|}{ Interpreting Functions F-IF } \\
\hline \multicolumn{2}{|l|}{ Understand the concept of a function and use function notation } \\
\hline $\begin{array}{l}\text { 1. Understand that a function from one set (called the domain) to another set } \\
\text { (called the range) assigns to each element of the domain exactly one element of } \\
\text { the range. If } f \text { is a function and } x \text { is an element of its domain, then } f(x) \text { denotes the } \\
\text { output of } f \text { corresponding to the input } x \text {. The graph of } f \text { is the graph of the } \\
\text { equation } y=f(x) \text {. }\end{array}$ & 2 \\
\hline $\begin{array}{l}\text { 2. Use function notation, evaluate functions for inputs in their domains, and } \\
\text { interpret statements that use function notation in terms of a context. }\end{array}$ & 1 \\
\hline \multicolumn{2}{|l|}{ Interpret functions that arise in applications in terms of the context } \\
\hline $\begin{array}{l}\text { 4. For a function that models a relationship between two quantities, interpret key } \\
\text { features of graphs and tables in terms of the quantities, and sketch graphs } \\
\text { showing key features given a verbal description of the relationship. Key features } \\
\text { include: intercepts; intervals where the function is increasing, decreasing, positive, } \\
\text { or negative; relative maximums and minimums; symmetries; end behavior; and } \\
\text { periodicity. }\end{array}$ & 2 \\
\hline \multicolumn{2}{|l|}{ Analyze functions using different representations } \\
\hline \multicolumn{2}{|l|}{$\begin{array}{l}\text { 7. Graph functions expressed symbolically and show key features of the graph, by } \\
\text { hand in simple cases and using technology for more complicated cases. }\end{array}$} \\
\hline a. Graph linear and quadratic functions and show intercepts, maxima, and minima. & 2 \\
\hline $\begin{array}{l}\text { 8. Write a function defined by an expression in different but equivalent forms to } \\
\text { reveal and explain different properties of the function. }\end{array}$ & \\
\hline
\end{tabular}




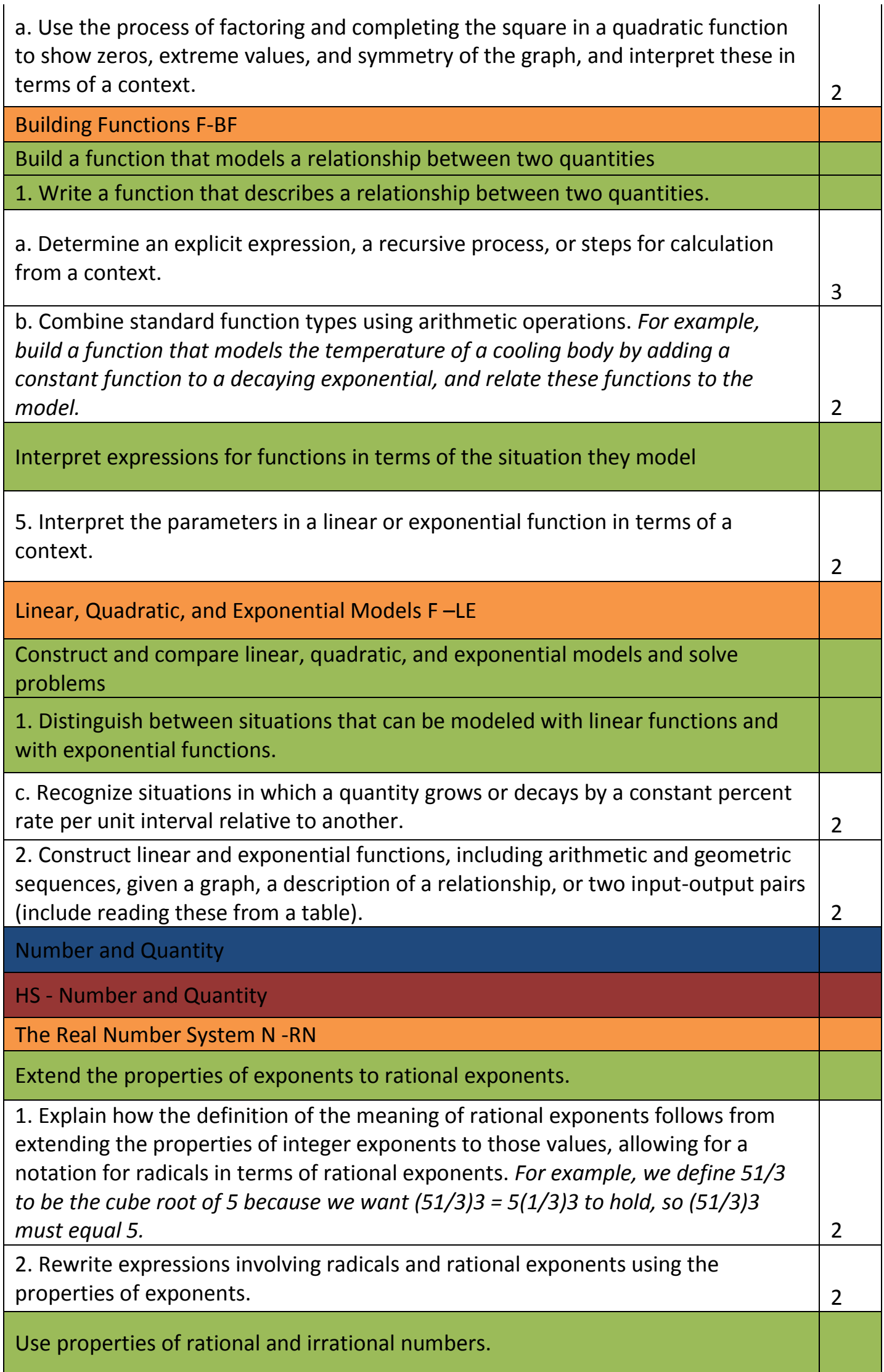


3. Explain why the sum or product of two rational numbers is rational; that the sum of a rational number and an irrational number is irrational; and that the product of a nonzero rational number and an irrational number is irrational.

Quantities N-Q

Reason quantitatively and use units to solve problems.

1. Use units as a way to understand problems and to guide the solution of multistep problems; choose and interpret units consistently in formulas; choose and interpret the scale and the origin in graphs and data displays.

2. Define appropriate quantities for the purpose of descriptive modeling.

3. Choose a level of accuracy appropriate to limitations on measurement when reporting quantities.

The Complex Number System N -CN

Perform arithmetic operations with complex numbers.

2. Use the relation $i 2=-1$ and the commutative, associative, and distributive properties to add, subtract, and multiply complex numbers.

Algebra

HS -Algebra

Seeing Structure in Expressions A-SSE

Interpret the structure of expressions

1. Interpret expressions that represent a quantity in terms of its context.

a. Interpret parts of an expression, such as terms, factors, and coefficients.

2. Use the structure of an expression to identify ways to rewrite it. For example, see $x 4-y 4$ as $(x 2) 2-(y 2) 2$, thus recognizing it as a difference of squares that can be factored as $(x 2-y 2)(x 2+y 2)$.

Write expressions in equivalent forms to solve problems

3. Choose and produce an equivalent form of an expression to reveal and explain properties of the quantity represented by the expression.

a. Factor a quadratic expression to reveal the zeros of the function it defines.

b. Complete the square in a quadratic expression to reveal the maximum or minimum value of the function it defines.

c. Use the properties of exponents to transform expressions for exponential functions. For example the expression $1.15 t$ can be rewritten as $(1.151 / 12) 12 t \approx$ $1.01212 \mathrm{t}$ to reveal the approximate equivalent monthly interest rate if the annual rate is $15 \%$.

Arithmetic with Polynomials and Rational Expressions A -APR

Perform arithmetic operations on polynomials

1. Understand that polynomials form a system analogous to the integers, namely, they are closed under the operations of addition, subtraction, and multiplication; add, subtract, and multiply polynomials. 


\begin{tabular}{|c|c|}
\hline Understand the relationship between zeros and factors of polynomials & \\
\hline $\begin{array}{l}\text { 3. Identify zeros of polynomials when suitable factorizations are available, and use } \\
\text { the zeros to construct a rough graph of the function defined by the polynomial. }\end{array}$ & 2 \\
\hline Rewrite rational expressions & \\
\hline $\begin{array}{l}\text { 6. Rewrite simple rational expressions in different forms; write } a(x) / b(x) \text { in the } \\
\text { form } q(x)+r(x) / b(x) \text {, where } a(x), b(x), q(x) \text {, and } r(x) \text { are polynomials with the } \\
\text { degree of } r(x) \text { less than the degree of } b(x) \text {, using inspection, long division, or, for } \\
\text { the more complicated examples, a computer algebra system. }\end{array}$ & 2 \\
\hline Creating Equations A -CED & \\
\hline Create equations that describe numbers or relationships & \\
\hline $\begin{array}{l}\text { 1. Create equations and inequalities in one variable and use them to solve } \\
\text { problems. Include equations arising from linear and quadratic functions, and } \\
\text { simple rational and exponential functions. }\end{array}$ & 3 \\
\hline $\begin{array}{l}\text { 2. Create equations in two or more variables to represent relationships between } \\
\text { quantities; graph equations on coordinate axes with labels and scales. }\end{array}$ & 2 \\
\hline $\begin{array}{l}\text { 3. Represent constraints by equations or inequalities, and by systems of equations } \\
\text { and/or inequalities, and interpret solutions as viable or nonviable options in a } \\
\text { modeling context. For example, represent inequalities describing nutritional and } \\
\text { cost constraints on combinations of different foods. }\end{array}$ & 3 \\
\hline $\begin{array}{l}\text { 4. Rearrange formulas to highlight a quantity of interest, using the same reasoning } \\
\text { as in solving equations. For example, rearrange Ohm's law } V=I R \text { to highlight } \\
\text { resistance } R \text {. }\end{array}$ & 2 \\
\hline Reasoning with Equations and Inequalities A -RE I & \\
\hline Understand solving equations as a process of reasoning and explain the reasoning & \\
\hline $\begin{array}{l}\text { 2. Solve simple rational and radical equations in one variable, and give examples } \\
\text { showing how extraneous solutions may arise. }\end{array}$ & 2 \\
\hline Solve equations and inequalities in one variable & \\
\hline $\begin{array}{l}\text { 3. Solve linear equations and inequalities in one variable, including equations with } \\
\text { coefficients represented by letters. }\end{array}$ & 1 \\
\hline 4. Solve quadratic equations in one variable. & \\
\hline $\begin{array}{l}\text { a. Use the method of completing the square to transform any quadratic equation } \\
\text { in } x \text { into an equation of the form }(x-p) 2=q \text { that has the same solutions. Derive } \\
\text { the quadratic formula from this form. }\end{array}$ & 3 \\
\hline $\begin{array}{l}\text { b. Solve quadratic equations by inspection (e.g., for } x 2=49 \text { ), taking square roots, } \\
\text { completing the square, the quadratic formula and factoring, as appropriate to the } \\
\text { initial form of the equation. }\end{array}$ & 2 \\
\hline $\begin{array}{l}\text { c. Recognize when the quadratic formula gives complex solutions and write them } \\
\text { as } a \pm b i \text { for real numbers } a \text { and } b \text {. }\end{array}$ & 2 \\
\hline Solve systems of equations & \\
\hline
\end{tabular}


5. Prove that, given a system of two equations in two variables, replacing one equation by the sum of that equation and a multiple of the other produces a system with the same solutions.

6. Solve systems of linear equations exactly and approximately (e.g., with graphs), focusing on pairs of linear equations in two variables.

Represent and solve equations and inequalities graphically

10. Understand that the graph of an equation in two variables is the set of all its solutions plotted in the coordinate plane, often forming a curve (which could be a line).

12. Graph the solutions to a linear inequality in two variables as a half-plane (excluding the boundary in the case of a strict inequality), and graph the solution set to a system of linear inequalities in two variables as the intersection of the corresponding half-planes.

\section{Part II-Alignment of College Expectations with Placement Examinations}

Part II of this study compared the common expectations determined from Part I of the study and the KM-CRE to what is assessed by placement examinations. Placement examinations for this study included ACT, COMPASS, and KYOTE. Each placement examination was analyzed using the KM-CRE matrix (see table 12) to determine alignment. Categorical Concurrence, Range of Knowledge, and Balance of Representation categories were used to determine content alignment. The Depth of Knowledge Consistency category was used to determine cognitive complexity alignment. This task used the hit system implemented in part I of the research study. I determined "hits" and depth of knowledge level for each examination assessment item for standards under the seven domains listed in the KM-CRE. The number of hits that a domain received, the number of hits that a standard received, and total number of standards assessed within a domain were used to complete the alignment study. Appendix D is a matrix of the KM-CRE and placement examinations' analysis.

\section{Categorical Concurrence}


Categorical concurrence indicated if a sufficient number of assessment items were included from each content domain. According to Webb (2007), this general guideline for content match assumes that all standards equally measure the same domain. Although that assumption is not necessarily true, it was the justification for including all standards from each university once the domain was established as part of the KM-CRE document. The categorical concurrence was measured by determining the number of "hits" in each of the KM-CRE domains on each placement examination. According to Webb, if six or more "hits" in each domain occurs, then sufficient coverage of content is ensured. The KM-CRE's seven domains and number of standards within each domain were: Ratios and Proportional Relationships (5); The Number System (17); Expressions and Equations (9); Geometry (7); Functions (14); Number and Quantity (7); and Algebra (21). With fewer than six standards in some domains, it seems to reason that fewer hits would be required for those domains to meet categorical concurrence. For this reason, I modified the criteria. Proportional Relationships (5 standards) required three hits within the domain. Concurrence for Number and Quantity (7 standards) and Geometry (7 standards) required five hits within the domain.

For categorical concurrence analysis, I counted the number of "hits" each domain received. Each "hit" did not necessarily coincide with every standard. Some standards received multiple "hits" while other standards did not receive any "hits." This analysis determined only if a sufficient number of questions were asked to cover all domains within the Expectations. It did not necessarily determine how thorough each domain was assessed. The analysis of categorical concurrence for each placement examination is displayed in table 13 . 


\section{Table 13}

\section{Categorical Concurrence Analysis Table}

\begin{tabular}{|l|c|c|c|c|c|}
\hline Domains & $\begin{array}{l}\text { KM-CRE } \\
\text { Standard } \\
\text { Numbers }\end{array}$ & $\begin{array}{l}\text { Required } \\
\text { "Hit" Count }\end{array}$ & $\begin{array}{l}\text { ACT "Hit" } \\
\text { Count }\end{array}$ & $\begin{array}{l}\text { KYOTE "Hit" } \\
\text { Count }\end{array}$ & $\begin{array}{l}\text { COMPASS } \\
\text { "Hit" Count }\end{array}$ \\
\hline $\begin{array}{l}\text { Ratios and } \\
\text { Proportional } \\
\text { Relationships }\end{array}$ & 5 & $3^{*}$ & 5 & 1 & 9 \\
\hline Geometry & 7 & $5^{*}$ & 7 & 0 & 0 \\
\hline $\begin{array}{l}\text { Number and } \\
\text { Quantity }\end{array}$ & 7 & $5^{*}$ & 1 & 1 & 3 \\
\hline $\begin{array}{l}\text { The Number } \\
\text { System }\end{array}$ & 11 & 6 & 10 & 6 & 6 \\
\hline $\begin{array}{l}\text { Expressions and } \\
\text { Equations }\end{array}$ & 15 & 6 & 22 & 14 & 26 \\
\hline Functions & 13 & 6 & 15 & 8 & 12 \\
\hline Algebra & 21 & 6 & 14 & 8 & 16 \\
\hline
\end{tabular}

Shaded boxes indicate that categorical concurrence occurred.

*Using modified Webb concurrence strategy

Six of the seven domains in the ACT had sufficient coverage to meet categorical concurrence. These domains were Ratios and Proportional Relationships, Geometry, The Number System, Expressions and Equations, Functions, and Algebra. The only domain not receiving an acceptable number of hits to meet categorical concurrence was Number and Quantity.

Four of the seven domains of KYOTE had sufficient coverage to meet categorical concurrence. These domains were The Number System, Expressions and Equations, Functions, and Algebra. The domains not receiving an acceptable number of hits to meet categorical concurrence were Ratios and Proportional Relationships, Geometry, and Number and Quantity.

Five of the seven domains of COMPASS had sufficient coverage to meet categorical concurrence. These domains were The Number System, Expressions and Equations, Functions, and Algebra. The domains not receiving an acceptable number of 
hits to meet categorical concurrence were Ratios and Proportional Relationships, Geometry, and Number and Quantity.

\section{Range of Knowledge Correspondence}

For Range of Knowledge correspondence to occur, Webb indicated that all standards within a domain should be assessed; however a match of at least $50 \%$ of each standard per domain was considered acceptable. For instance, the Geometry domain had seven standards in KM-CRE. In order for sufficient coverage of the Geometry domain, half (3.5 or 4$)$ of the standards must be assessed. Table 14 displays the number of different standards assessed in each domain for placement examinations ACT, KYOTE, and COMPASS.

\section{Table 14.}

\section{Range of Knowledge Analysis Table}

\begin{tabular}{|l|c|c|c|c|}
\hline KM-CRE Domains & $\begin{array}{c}\text { Number } \\
\text { of } \\
\text { Standards }\end{array}$ & $\begin{array}{c}\text { Number } \\
\text { of ACT } \\
\text { Assessed } \\
\text { Standards }\end{array}$ & $\begin{array}{c}\text { Number } \\
\text { of } \\
\text { KYOTE } \\
\text { Assessed } \\
\text { Standards }\end{array}$ & $\begin{array}{c}\text { Number of } \\
\text { COMPASS } \\
\text { Assessed } \\
\text { Standards }\end{array}$ \\
\hline Ratios/Proportional Relationships & 5 & 3 & 1 & 2 \\
\hline Geometry & 7 & 4 & 0 & 0 \\
\hline Number and Quantity & 7 & 1 & 1 & 1 \\
\hline The Number System & 11 & 7 & 5 & 5 \\
\hline Expressions and Equations & 15 & 8 & 7 & 7 \\
\hline Functions & 13 & 8 & 7 & 8 \\
\hline Algebra & 21 & 9 & 5 & 2 \\
\hline
\end{tabular}

Solid shaded boxes indicate that range of knowledge correspondence was met. Horizontally shaded boxes indicate weakly met.

For ACT, Range of Knowledge correspondence was met in Ratios and Proportional Relationships (60\%), Geometry (57\%), The Number System (64\%), Expressions and Equations (50\%), and Functions (57\%). Using Webb's model for weakly 
met of $40 \%$ to $49 \%$, Algebra was categorized as weakly met at $43 \%$. Only Number and Quantity was not met by ACT.

For KYOTE, Range of Knowledge correspondence was met by Expressions and Functions at 50\%. The Number System and Expressions and Equations were weakly met at a rate of $45 \%$ and $43 \%$ respectively.

For COMPASS, Range of Knowledge correspondence was met by Functions and Expressions and Equations with rates of 50\% and 56\% respectively. Ratios and Proportional Relationships and The Number System were weakly met at rates of $40 \%$ and $45 \%$ respectively.

\section{Balance of Representation}

Balance of Representation criterion is used to determine the degree to which emphasis is placed on one standard over another on an assessment. Webb indicated that each standard within a domain should be assessed an equal number of times so that more emphasis is not placed on one standard over another. An index number measures this criterion by using only standards that receive at least one hit. The index is computed by determining the difference in the proportion of the standards hit in each domain and the number of hits each standard receives. The index is found by applying the following formula:

$$
1-\frac{\left(\sum_{\mathrm{k}=1}^{\mathrm{T}}\left|\frac{1}{\mathrm{~T}}-\frac{\mathrm{h}(\mathrm{k})}{\mathrm{H}}\right|\right)}{2}
$$

Where $\mathrm{T}=$ total number of standards hit for the domain $h(k)=$ number of items hits corresponding to standard $h$

$\mathrm{H}=$ total number of items hit for the domain (N. L. Webb, 2007, p. 14). 
If all objectives were equally balanced between the assessment and its expectations, then the index would be 1 . Webb determined that an acceptable index is in a range from 0.7 to 1. Values between 0.6 and 0.7 indicate a weakly met a Balance of Representation criterion. Table 15 displays the placement examinations balance of representation index for each domain.

\section{Table 15}

Balance of Representation Index Values

\begin{tabular}{|l|c|c|c|}
\hline KM-CRE Domains & ACT & KYOTE & COMPASS \\
\hline $\begin{array}{l}\text { Ratios/Proportional } \\
\text { Relationships }\end{array}$ & 0.867 & 1 & 0.833 \\
\hline Geometry & 0.679 & none & none \\
\hline Number and Quantity & 1 & 1 & 1 \\
\hline The Number System & 0.786 & 0.867 & 0.867 \\
\hline Expressions and Equations & 0.8375 & 0.786 & 0.607 \\
\hline Functions & 0.825 & 0.899 & 0.703 \\
\hline Algebra & 0.82 & 0.775 & 0.688 \\
\hline \multicolumn{1}{|c|}{ Key } & \multicolumn{1}{c}{} \\
\hline \multicolumn{1}{|c|}{ Weakly Met } \\
\cline { 1 - 2 }
\end{tabular}

According to Webb's formulas, ACT met Balance of Representation in The Number System (.786), Expressions and Equations (.841), Functions (.825), Algebra (.820) and Ratios and Proportions (.867). It met the criterion weakly in Geometry with .679. Geometry had a lower index value because ACT had four hits on one standard in a $7^{\text {th }}$-grade geometry strand and only one hit on three other standards within the Geometry domain. This finding revealed that more emphasis was placed on the standard, "Know the formulas for the area and circumference of a circle and use them to solve problems." Therefore, on the ACT Placement examination, all but one domain of KM-CRE had an acceptable Balance of Representation index, and it had one index value that established it 
as weakly met. This finding indicates, for the readiness standards that were assessed by ACT, one standard was not assessed at a relatively larger rate than the other standards within a domain.

Applying Webb's formula for Balance of Representation to KYOTE data was trivial for Number and Quantity, Ratios and Proportional Reasoning, and Geometry. The first two domains assessed one standard with 1 hit. Geometry was not assessed. Using Webb's model, the Balance of Representation index for these items was $100 \%$ because all standards that were assessed were assessed equally. The Number System had hits on five standards with a total of six hits for the domain with a Balance of Representation value of .867. Expressions and Equations had a Balance of Representation value of .786. This domain hit seven different standards and had a total of 14 hits for the domain. Algebra had a Balance of Representation value of .775 with five standards assessed and eight total hits. Functions had a Balance of Representation index of.899 with seven standards assessed with a total of eight hits.

For COMPASS, The Number System domain had a Balance of Representation index of .867 having five standards assessed with six hits. The Balance of Representation index for Ratios and Proportional Reasoning was .833. This value was smaller due to having two standards with three hits and six hits each. The Balance of Representation index for Expressions and Equations was .607, having nine standards assessed and 26 hits. One standard, Write and evaluate numerical expressions involving whole-number exponents, received 12 hits. Algebra had a Balance of Representation index of .688. Algebra had eight standards assessed with 16 hits with two standards receiving four hits, one standard receiving three hits, and the remaining standards receiving one hit. The 
Functions domain had a Balance of Representation of .703 with two standards with three and four hits and the other five standards having one hit each. The categories of Algebra and Expressions and Equations domains were weakly met according to Webb's range of .6 to .7. Number and Quantity was met with an index of $100 \%$, with one standard was assessed by three hits. The Geometry domain did not have hits on any standards.

\section{Depth of Knowledge Consistency}

For Depth of Knowledge Consistency criterion to be met, an assessment must have at least $50 \%$ of the hits on test items at or above the cognitive level (DOK level) as the corresponding objective standard. Webb applies the 50 percent rule to this category as well. The percent of match was found by dividing the number of standards assessed at a matching DOK level or higher by the number of standards assessed. The results are displayed in Table 16.

Table 16

Percent of DOK levels that meet or exceed KM-CRE DOK Levels

\begin{tabular}{|l|c|c|c|}
\hline KM-CRE Domains & $\begin{array}{c}\text { ACT } \\
\text { matches/assessed } \\
\text { standards }\end{array}$ & $\begin{array}{c}\text { KYOTE } \\
\text { matches/assessed } \\
\text { standards }\end{array}$ & $\begin{array}{c}\text { COMPASS } \\
\text { matches/assessed } \\
\text { standards }\end{array}$ \\
\hline Ratios/Proportional Relationships & $3 / 3=100 \%$ & $1 / 1=100 \%$ & $2 / 2=100 \%$ \\
\hline Geometry & $4 / 4=100 \%$ & none & none \\
\hline Number and Quantity & $0 / 1=0 \%$ & $1 / 1=100 \%$ & $1 / 1=100 \%$ \\
\hline The Number System & $5 / 7=71 \%$ & $3 / 5=60 \%$ & $5 / 5=100 \%$ \\
\hline Expressions and Equations & $8 / 8=100 \%$ & $8 / 8=100 \%$ & $8 / 9=89 \%$ \\
\hline Functions & $8 / 8=100 \%$ & $5 / 7=71 \%$ & $7 / 7=100 \%$ \\
\hline Algebra & $9 / 9=100 \%$ & $3 / 4=75 \%$ & $8 / 8=100 \%$ \\
\hline \hline Total & $37 / 40=92.5 \%$ & $21 / 26=81 \%$ & $31 / 32=97 \%$ \\
\hline
\end{tabular}


ACT not only met but exceeded the criterion for depth of knowledge consistency. Forty different standards were assessed on the ACT examination. Only three items were assessed below the level of the matching KM-CRE standard. This finding indicated that 92.5 percent of the test items assessed on the ACT were at or above the cognitive level identified on the matching KM-CRE standard. In fact, approximately 28 percent (11 of 40) of the assessment items were above the DOK level of the KM-CRE standards.

KYOTE placement examination met the criterion for depth-of-knowledge consistency with twenty-one of the twenty-six standards assessed (77\%) meeting or exceeding the depth-of-knowledge level of the matching standard. One of the fourteen standards was assessed at a higher DOK level than the matching KM-CRE standard. Therefore, five standards were assessed below the cognitive level on the KM-CRE. COMPASS met the criterion for depth-of-knowledge consistency with 31 of 32 standards assessed at or exceeding the DOK level of the matching KM-CRE standard. Ten of the assessed standards had a higher depth-of- knowledge level than the KM-CRE standard.

\section{Summary}

In Part I of the study, the KM-CRE was developed by analyzing highest level remediation course finals. Each question of the final was matched to a Common Core State Standard. A comparison between the universities' percent of emphasis on domains within the CCSSM was made. Consistency across Kentucky universities 'percent of emphasis was found. Probability and Statistics was not assessed by any university in the study. Additionally, the most emphasized domains were Equations and Expression and Algebra by all universities. 
In Part II of the study, the KM-CRE matrix was developed using the consistent CCSSM domains assessed across 5 public universities. Each standard within the domain was assigned a DOK at the level that $50 \%$ of the universities assessed the standard. The KM-CREE matrix of standards and DOK levels were used to determine the alignment between university expectations and placement examinations used in Kentucky. Using Webb's model for content alignment, Categorical Concurrence was not met completely by any placement examination but ACT did meet 6 of 7 domains. Without meeting Categorical Concurrence the placement examinations were unable to meet Range of Knowledge content alignment. Again, ACT was the closest meeting 5 of 7 domains. Balance of Representation content alignment was met or weakly met by ACT in all domains. KYOTE met all domains but Geometry, which was not assessed. Likewise, COMPASS met or weakly met all domains but Geometry, which was not assessed. Cognitive complexity alignment was measured using Depth of Knowledge Consistency. This category was met by all placement examinations; ACT, COMPASS, and KYOTE. 


\section{CHAPTER V}

\section{FINDINGS, CONCLUSIONS, AND IMPLICATIONS}

This final chapter revisits the purposes of this research study, presents research findings, and discusses answers to the research questions. After the discussion of the research, I will describe the limitations of the research study and explain how these limitations were addressed or will be considered when sharing the results. Lastly, I will offer suggestions for future alignment studies and how they can be influenced by this research.

The purposes of this research study were to: 1) compare the assessment of CCSSM across five Kentucky universities: Morehead State University, Eastern Kentucky University, Northern Kentucky University, Kentucky State Univesity, and Western Kentucky University; and 2) create Kentucky Mathematics College Readiness Expectations (KM-CRE) to determine the extent to which alignment across university mathematics college readiness expectations and college placement examinations existed. The study was completed in two phases. In Phase 1, the course final examinations in the highest mathematics remediation classes at the five universities were analyzed using the Common Core State Standards (CCSS, 2011). Each final examination test item was coded to match one or more Common Core State Standards for Mathematics. A comparison analysis of percent of content domain emphasis on the final examination from each university was completed. Phase 2 of the research study involved an 
alignment analysis among KM-CRE and Kentucky's regulated college placement examinations: ACT, KYOTE, and COMPASS. The KM-CRE were developed using the five university remedial mathematics course finals that were collected. Four alignment categories based on Webb's alignment model were used to compare each KM-CRE to each placement examination. The categories were: Categorical Concurrence; Range of Knowledge; Depth of Knowledge Consistency; and Balance of Representation. Together, these two phases answered the research questions: (1) What mathematical prerequisite knowledge do state universities consider necessary to be college ready. Specifically 1a) What content domains do the state universities emphasize in their remediation courses?; 1b) Is there consistency across the state public universities with regard to the content domains?; and 2) How well do Kentucky's mathematics placement assessments (ACT, COMPASS, and KYOTE) align in both content and cognitive demand with four-year universities' KM-CRE?

\section{Research Findings}

\section{Phase 1}

The mathematical prerequisite knowledge state universities consider necessary to be college ready fall in the following CCSSM domains: Ratios and Proportional Relationships, The Number System, Expressions and Equations, Geometry, Statistics and Probability, Functions, Number and Quantity, and Algebra. The analysis of these domains indicated consistency of percent of emphasis with a range value of no more than $3 \%$ across 3 of the 5 universities (See table 17). 
CCSS Consistency Table across 5 Universities

\begin{tabular}{|c|c|c|c|c|c|}
\hline Domain Category & 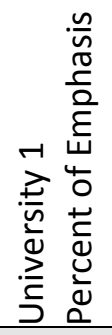 & 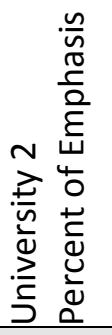 & 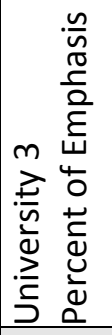 & 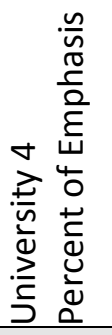 & 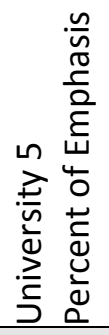 \\
\hline Measurement and Data & $0 \%$ & $1 \%$ & $0 \%$ & $0 \%$ & $3 \%$ \\
\hline Number and Operations- fractions & $2 \%$ & $0 \%$ & $0 \%$ & $0 \%$ & $0 \%$ \\
\hline Ratios and Proportional Relationships & $4 \%$ & $4 \%$ & $5 \%$ & $0 \%$ & $1 \%$ \\
\hline The Number System & $8 \%$ & $3 \%$ & $0 \%$ & $9 \%$ & $7 \%$ \\
\hline Expressions and Equations & $27 \%$ & $34 \%$ & $29 \%$ & $9 \%$ & $27 \%$ \\
\hline Geometry & $3 \%$ & $1 \%$ & $0 \%$ & $3 \%$ & $12 \%$ \\
\hline Statistics and Probability & $0 \%$ & $0 \%$ & $0 \%$ & $0 \%$ & $0 \%$ \\
\hline Functions & $13 \%$ & $12 \%$ & $11 \%$ & $22 \%$ & $14 \%$ \\
\hline Number and Quantity & $10 \%$ & $7 \%$ & $9 \%$ & $19 \%$ & $0 \%$ \\
\hline Algebra & $33 \%$ & $37 \%$ & $45 \%$ & $38 \%$ & $36 \%$ \\
\hline
\end{tabular}

Percent of Emphasis placed on Middle School Content Domains: This

research study was intended to determine the mathematics content considered necessary for college readiness. Surprisingly, a large percentage of the identified college readiness mathematics from universities across the state was from middle school level CCSS domains (See table 18). Universities 1 and 2 had a near 50\% split between middle school and high school content domains. Universities 3 and 5 were close to a 40/60 split between middle and high school content. And, university 4 had a 30/70 split.

Considering that students are required to take four years of high school mathematics in Kentucky, I find the amount of emphasis placed on middle school mathematics interesting. Spending four years in a mathematics class should prepare students well 
beyond middle school mathematics content. With the adoptions of the new Common Core State Standards expectations for college and career readiness are intended to increase. As more and more students proceed through school with the adopted standards governing their mathematics classes, expectations from universities must increase.

\section{Table 18}

\section{Percent of Emphasis Table across Grade Bands}

\begin{tabular}{|c|c|c|c|c|c|c|}
\hline Domain Category & 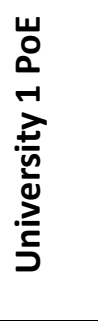 & 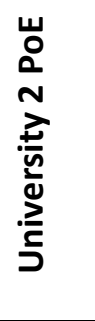 & 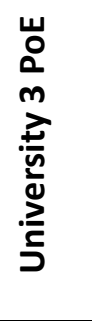 & 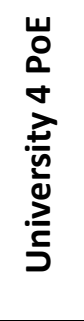 & 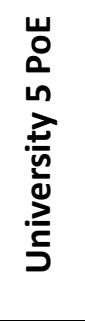 & 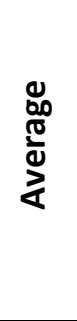 \\
\hline \multicolumn{7}{|c|}{ Grades level 6th-8th } \\
\hline $\begin{array}{l}\text { Ratios and Proportional Relationships } \\
\text { (6th-7th grade) }\end{array}$ & $4 \%$ & $4 \%$ & $5 \%$ & $0 \%$ & $1 \%$ & $3 \%$ \\
\hline The Number System (6th-8th grade) & $8 \%$ & $3 \%$ & $0 \%$ & $9 \%$ & $7 \%$ & $5 \%$ \\
\hline $\begin{array}{l}\text { Expressions and Equations (6th-8th } \\
\text { grade) }\end{array}$ & $27 \%$ & $34 \%$ & $29 \%$ & $9 \%$ & $27 \%$ & $25 \%$ \\
\hline Geometry (6-8) & $1 \%$ & $1 \%$ & $0 \%$ & $0 \%$ & $1 \%$ & $1 \%$ \\
\hline Statistics and Probability (6th-8th) & $0 \%$ & $0 \%$ & $0 \%$ & $0 \%$ & $0 \%$ & $0 \%$ \\
\hline Functions 8th & $7 \%$ & $4 \%$ & $3 \%$ & $9 \%$ & $4 \%$ & $5 \%$ \\
\hline Total & $47 \%$ & $46 \%$ & $37 \%$ & $27 \%$ & $40 \%$ & $39 \%$ \\
\hline \multicolumn{7}{|c|}{ High School Level } \\
\hline Geometry HS & $2 \%$ & $0 \%$ & $0 \%$ & $3 \%$ & $11 \%$ & $3 \%$ \\
\hline Functions HS & $7 \%$ & $7 \%$ & $8 \%$ & $13 \%$ & $9 \%$ & $9 \%$ \\
\hline Number and Quantity (HS) & $10 \%$ & $7 \%$ & $9 \%$ & $19 \%$ & $0 \%$ & $9 \%$ \\
\hline Algebra (HS) & $33 \%$ & $37 \%$ & $45 \%$ & $38 \%$ & $36 \%$ & $38 \%$ \\
\hline Statistics HS & $0 \%$ & $0 \%$ & $0 \%$ & $0 \%$ & $0 \%$ & $0 \%$ \\
\hline Total & $52 \%$ & $51 \%$ & $62 \%$ & $73 \%$ & $56 \%$ & $59 \%$ \\
\hline
\end{tabular}

Percent of Emphasis placed in the "Algebra" Domain: Another interesting finding in the analysis of percent of emphasis of content domains across universities is 
the amount of emphasis placed on Expressions and Equations, Functions, and Algebra. All of these combine to describe Algebra readiness. Colleges, on average, have a $38 \%$ emphasis on Algebra, a 28\% emphasis on Expressions and Equations, and 13\% emphasis on functions on their final examinations. This combines for $79 \%$ of emphasis placed on Algebra readiness. In order to determine if the placement examinations ACT, COMPASS, and KYOTE gave similar emphasis on these domains, I completed an analysis chart and graph (See table 19 and figure 4). The chart and graph, indicate that similar percent of emphasis is placed on Expressions and Equations, Functions, and and KYOTE. ACT de-emphasizes Expressions and Equations, and Algebra while emphasizing Geometry at a rate of $24 \%$. Falling in line with the university's percent of emphasis on Algebra readiness, COMPASS, and KYOTE place a combined emphasis on Expressions and Equations, Functions, and Algebra at $77 \%$ and $72 \%$, respectively. This is an extremely high value being placed on Algebra above the other mathematical domains established by CCSS to be college and career ready. ACT better balances their emphasis with only a $55 \%$ emphasis placed on Algebra readiness. Based on these findings, the KM-CRE document established in this study may better be described as KM-ARE (Kentucky Mathematics Algebra Readiness Expectations). 


\section{Table 19}

Percent of Emphasis of CCSS Domains

\begin{tabular}{|c|c|c|c|c|}
\hline Domain Category & 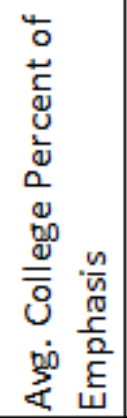 & 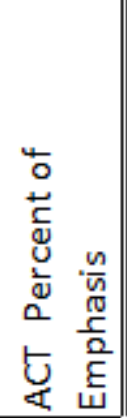 & 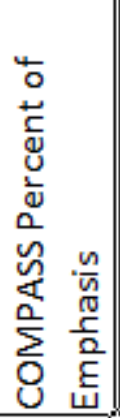 & 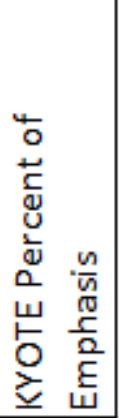 \\
\hline Number and Operations- fractions & $1 \%$ & $0 \%$ & $0 \%$ & $7 \%$ \\
\hline Ratios and Proportinal Relationsh & $4 \%$ & $6 \%$ & $14 \%$ & $2 \%$ \\
\hline The Number System (6th-8th grad & $5 \%$ & $11 \%$ & $1 \%$ & $14 \%$ \\
\hline Expressions and Equations (6th-8 & $28 \%$ & $23 \%$ & $37 \%$ & $33 \%$ \\
\hline Geometry ( $k-8$ and HS) & $1 \%$ & $24 \%$ & $4 \%$ & $2 \%$ \\
\hline Statistics and Probability (6th-8th & $0 \%$ & $3 \%$ & $0 \%$ & $0 \%$ \\
\hline Functions (8th and HS) & $13 \%$ & $17 \%$ & $17 \%$ & $19 \%$ \\
\hline Number and Quantity (HS) & $10 \%$ & $1 \%$ & $4 \%$ & $2 \%$ \\
\hline Algebra (HS) & $38 \%$ & $15 \%$ & $23 \%$ & $19 \%$ \\
\hline Total & $100 \%$ & $100 \%$ & $100 \%$ & $100 \%$ \\
\hline
\end{tabular}


Figure 4

Percent of Emphasis by Colleges and Placement Examinations on CCSSM

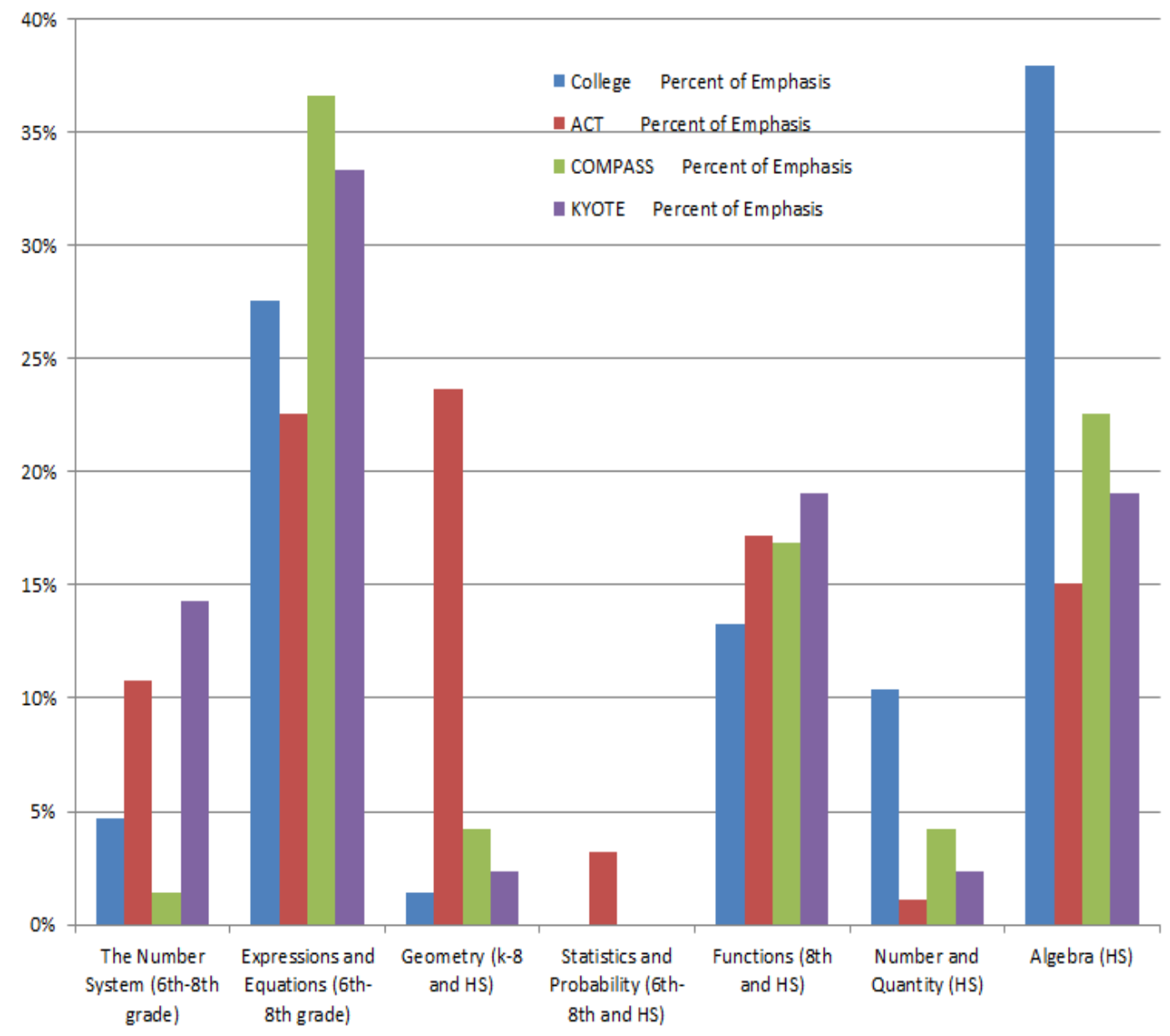

Percent of Emphasis placed in the "Data and Measurement" Domain: The amount of emphasis placed on statistics and probability and geometry by college readiness examinations is surprising. ACT is the only examination in the study that assesses Statistics and Probability; however, it is only a small percent of emphasis of $3 \%$. Likewise, Geometry is virtually ignored by all college readiness examinations except 
ACT, KYOTE (2\%) and COMPASS (4\%) which only assess Geometry at a little higher rate than the universities (1\%). In a data driven world, it is surprising to see such little emphasis placed on data and measurement. These domains easily reason to be the most applicable to the real world, yet have the smallest amount of percent of emphasis on most college readiness assessments. Even more surprising is the fact that the cut scores established by placement examinations or successful completion of the college remediation course at the included universities, allows a student to enroll in an Introduction to Statistics course. With no statistics' assessment items on an examination, a student cannot be appropriately deemed college ready for a statistics course; yet the universities are allowing student enrollment.

\section{Phase 2}

To answer the research question regarding how well Kentucky's mathematics placement examinations (ACT, COMPASS, and KYOTE) aligned in both content and cognitive demand with four-year universities' KM-CRE, I considered each alignment category for content and depth of knowledge. Content alignment was measured by Webb's categories of Categorical Concurrence, Range of Knowledge, and Balance of Representation. Depth of knowledge was measured by Webb's category of Depth of Knowledge Consistency.

ACT aligned in Categorical Correspondence in all but one domain. It aligned in Range of Knowledge in 5 of 7 domains. The domain Number and Quantity was not met in either of the first two categories. ACT aligned in Balance of Representation category in all domains and aligned in Depth of Knowledge Consistency. From this research 
analysis, ACT highly aligned with KM-CRE in cognitive demand and somewhat aligned in content demand.

COMPASS aligned in Categorical Correspondence in 5 of 7 domains and in Range of Knowledge in only 2 of 7 domains. COMPASS did not align well in Balance of Representation category, but aligned well in Depth of Knowledge Consistency. From this analysis, COMPASS aligned well with KM-CRE in cognitive demand, but not in content demand.

KYOTE aligned in Categorical Correspondence in 4 of 7 domains and in Range of Knowledge in only 1 of 7 domains. It did not align in Balance of Representation in categories when multiple standards received hits. It aligned well in Depth of Knowledge Consistency. From this analysis, KYOTE aligned with KM-CRE in cognitive demand but not in content demand.

Length of Assessment: The length of the assessment directly affects how well it aligns with KM-CRE. In order for categorical correspondence to occur 37 hits have to occur. Additionally, to meet the Range of Knowledge alignment category 40 standards need to be assessed and ideally to meet Balance of Representation each of these 40 standards need to be assessed with the same number of questions. Although a question may have multiple hits on multiple standards, it would be very difficult to create an aligned examination with fewer than 40 well developed and specifically designed questions. Considering this fact, KYOTE needs to lengthen their examination to better alignment and coverage of content. ACT and COMPASS, although ask a larger number of questions, need to focus on accessing a wider range of content and specifically address the expectations established in KM-CRE. 
Intentional Item Development on Examinations: It is very apparent in the alignment analysis of the KM-CRE document and the placement examinations that little communication is occurring between the entities. The universities have established what knowledge is essential to being successful at their respective universities. Additionally, the developers of the placement examinations have established their own criteria. From this study, it is evident that content alignment is not occurring between these two groups.

The universities have the right to establish their own criteria for success. According to research studies across the nation, students who are successful in their remediation courses are likely to graduate from college. This indicates that universities have been successful in establishing their own college readiness expectations and preparing their students to meet the challenges of college mathematics through their remediation courses. Therefore, universities should ultimately drive the development of placement examinations considering they are the intended benefactor of appropriately placed students.

With the adoption of the CCSSM as the standards for college and career ready, both the university and placement examination developers should intentionally develop assessment items aligned with the new standards. If all parties involved use these as the expectations and develop curriculum and assessments accordingly, then alignment would have to occur. From the research completed, it is apparent that several parts of the CCSSM are not being assessed. Currently, the universities are assessing their students to determine if they are algebra ready for college. To holistically prepare a student mathematically, all domains must be assessed by both the university and the placement examination developers. Raising the level of required preparedness for mathematics will 
reinforce the intentions of the CCSSM that almost every state in the United States adopted.

\section{Implications on Future Assessments}

Roach, Niebling, and Kurz (2008) stated that educational testing systems are federally mandated to have standards-based alignment; yet few research studies have been conducted to ensure that such alignments occur. Students in Kentucky are required to take placement examinations to determine if they are college ready; yet this research indicates that Kentucky's testing system is not in alignment. Test developers in Kentucky should take into consideration what state colleges expect students taking mathematics need to know and be able to do when entering college. These expectations are apparent through their performance on remediation course finals. The KM-CRE data should be considered when developing assessments that deem high school graduates college-ready. As Brown and Conley (2007) suggest, "If states do wish to employ their high school exams to generate information on college readiness or placement, they will likely need to revisit the content domains from which examination items are drawn, the number and difficulty of test items, and the format used for testing" (pg. 153). Their point is supported by research data from my study. Content domains that the KM-CRE clearly addressed were not included in the assessments used in Kentucky. Revision of assessments to include domains, clusters, and standards that Kentucky college faculty value should be made to improve alignment.

A second advantage to clear alignment among college expectations and high school assessments is accurate placement of students into mathematics courses which has the potential to increase college retention rates. Ishitani and DesJardins (2002) found that 
the higher a student's GPA at the end of his/her freshman year, the less likely the student dropped out of college. Additionally, Waycaster found that (2011) if students entered college underprepared and had success in a remediation course; they were more likely to complete college. Through alignment of expectations and assessments, students will be placed in courses in which they are likely to succeed. This practice has the potential to result in higher retention rates and a larger number of college graduates.

\section{Limitations}

Several limitations were evident in this alignment study. For the placement examinations, a limited sample of items from ACT, COMPASS, and KYOTE were used from multiple versions. Although a large pool of questions is used, the research and development department of ACT and COMPASS ensures a high reliability among their different forms or versions of their assessment Therefore my results should be accurate.

Another limitation of the study was that a second researcher did not match test items to the coding instrument. My credentials as a mathematics educator should validate me as an appropriate researcher in this field. I have taught mathematics for 20 years dividing my time between middle school, high school, and higher education. I have received training in graduate-level courses on depth of knowledge and have taught several courses on the subject. To further substantiate my ability to code mathematics content and DOK levels, I began my research analysis with a practice coding session with two other mathematics instructors who were also knowledgeable of Common Core State Standards and DOK levels. We reached a 95\% agreement level on content match and $100 \%$ agreement level on DOK match. With these levels of agreement, I am confident in my ability to accurately code content and cognitive demand. 
The restriction of having a comprehensive final for the highest remediation course constituted another limitation. Without administering comprehensive finals or offering remediation classes, I could not include these universities in the study. With five of the eight state colleges represented in the study and finding consistency across the included universities, I believe that the absences of the remaining colleges were negligible.

Lastly, the coding of depth of knowledge is not absolute. Depending on the background knowledge and mathematical understanding of a student, a question could be coded as multiple levels. For some students creating an equation is simple a recall of facts while another student has to strategically creating the equation. With only one researcher coded all questions there should be consistency of the DOK coding. Considering Webb's model requires a 50\% match between DOK levels of expectations and assessments, the consistency of coding is more important than the actual DOK level assigned.

\section{Future Studies}

With the recent release of the Common Core State Standards in Mathematics, I anticipate that changes will be made both at the college and placement testing levels. Both ACT and COMPASS are currently aligning their examinations to the CCSSM, but they have not yet released the new versions (Sconing, 2013). Additionally, in phone conversations with university administrators, I was told that current revisions are underway in some remedial mathematics courses to better align them with the CCSSM. Kentucky Department of Education has issued indicators for college and career readiness, and these indicators are being embedded in the remediation courses. For some universities, this alignment may cause remediation courses to change greatly. With both 
placement examinations and remedial courses changing, this study will need to be repeated in the next five years.

Although this study was conducted using public universities in Kentucky, it could easily be expanded to private and community colleges. By expanding the Kentucky Mathematics College Readiness Standards to include all two-year and four-year institutions, new standards or emphasis placed on CCSSM domains may change. With both a national and state push for high stakes testing and accountability, all states should re-evaluate their testing systems to determine if they align with college readiness expectations. Furthermore, these readiness standards need to be consistent across state lines and developed by educators and professionals in the field. Studies are needed to determine what mathematical readiness content knowledge universities across the nation value and placement examinations need to be developed to evaluate this knowledge. Placement examinations need to be carefully developed with the clear purpose of aligning to college readiness mathematics content. Research should include university faculty to determine exactly what content is valued and needed for college success. Although Common Core State Standards have been developed and adopted by most states across the country, the Standards do not automatically correlate to university expectations for college success. Some standards in the Common Core are emphasized more than others depending on how they align with the college curriculum. As my research indicated, no emphasis was placed on probability and statistics by the Kentucky state universities. Other mathematics areas may also receive more or less emphasis. Once college expectations are established and placement examinations developed, further alignment studies need to occur. These studies need to explore whether the examinations not only 
align in breadth of content knowledge, but also depth of content knowledge. For assessments to be aligned, they need to have sufficient coverage of college readiness standard domains or strands and balance of representation of content within those domains. Depth of knowledge measured in the assessments should also be comparable to the depth of knowledge level in the college readiness expectations. From these studies, states implementing the placement examinations as a part of their accountability systems, as well as the universities excepting the scores from the examinations, will be assured that the intended measurement of college readiness has occurred. 


\section{REFERENCES}

ACT. (2010) Retrieved July 1, 2010, from http://www.act.org/

ACT. (2010a). COMPASS Retrieved November 18, 2010, from

http://www.act.org/compass/tests/math.html

ACT. (2010b). Concordant ACT®, COMPASS®, and ASSET® Scores Retrieved

November 22, 2010, from http://www.act.org/compass/pdf/Concordance.pdf

ACT. (2010c). What Are ACT's College Readiness Benchmarks? Retrieved March 12, 2012, from http://www.act.org/research/policymakers/pdf/benchmarks.pdf

Association, K. S. B. (2010). Kentucky online testing college readiness program selected as national model Retrieved November 22, 2010, from http://www.ksba.org/boardcast/article/kentucky-online-testing-kyote-collegereadiness-program-selected-as-nationa

Attewell, P., Lavin, D., Domina, T., \& Levey, T. (2006). New Evidence on College Remediation. [Article]. Journal of Higher Education, 77(5), 886-924.

Bahr, P. (2008). Does Mathematics Remediation Work?: A Comparative Analysis of Academic Attainment among Community College Students. Research in Higher Education, 49(5), 420-450. 
Bettinger, E. P., \& Long, B. T. (2005). Remediation at the community college: Student participation and outcomes. [Article]. New Directions for Community Colleges, 2005(129), 17-26.

Bhola, D., Impara, J., \& Buckendahl, C. (2003). Aligning tests with states' content standards: Methods and issues.

Brown, R. S., \& Conley, D. T. (2007). Comparing State High School Assessments to Standards for Success in Entry-Level University Courses. Educational Assessment, 12(2), 137-160.

Brown, R. S., \& Niemi, D. N. (2007). Investigating the Alignment of High School and Community College Assessments in California. National Center Report \#07-3: National Center for Public Policy and Higher Education. 152 North Third Street Suite 705, San Jose, CA 95112. Tel: 408-271-2699; Fax: 408-271-2697; e-mail: center@highereducation.org; Web site: http://www.highereducation.org/reports/reports.shtml.

Center, U. o. C. E. S. (2008). Validity study of developmental math placement test (pp. 35). Cincinnati: University of Cincinnati.

The college completion agenda. (2011), from http://completionagenda.collegeboard.org/freshman-sophomore-retention-rate

College Readiness Indicators. (2010) Retrieved February 14, 2012, from http://cpe.ky.gov/NR/rdonlyres/78B3510A-CECD-4157-8F20$\underline{\text { 3E3499707DAA/0/CollegeReadinessIndicators.pdf }}$

Common core state standards inititative. (2011), from www.corestandards.org/ 
Common Core State Standards Intiative (2012) Retrieved Februray 12, 2013, from http://www.corestandards.org/Math/Practice

COMPASS Tests. (2010) Retrieved February 14, 2010, from http://www.act.org/compass/tests/index.html

Conley, D. (2003). Understanding university success. Eugene: University of Oregon, Center for Educational Policy Research.

Conley, D. T. (2008). Rethinking college readiness. [Article]. New Directions for Higher Education(144), 3-13.

Developmental Education Needs in the 2006 Entering Cohort. (2008, August 28, 2008) Retrieved August 27, 2011, from http://cpe.ky.gov/nr/rdonlyres/b42243cb-d19a4ec4-ad34-ecf2900d51b1/0/dev_needs_2006_20090605.pdf

Developmental math placement test results Ashland Community and Technical College (2007).

Gross, L. (2010). Kentucky accepts core academic standards Retrieved February 12, 2012, from http://www.education.ky.gov/kde/homepagerepository/news+room/current+press +releases+and+advisories/10-009.htm

Grubb, N. W., \& Associates. (1999). Honored but invisible: An inside look at teaching in community colleges. New York: Routlege.

Guidelines for admission to the state-supported postsecondary education institutions in Kentucky § 6 (2011). 
Holiday, T. (2010). Unbridled learning: Transforming education in Kentucky Retrieved May 21, 2012, from http://www.education.ky.gov/nr/rdonlyres/1b502167-c41e4464-b3c0-b795d24aaf49/0/ctp9910leadershipkentucky.pdf

Horn, C., McCoy, Z., Campbell, L., \& Brock, C. (2009). Remedial Testing and Placement in Community Colleges. [Article]. Community College Journal of Research \& Practice, 33(6), 510-526. doi: 10.1080/10668920802662412

Illich, P. A., Hagan, C., \& MeCallister, L. (2004). Perfomance in college-level coures among students concurrently enrolled in remedial courses: Policy implications [Article]. Community College Journal of Research \& Practice, 28(5), 435-453. doi: $10.1080 / 10668920490444463$

Ishitani, T., \& DesJardins, S. (2002). A longitudinal investigation of dropout from college in the United States. Journal of College Student Retention: Research, Theory \& Practice, 4(2), 173-201.

LaMarca, P., Redfield, D., \& Winter, P. (2000). State standards and state assessment systems: A guide to alignment Series on Standards and Assessments (pp. 36). Washington, DC: Council of Chief State School Officers.

Levin, H. M., \& Calcagno, J. C. (2008). Remediation in the Community College. Community College Review, 35(3), 181-207.

McCabe, R. H. (1998). The reasonable price of remediation. [Article]. Community College Week, 11(1), 4.

Minimum requirements for high school graduation, Kentucky Department of Education 704 KAR 3:305 Stat. (2011).

Next generation learners, Kentucky Board of Education, 703 KAR 5:200 Stat. (2011). 
Oudenhoven, B. (2002). Remediation at the Community College: Pressing Issues, Uncertain Solutions. [Article]. New Directions for Community Colleges, 2002(117), 35 .

Paduraru, C. (2013). Pupose of Community Colleges Retrieved January 3, 2013, from http://www.ehow.com/info_7878643_purpose-community-colleges.html

Patterson, A. (2011). Senate Bill 1 (2009) College and Career Readiness Retrieved August 21, 2011, from http://www.education.ky.gov/kde/instructional+resources/secondary+and+virtual +learning/senate+bill+1+\%282009\%29+college+and+career+readiness.htm

. Reinventing the federal role in education: Supporting the goal of college and career readiness for all students. (2009) Retrieved September 12, 2011, from $\underline{\text { Www.eddigest.com }}$

Roach, A. T., Niebling, B. C., \& Kurz, A. (2008). Evaluating the alignment among curriculum, instruction, and assessments: Implications and applications for research and practice. [Article]. Psychology in the Schools, 45(2), 158-176.

Rothman, R. (2003). Imperfect matches: The alignment of standards and tests: Anneberg Institute for School Reform.

Saxon, D. P., \& Boylan, H. R. (2001). The cost of remedial education in higher education. Journal of Developmental Education, 25, 2-8.

Schachter, R. (2008). Remedial Nation. [Article]. University Business, 11(12), 52-56.

Sconing, J. (2013). [COMPASS and Common Core].

Senate Bill 1 (2009) College and Career Readiness. (2011) Retrieved August 27, 2011, from 
http://www.education.ky.gov/kde/instructional+resources/secondary+and+virtual +learning/senate+bill+1+\%282009\%29+college+and+career+readiness.htm

Senate Bill 1 (2009) College and Career Readiness. (2012) Retrieved May 15, 2012, from http://www.education.ky.gov/kde/instructional+resources/secondary+and+virtual +learning/senate+bill+1+\%282009\%29+college+and+career+readiness.htm

Subkoviak, M. (1988). A practitioner's guide to computation and interpretation of reliability of indices for mastery tests. Journal of Educational Measurement, 25(1), 47-55.

Troseth, K. (2008). SAT and ACT for college entry

Retrieved July 1, 2010, from http://colleges.suite101.com/article.cfm/act_or_sat_which_to_take

WAT Web Alignment Tool. Retrieved April 12, 2012, from http://wat.wceruw.org/Tutorial/MathDOKDef.aspx

Waycaster, P. W. (2001). Factors impacting success in community college developmental mathematics courses and subsequent courses [Article]. Community College Journal of Research \& Practice, 25(5/6), 403-416. doi:

$10.1080 / 106689201750192256$

Webb, N. (1997). Criteria for alignment of expecations and asessmetns in mathematics and science education. Research Monograph No. 8.

Webb, N. L. (2007). Issues related to judging the alignment of curriculum standards and assessments. [Article]. Applied Measurement in Education, 20(1), 7-25. doi: 10.1207/s15324818ame2001_2 
Zucker, A., Shields, P., Adelman, N., \& Powell, J. (1995). Evaluation of NSF's statewide systemic initiatives (SSS) program: Second year report, cross-cutting themes. Menlo Park: CA:SRI International. 
Appendix A.

Common Core State Standards Coding Instrument

Below is a list of all Common Core State Standards in Mathematics for Middle and High School, along with a few elementary standards in measurement and data, and Geometry.

Key:

DOMAINS -are larger groups of related standards. Standards from different domains may sometimes be closely related.

CLUSTERS -summarize groups of related standards. Note that standards from different clusters may sometimes be closely related, because mathematics is a connected subject.

STANDARD GROUPS -define what students should understand and be able to do.

\begin{tabular}{l} 
3rd Grade \\
\hline Measurement and Data $3 . \mathrm{md}$ \\
\hline $\begin{array}{l}\text { Geometric measurement: } \text { understand concepts of area and relate } \\
\text { area to multiplication and to addition. }\end{array}$ \\
\hline
\end{tabular}

7. Relate area to the operations of multiplication and addition.

a. Find the area of a rectangle with whole-number side lengths by tiling it, and show that the area is the same as would be found by multiplying the side lengths.

\section{Solve real world and mathematical problems involving perimeters}

8. Geometric measurement: recognize perimeter as an attribute of plane figures and distinguish between linear and area measures. of polygons, including finding the perimeter given the side lengths, finding an unknown side length, and exhibiting rectangles with the same perimeter and different areas or with the same area and different perimeters.

\section{4th Grade}

Number and Operations-fractions 4.nf

\section{Extend understanding of fraction equivalence and ordering.}

Explain why a fraction $a / b$ is equivalent to a fraction $(n \times a) /(n \times b)$ by using visual fraction models, with attention to how the number and size of the parts differ even though the two fractions themselves are the same size. Use this principle to recognize and generate equivalent fractions.

\section{5th Grade Standards}

\section{Number and Operations-Fractions 5.nf}

Use equivalent fractions as a strategy to add and subtract fractions.

1 Add and subtract fractions with unlike denominators (including mixed numbers) by replacing given fractions with equivalent fractions in such a 


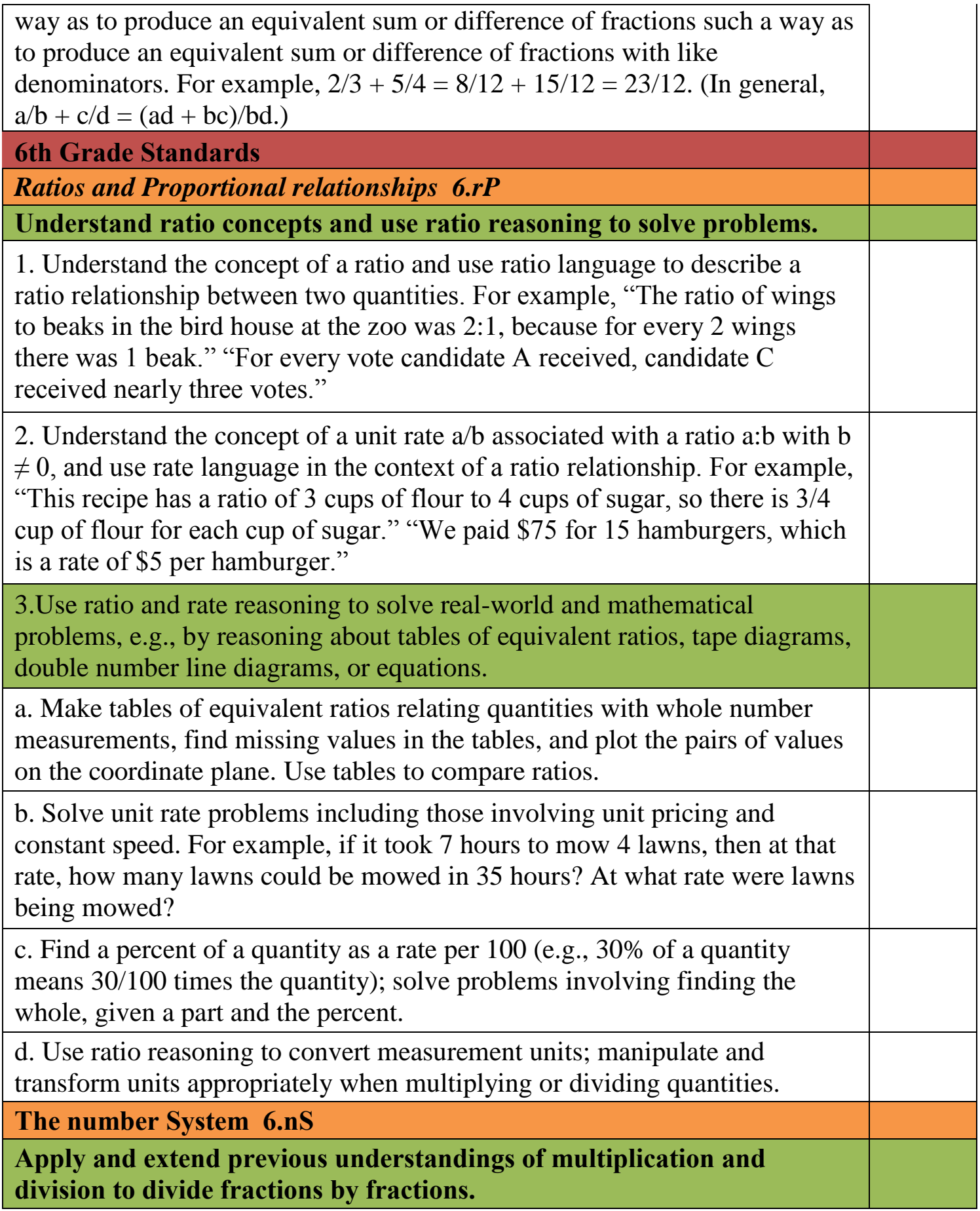


1. Interpret and compute quotients of fractions, and solve word problems involving division of fractions by fractions, e.g., by using visual fraction models and equations to represent the problem. For example, create a story context for $(2 / 3) \div(3 / 4)$ and use a visual fraction model to show the quotient; use the relationship between multiplication and division to explain that $(2 / 3) \div(3 / 4)=8 / 9$ because $3 / 4$ of $8 / 9$ is $2 / 3$. (In general, $(a / b) \div(c / d)=$ $\mathrm{ad} / \mathrm{bc}$.) How much chocolate will each person get if 3 people share $1 / 2 \mathrm{lb}$ of chocolate equally? How many 3/4-cup servings are in $2 / 3$ of a cup of yogurt? How wide is a rectangular strip of land with length $3 / 4 \mathrm{mi}$ and area $1 / 2$ square mi?

\section{Compute fluently with multi-digit numbers and find common factors} and multiples.

2. Fluently divide multi-digit numbers using the standard algorithm.

3. Fluently add, subtract, multiply, and divide multi-digit decimals using the standard algorithm for each operation.

4. Find the greatest common factor of two whole numbers less than or equal to 100 and the least common multiple of two whole numbers less than or equal to 12 . Use the distributive property to express a sum of two whole numbers 1-100 with a common factor as a multiple of a sum of two whole numbers with no common factor. For example, express $36+8$ as $4(9+2)$. Expectations for unit rates in this grade are limited to non-complex fractions.

Apply and extend previous understandings of numbers to the system of rational numbers.

5. Understand that positive and negative numbers are used together to describe quantities having opposite directions or values (e.g., temperature above/below zero, elevation above/below sea level, credits/debits, positive/negative electric charge); use positive and negative numbers to represent quantities in real-world contexts, explaining the meaning of 0 in each situation.

\section{Understand a rational number as a point on the number line. Extend} number line diagrams and coordinate axes familiar from previous grades to represent points on the line and in the plane with negative number coordinates.

a. Recognize opposite signs of numbers as indicating locations on opposite sides of 0 on the number line; recognize that the opposite of the opposite of a number is the number itself, e.g., $-(-3)=3$, and that 0 is its own opposite.

b. Understand signs of numbers in ordered pairs as indicating locations in quadrants of the coordinate plane; recognize that when two ordered pairs differ only by signs, the locations of the points are related by reflections across one or both axes.

c. Find and position integers and other rational numbers on a horizontal or vertical number line diagram; find and position pairs of integers and other rational numbers on a coordinate plane. 


\section{Understand ordering and absolute value of rational numbers.}

a. Interpret statements of inequality as statements about the relative position of two numbers on a number line diagram. For example, interpret $-3>-7$ as a statement that -3 is located to the right of -7 on a number line oriented from left to right.

b. Write, interpret, and explain statements of order for rational numbers in real-world contexts. For example, write -3 o $\mathrm{C}>-7$ oC to express the fact that -3 o $\mathrm{C}$ is warmer than $-7 \mathrm{oC}$.

c. Understand the absolute value of a rational number as its distance from 0 on the number line; interpret absolute value as magnitude for a positive or negative quantity in a real-world situation. For example, for an account balance of -30 dollars, write $|-30|=30$ to describe the size of the debt in dollars.

d. Distinguish comparisons of absolute value from statements about order. For example, recognize that an account balance less than -30 dollars represents a debt greater than 30 dollars.

8. Solve real-world and mathematical problems by graphing points in all four quadrants of the coordinate plane. Include use of coordinates and absolute value to find distances between points with the same first coordinate or the same second coordinate.

\section{Expressions and Equations 6.ee}

\section{Apply and extend previous understandings of arithmetic to algebraic} expressions.

1. Write and evaluate numerical expressions involving whole-number exponents.

\section{Write, read, and evaluate expressions in which letters stand for} numbers.

a. Write expressions that record operations with numbers and with letters standing for numbers. For example, express the calculation "Subtract $\mathrm{y}$ from 5 " as $5-\mathrm{y}$.

b. Identify parts of an expression using mathematical terms (sum, term, product, factor, quotient, coefficient); view one or more parts of an expression as a single entity. For example, describe the expression $2(8+7)$ as a product of two factors; view $(8+7)$ as both a single entity and a sum of two terms.

c. Evaluate expressions at specific values of their variables. Include expressions that arise from formulas used in real-world problems. Perform arithmetic operations, including those involving whole number exponents, in the conventional order when there are no parentheses to specify a particular order (Order of Operations). For example, use the formulas V = s 3 and $\mathrm{A}=6 \mathrm{~s} 2$ to find the volume and surface area of a cube with sides of length $\mathrm{s}=1 / 2$. 
3. Apply the properties of operations to generate equivalent expressions. For example, apply the distributive property to the expression $3(2+x)$ to produce the equivalent expression $6+3 x$; apply the distributive property to the expression $24 x+18 y$ to produce the equivalent expression $6(4 x+3 y)$; apply properties of operations to $\mathrm{y}+\mathrm{y}+\mathrm{y}$ to produce the equivalent expression $3 y$.

4. Identify when two expressions are equivalent (i.e., when the two expressions name the same number regardless of which value is substituted into them). For example, the expressions $y+y+y$ and $3 y$ are equivalent because they name the same number regardless of which number y stands for.

\section{Reason about and solve one-variable equations and inequalities.}

5. Understand solving an equation or inequality as a process of answering a question: which values from a specified set, if any, make the equation or inequality true? Use substitution to determine whether a given number in a specified set makes an equation or inequality true.

6. Use variables to represent numbers and write expressions when solving a real-world or mathematical problem; understand that a variable can represent an unknown number, or, depending on the purpose at hand, any number in a specified set.

7. Solve real-world and mathematical problems by writing and solving equations of the form $\mathrm{x}+\mathrm{p}=\mathrm{q}$ and $\mathrm{px}=\mathrm{q}$ for cases in which $\mathrm{p}, \mathrm{q}$ and $\mathrm{x}$ are all nonnegative rational numbers.

8. Write an inequality of the form $\mathrm{x}>\mathrm{c}$ or $\mathrm{x}<\mathrm{c}$ to represent a constraint or condition in a real-world or mathematical problem. Recognize that inequalities of the form $\mathrm{x}>\mathrm{c}$ or $\mathrm{x}<\mathrm{c}$ have infinitely many solutions; represent solutions of such inequalities on number line diagrams.

\section{Represent and analyze quantitative relationships between dependent} and independent variables.

9. Use variables to represent two quantities in a real-world problem that change in relationship to one another; write an equation to express one quantity, thought of as the dependent variable, in terms of the other quantity, thought of as the independent variable. Analyze the relationship between the dependent and independent variables using graphs and tables, and relate these to the equation. For example, in a problem involving motion at constant speed, list and graph ordered pairs of distances and times, and write the equation $d=65 t$ to represent the relationship between distance and time.

\section{Geometry 6.G}

\section{Solve real-world and mathematical problems involving area, surface} area, and volume.

1. Find the area of right triangles, other triangles, special quadrilaterals, and polygons by composing into rectangles or decomposing into triangles and 
other shapes; apply these techniques in the context of solving real-world and mathematical problems.

2.Find the volume of a right rectangular prism with fractional edge lengths by packing it with unit cubes of the appropriate unit fraction edge lengths, and show that the volume is the same as would be found by multiplying the edge lengths of the prism. Apply the formulas $\mathrm{V}=1 \mathrm{w} \mathrm{h}$ and $\mathrm{V}=\mathrm{b}$ h to find volumes of right rectangular prisms with fractional edge lengths in the context of solving real-world and mathematical problems.

3. Draw polygons in the coordinate plane given coordinates for the vertices; use coordinates to find the length of a side joining points with the same first coordinate or the same second coordinate. Apply these techniques in the context of solving real-world and mathematical problems.

4.Represent three-dimensional figures using nets made up of rectangles and triangles, and use the nets to find the surface area of these figures. Apply these techniques in the context of solving real-world and mathematical problems.

\section{Statistics and Probability 6.SP}

\section{Develop understanding of statistical variability.}

1. Recognize a statistical question as one that anticipates variability in the data related to the question and accounts for it in the answers. For example, "How old am I?" is not a statistical question, but "How old are the students in my school?" is a statistical question because one anticipates variability in students' ages.

2. Understand that a set of data collected to answer a statistical question has a distribution which can be described by its center, spread, and overall shape.

3. Recognize that a measure of center for a numerical data set summarizes all of its values with a single number, while a measure of variation describes how its values vary with a single number.

\section{Summarize and describe distributions.}

4. Display numerical data in plots on a number line, including dot plots, histograms, and box plots.

\section{Summarize numerical data sets in relation to their context, such as by:}

a. Reporting the number of observations.

b.Describing the nature of the attribute under investigation, including how it was measured and its units of measurement.

c.Giving quantitative measures of center (median and/or mean) and variability (interquartile range and/or mean absolute deviation), as well as describing any overall pattern and any striking deviations from the overall pattern with reference to the context in which the data were gathered. 
d. Relating the choice of measures of center and variability to the shape of the data distribution and the context in which the data were gathered.

7th Grade Standards

Ratios and Proportional Relationships 7.rP

Analyze proportional relationships and use them to solve real-world and mathematical problems.

1. Compute unit rates associated with ratios of fractions, including ratios of lengths, areas and other quantities measured in like or different units. For example, if a person walks $1 / 2$ mile in each $1 / 4$ hour, compute the unit rate as the complex fraction 1/2/1/4 miles per hour, equivalently 2 miles per hour.

\section{Recognize and represent proportional relationships between} quantities.

a. Decide whether two quantities are in a proportional relationship, e.g., by testing for equivalent ratios in a table or graphing on a coordinate plane and observing whether the graph is a straight line through the origin.

b. Identify the constant of proportionality (unit rate) in tables, graphs, equations, diagrams, and verbal descriptions of proportional relationships.

c. Represent proportional relationships by equations. For example, if total cost $t$ is proportional to the number $n$ of items purchased at a constant price $\mathrm{p}$, the relationship between the total cost and the number of items can be expressed as $t=p n$.

d. Explain what a point $(x, y)$ on the graph of a proportional relationship means in terms of the situation, with special attention to the points $(0,0)$ and $(1, r)$ where $r$ is the unit rate.

3. Use proportional relationships to solve multistep ratio and percent problems. Examples: simple interest, tax, markups and markdowns, gratuities and commissions, fees, percent increase and decrease, percent error.

\section{The Number System 7.nS}

Apply and extend previous understandings of operations with fractions to add, subtract, multiply, and divide rational numbers.

1. Apply and extend previous understandings of addition and subtraction to add and subtract rational numbers; represent addition and subtraction on a horizontal or vertical number line diagram.

a. Describe situations in which opposite quantities combine to make 0 . For example, a hydrogen atom has 0 charge because its two constituents are oppositely charged.

b. Understand $p+q$ as the number located a distance $|q|$ from $p$, in the positive or negative direction depending on whether $\mathrm{q}$ is positive or negative. Show that a number and its opposite have a sum of 0 (are additive inverses). Interpret sums of rational numbers by describing real-world contexts. 
c. Understand subtraction of rational numbers as adding the additive inverse, $\mathrm{p}-\mathrm{q}=\mathrm{p}+(-\mathrm{q})$. Show that the distance between two rational numbers on the number line is the absolute value of their difference, and apply this principle in real-world contexts.

d. Apply properties of operations as strategies to add and subtract rational numbers.

\section{Apply and extend previous understandings of multiplication and division and of fractions to multiply and divide rational numbers.}

a. Understand that multiplication is extended from fractions to rational numbers by requiring that operations continue to satisfy the properties of operations, particularly the distributive property, leading to products such as $(-1)(-1)=1$ and the rules for multiplying signed numbers. Interpret products of rational numbers by describing real-world contexts.

b. Understand that integers can be divided, provided that the divisor is not zero, and every quotient of integers (with non-zero divisor) is a rational number. If $p$ and $q$ are integers, then $-(p / q)=(-p) / q=p /(-q)$. Interpret quotients of rational numbers by describing realworld contexts.

c. Apply properties of operations as strategies to multiply and divide rational numbers.

d. Convert a rational number to a decimal using long division; know that the decimal form of a rational number terminates in 0s or eventually repeats.

3. Solve real-world and mathematical problems involving the four operations with rational numbers.

Expressions and Equations 7.ee

Use properties of operations to generate equivalent expressions.

1. Apply properties of operations as strategies to add, subtract, factor, and expand linear expressions with rational coefficients.

2. Understand that rewriting an expression in different forms in a problem context can shed light on the problem and how the quantities in it are related. For example, a $+0.05 a=1.05 a$ means that "increase by $5 \%$ " is the same as "multiply by 1.05." Solve real-life and mathematical problems using numerical and algebraic expressions and equations.

3. Solve multi-step real-life and mathematical problems posed with positive and negative rational numbers in any form (whole numbers, fractions, and decimals), using tools strategically. Apply properties of operations to calculate with numbers in any form; convert between forms as appropriate; and assess the reasonableness of answers using mental computation and estimation strategies. For example: If a woman making $\$ 25$ an hour gets a $10 \%$ raise, she will make an additional $1 / 10$ of her salary an hour, or $\$ 2.50$, for a new salary of $\$ 27.50$. If you want to place a towel bar $93 / 4$ inches long in the center of a door that is $271 / 2$ inches wide, you will need to place the bar about 9 inches from each edge; this estimate can be used as a check on the exact computation. 


\section{Use variables to represent quantities in a real-world or mathematical problem, and construct simple equations and inequalities to solve problems by reasoning about the quantities.}

a. Solve word problems leading to equations of the form $\mathrm{px}+\mathrm{q}=\mathrm{r}$ and $\mathrm{p}(\mathrm{x}$ $+q)=r$, where $p$, $q$, and $r$ are specific rational numbers. Solve equations of these forms fluently. Compare an algebraic solution to an arithmetic solution, identifying the sequence of the operations used in each approach. For example, the perimeter of a rectangle is $54 \mathrm{~cm}$. Its length is $6 \mathrm{~cm}$. What is its width?

b. Solve word problems leading to inequalities of the form $\mathrm{px}+\mathrm{q}>\mathrm{r}$ or $\mathrm{px}+$ $\mathrm{q}<\mathrm{r}$, where $\mathrm{p}, \mathrm{q}$, and $\mathrm{r}$ are specific rational numbers. Graph the solution set of the inequality and interpret it in the context of the problem. For example: As a salesperson, you are paid $\$ 50$ per week plus $\$ 3$ per sale. This week you want your pay to be at least $\$ 100$. Write an inequality for the number of sales you need to make, and describe the solutions.

\section{Geometry 7.G}

\section{Draw, construct, and describe geometrical figures and describe the} relationships between them.

1. Solve problems involving scale drawings of geometric figures, including computing actual lengths and areas from a scale drawing and reproducing a scale drawing at a different scale. Computations with rational numbers extend the rules for manipulating fractions to complex fractions.

2. Draw (freehand, with ruler and protractor, and with technology) geometric shapes with given conditions. Focus on constructing triangles from three measures of angles or sides, noticing when the conditions determine a unique triangle, more than one triangle, or no triangle.

3. Describe the two-dimensional figures that result from slicing three dimensional figures, as in plane sections of right rectangular prisms and right rectangular pyramids. Solve real-life and mathematical problems involving angle measure, area, surface area, and volume.

4. Know the formulas for the area and circumference of a circle and use them to solve problems; give an informal derivation of the relationship between the circumference and area of a circle.

5. Use facts about supplementary, complementary, vertical, and adjacent angles in a multi-step problem to write and solve simple equations for an unknown angle in a figure.

6. Solve real-world and mathematical problems involving area, volume and surface area of two- and three-dimensional objects composed of triangles, quadrilaterals, polygons, cubes, and right prisms.

\section{Statistics and Probability 7.SP}

\section{Use random sampling to draw inferences about a population.}


1. Understand that statistics can be used to gain information about a population by examining a sample of the population; generalizations about a population from a sample are valid only if the sample is representative of that population. Understand that random sampling tends to produce representative samples and support valid inferences.

2. Use data from a random sample to draw inferences about a population with an unknown characteristic of interest. Generate multiple samples (or simulated samples) of the same size to gauge the variation in estimates or predictions. For example, estimate the mean word length in a book by randomly sampling words from the book; predict the winner of a school election based on randomly sampled survey data. Gauge how far off the estimate or prediction might be. Draw informal comparative inferences about two populations.

3. Informally assess the degree of visual overlap of two numerical data distributions with similar variabilities, measuring the difference between the centers by expressing it as a multiple of a measure of variability. For example, the mean height of players on the basketball team is $10 \mathrm{~cm}$ greater than the mean height of players on the soccer team, about twice the variability (mean absolute deviation) on either team; on a dot plot, the separation between the two distributions of heights is noticeable.

4. Use measures of center and measures of variability for numerical data from random samples to draw informal comparative inferences about two populations. For example, decide whether the words in a chapter of a seventh-grade science book are generally longer than the words in a chapter of a fourth-grade science book. Investigate chance processes and develop, use, and evaluate probability models.

5. Understand that the probability of a chance event is a number between 0 and 1 that expresses the likelihood of the event occurring. Larger numbers indicate greater likelihood. A probability near 0 indicates an unlikely event, a probability around $1 / 2$ indicates an event that is neither unlikely nor likely, and a probability near 1 indicates a likely event.

6. Approximate the probability of a chance event by collecting data on the chance process that produces it and observing its long-run relative frequency, and predict the approximate relative frequency given the probability. For example, when rolling a number cube 600 times, predict that a 3 or 6 would be rolled roughly 200 times, but probably not exactly 200 times.

7. Develop a probability model and use it to find probabilities of events. Compare probabilities from a model to observed frequencies; if the agreement is not good, explain possible sources of the discrepancy. 
a. Develop a uniform probability model by assigning equal probability to all outcomes, and use the model to determine probabilities of events. For example, if a student is selected at random from a class, find the probability that Jane will be selected and the probability that a girl will be selected.

b. Develop a probability model (which may not be uniform) by observing frequencies in data generated from a chance process. For example, find the approximate probability that a spinning penny will land heads up or that a tossed paper cup will land open-end down. Do the outcomes for the spinning penny appear to be equally likely based on the observed frequencies?

\section{Find probabilities of compound events using organized lists, tables, tree diagrams, and simulation.}

a. Understand that, just as with simple events, the probability of a compound event is the fraction of outcomes in the sample space for which the compound event occurs.

b. Represent sample spaces for compound events using methods such as organized lists, tables and tree diagrams. For an event described in everyday language (e.g., "rolling double sixes"), identify the outcomes in the sample space which compose the event.

c. Design and use a simulation to generate frequencies for compound events. For example, use random digits as a simulation tool to approximate the answer to the question: If $40 \%$ of donors have type A blood, what is the probability that it will take at least 4 donors to find one with type A blood?

\section{8th Grade Standards \\ The Number System 8.nS}

Know that there are numbers that are not rational, and approximate them by rational numbers.

1. Know that numbers that are not rational are called irrational. Understand informally that every number has a decimal expansion; for rational numbers show that the decimal expansion repeats eventually, and convert a decimal expansion which repeats eventually into a rational number.

2. Use rational approximations of irrational numbers to compare the size of irrational numbers, locate them approximately on a number line diagram, and estimate the value of expressions (e.g., $\pi$ ). For example, by truncating the decimal expansion of $\sqrt{2}$, show that $\sqrt{2}$ is between 1 and 2 , then between 1.4 and 1.5, and explain how to continue on to get better approximations.

Expressions and Equations 8.ee Work with radicals and integer exponents.

1. Know and apply the properties of integer exponents to generate equivalent numerical expressions. 
2. Use square root and cube root symbols to represent solutions to equations of the form $x=p$ and $x=p$, where $p$ is a positive rational number. Evaluate square roots of small perfect squares and cube roots of small perfect cubes. Know that $\sqrt{2}$ is irrational.

3. Use numbers expressed in the form of a single digit times an integer power of 10 to estimate very large or very small quantities, and to express how many times as much one is than the other. For example, estimate the population of the United States as $3 \times 108$ and the population of the world as $7 \times 109$, and determine that the world population is more than 20 times larger.

4. Perform operations with numbers expressed in scientific notation, including problems where both decimal and scientific notation are used. Use scientific notation and choose units of appropriate size for measurements of very large or very small quantities (e.g., use millimeters per year for seafloor preading). Interpret scientific notation that has been generated by technology.

\section{Understand the connections between proportional relationships, lines, and linear equations.}

5. Graph proportional relationships, interpreting the unit rate as the slope of the graph. Compare two different proportional relationships represented in different ways. For example, compare a distance-time graph to a distancetime equation to determine which of two moving objects has greater speed.

6. Use similar triangles to explain why the slope $m$ is the same between any two distinct points on a non-vertical line in the coordinate plane; derive the equation $\mathrm{y}=\mathrm{mx}$ for a line through the origin and the equation $\mathrm{y}=\mathrm{mx}+\mathrm{b}$ for a line intercepting the vertical axis at $b$. Analyze and solve linear equations and pairs of simultaneous linear equations.

\section{Solve linear equations in one variable.}

a. Give examples of linear equations in one variable with one solution, infinitely many solutions, or no solutions. Show which of these possibilities is the case by successively transforming the given equation into simpler forms, until an equivalent equation of the form $\mathrm{x}=\mathrm{a}, \mathrm{a}=\mathrm{a}$, or $\mathrm{a}=\mathrm{b}$ results (where $\mathrm{a}$ and $\mathrm{b}$ are different numbers).

b. Solve linear equations with rational number coefficients, including equations whose solutions require expanding expressions using the distributive property and collecting like terms.

\section{Analyze and solve pairs of simultaneous linear equations.}

a. Understand that solutions to a system of two linear equations in two variables correspond to points of intersection of their graphs, because points of intersection satisfy both equations simultaneously. 
b. Solve systems of two linear equations in two variables algebraically, and estimate solutions by graphing the equations. Solve simple cases by inspection. For example, $3 x+2 y=5$ and $3 x+2 y=6$ have no solution because $3 x+2 y$ cannot simultaneously be 5 and 6 .

c. Solve real-world and mathematical problems leading to two linear equations in two variables. For example, given coordinates for two pairs of points, determine whether the line through the first pair of points intersects the line through the second pair.

\section{Functions 8.f \\ Define, evaluate, and compare functions.}

1.Understand that a function is a rule that assigns to each input exactly one output. The graph of a function is the set of ordered pairs consisting of an input and the corresponding output.

2. Compare properties of two functions each represented in a different way (algebraically, graphically, numerically in tables, or by verbal descriptions). For example, given a linear function represented by a table of values and a linear function represented by an algebraic expression, determine which function has the greater rate of change.

3. Interpret the equation $y=m x+b$ as defining a linear function, whose graph is a straight line; give examples of functions that are not linear. For example, the function $\mathrm{A}=\mathrm{s}$ giving the area of a square as a function of its side length is not linear because its graph contains the points $(1,1),(2,4)$ and $(3,9)$, which are not on a straight line.

\section{Use functions to model relationships between quantities.}

4. Construct a function to model a linear relationship between two quantities. Determine the rate of change and initial value of the function from a description of a relationship or from two $(x, y)$ values, including reading these from a table or from a graph. Interpret the rate of change and initial value of a linear function in terms of the situation it models, and in terms of its graph or a table of values.

5. Describe qualitatively the functional relationship between two quantities by analyzing a graph (e.g., where the function is increasing or decreasing, linear or nonlinear). Sketch a graph that exhibits the qualitative features of a function that has been described verbally.

\section{Geometry 8.G}

Understand congruence and similarity using physical models, transparencies, or geometry software.

\section{Verify experimentally the properties of rotations, reflections, and} translations:

a. Lines are taken to lines, and line segments to line segments of the same length.

b. Angles are taken to angles of the same measure. 
c. Parallel lines are taken to parallel lines.

2. Understand that a two-dimensional figure is congruent to another if the second can be obtained from the first by a sequence of rotations, reflections, and translations; given two congruent figures, describe a sequence that exhibits the congruence between them.

3. Describe the effect of dilations, translations, rotations, and reflections on two-dimensional figures using coordinates.

4.Understand that a two-dimensional figure is similar to another if the second can be obtained from the first by a sequence of rotations, reflections, translations, and dilations; given two similar two dimensional figures, describe a sequence that exhibits the similarity between them.

5. Use informal arguments to establish facts about the angle sum and exterior angle of triangles, about the angles created when parallel lines are cut by a transversal, and the angle-angle criterion for similarity of triangles. For example, arrange three copies of the same triangle so that the sum of the three angles appears to form a line, and give an argument in terms of transversals why this is so.

\section{Understand and apply the Pythagorean Theorem.}

6. Explain a proof of the Pythagorean Theorem and its converse.

7.Apply the Pythagorean Theorem to determine unknown side lengths in right triangles in real-world and mathematical problems in two and three dimensions.

8. Apply the Pythagorean Theorem to find the distance between two points in a coordinate system.

\section{Solve real-world and mathematical problems involving volume of} cylinders, cones, and spheres.

9. Know the formulas for the volumes of cones, cylinders, and spheres and use them to solve real-world and mathematical problems.

\section{Statistics and Probability 8.SP}

\section{Investigate patterns of association in bivariate data.}

1. Construct and interpret scatter plots for bivariate measurement data to investigate patterns of association between two quantities. Describe patterns such as clustering, outliers, positive or negative association, linear association, and nonlinear association.

2. Know that straight lines are widely used to model relationships between two quantitative variables. For scatter plots that suggest a linear association, informally fit a straight line, and informally assess the model fit by judging the closeness of the data points to the line. 
3. Use the equation of a linear model to solve problems in the context of bivariate measurement data, interpreting the slope and intercept. For example, in a linear model for a biology experiment, interpret a slope of 1.5 $\mathrm{cm} / \mathrm{hr}$ as meaning that an additional hour of sunlight each day is associated with an additional $1.5 \mathrm{~cm}$ in mature plant height.

4. Understand that patterns of association can also be seen in bivariate categorical data by displaying frequencies and relative frequencies in a twoway table. Construct and interpret a two-way table summarizing data on two categorical variables collected from the same subjects. Use relative frequencies calculated for rows or columns to describe possible association between the two variables. For example, collect data from students in your class on whether or not they have a curfew on school nights and whether or not they have assigned chores at home. Is there evidence that those who have a curfew also tend to have chores?

\begin{tabular}{|l|l|}
\hline High School Standards & \\
\hline Number and Quantity & \\
\hline The Real Number System N -RN & \\
\hline Extend the properties of exponents to rational exponents. & \\
\hline $\begin{array}{l}\text { 1. Explain how the definition of the meaning of rational exponents follows } \\
\text { from extending the properties of integer exponents to those values, allowing } \\
\text { for a notation for radicals in terms of rational exponents. For example, we } \\
\text { define } 51 / 3 \text { to be the cube root of } 5 \text { because we want }(51 / 3) 3=5(1 / 3) 3 \text { to } \\
\text { hold, so (51/3)3 must equal 5. }\end{array}$ & \\
\hline $\begin{array}{l}\text { 2. Rewrite expressions involving radicals and rational exponents using the } \\
\text { properties of exponents. }\end{array}$ & \\
\hline Use properties of rational and irrational numbers. & \\
\hline $\begin{array}{l}\text { 3. Explain why the sum or product of two rational numbers is rational; that } \\
\text { the sum of a rational number and an irrational number is irrational; and that } \\
\text { the product of a nonzero rational number and an irrational number is } \\
\text { irrational. }\end{array}$ & \\
\hline & \\
\hline Quantities N -Q & \\
\hline Reason quantitatively and use units to solve problems. & \\
\hline $\begin{array}{l}\text { 1. Use units as a way to understand problems and to guide the solution of } \\
\text { multi-step problems; choose and interpret units consistently in formulas; } \\
\text { choose and interpret the scale and the origin in graphs and data displays. }\end{array}$ & \\
\hline $\begin{array}{l}\text { 2. Define appropriate quantities for the purpose of descriptive modeling. } \\
\text { when reporting quantities. }\end{array}$ & \\
\hline Choose level of accuracy appropriate to limitations on measurement & \\
\hline
\end{tabular}




\begin{tabular}{|c|c|}
\hline The Complex Number System N -CN & \\
\hline Perform arithmetic operations with complex numbers. & \\
\hline $\begin{array}{l}\text { 1. Know there is a complex number } i \text { such that } i 2=-1 \text {, and every complex } \\
\text { number has the form } a+b i \text { with } a \text { and } b \text { real. }\end{array}$ & \\
\hline $\begin{array}{l}\text { 2. Use the relation } i 2=-1 \text { and the commutative, associative, and distributive } \\
\text { properties to add, subtract, and multiply complex numbers. }\end{array}$ & \\
\hline $\begin{array}{l}\text { 3. (+) Find the conjugate of a complex number; use conjugates to find } \\
\text { moduli and quotients of complex numbers. }\end{array}$ & \\
\hline Represent complex numbers and their operations on the complex plane. & \\
\hline $\begin{array}{l}\text { 4. (+) Represent complex numbers on the complex plane in rectangular and } \\
\text { polar form (including real and imaginary numbers), and explain why the } \\
\text { rectangular and polar forms of a given complex number represent the same } \\
\text { number. }\end{array}$ & \\
\hline $\begin{array}{l}\text { 5. (+) Represent addition, subtraction, multiplication, and conjugation of } \\
\text { complex numbers geometrically on the complex plane; use properties of this } \\
\text { representation for computation. For example, }(-1+\sqrt{3} \text { i) } 3=8 \text { because }(-1+ \\
\sqrt{3} \text { i) has modulus } 2 \text { and argument } 120^{\circ} \text {. }\end{array}$ & \\
\hline $\begin{array}{l}\text { 6. (+) Calculate the distance between numbers in the complex plane as the } \\
\text { modulus of the difference, and the midpoint of a segment as the average of } \\
\text { the numbers at its endpoints. }\end{array}$ & \\
\hline Use complex numbers in polynomial identities and equations. & \\
\hline $\begin{array}{l}\text { 7. Solve quadratic equations with real coefficients that have complex } \\
\text { solutions. }\end{array}$ & \\
\hline $\begin{array}{l}\text { 8. (+) Extend polynomial identities to the complex numbers. For example, } \\
\text { rewrite } x 2+4 \text { as }(x+2 i)(x-2 i) \text {. }\end{array}$ & \\
\hline $\begin{array}{l}\text { 9. (+) Know the Fundamental Theorem of Algebra; show that it is true for } \\
\text { quadratic polynomials. }\end{array}$ & \\
\hline Vector and Matrix Quantities N-VM & \\
\hline Represent and model with vector quantities. & \\
\hline $\begin{array}{l}\text { 1. (+) Recognize vector quantities as having both magnitude and direction. } \\
\text { Represent vector quantities by directed line segments, and use appropriate } \\
\text { symbols for vectors and their magnitudes (e.g., } v,|v|,\|v\|, v) \text {. }\end{array}$ & \\
\hline $\begin{array}{l}\text { 2. (+) Find the components of a vector by subtracting the coordinates of an } \\
\text { initial point from the coordinates of a terminal point. }\end{array}$ & \\
\hline $\begin{array}{l}\text { 3. (+) Solve problems involving velocity and other quantities that can be } \\
\text { represented by vectors. }\end{array}$ & \\
\hline Perform operations on vectors. & \\
\hline 4. (+) Add and subtract vectors. & \\
\hline
\end{tabular}


a. Add vectors end-to-end, component-wise, and by the parallelogram rule. Understand that the magnitude of a sum of two vectors is typically not the sum of the magnitudes.

b. Given two vectors in magnitude and direction form, determine the magnitude and direction of their sum.

c. Understand vector subtraction $\boldsymbol{v}-\boldsymbol{w}$ as $\boldsymbol{v}+(-\boldsymbol{w})$, where $-\boldsymbol{w}$ is the additive inverse of $\boldsymbol{w}$, with the same magnitude as $\boldsymbol{w}$ and pointing in the opposite direction. Represent vector subtraction graphically by connecting the tips in the appropriate order, and perform vector subtraction component-wise.

5. (+) Multiply a vector by a scalar.

a. Represent scalar multiplication graphically by scaling vectors and possibly reversing their direction; perform scalar multiplication componentwise, e.g., as $c(v \mathrm{x}, v \mathrm{y})=(c v \mathrm{x}, c v \mathrm{y})$.

b. Compute the magnitude of a scalar multiple $c v$ using $\|c v\|=|c| v$. Compute the direction of $c v$ knowing that when $|c| v \neq \square 0$, the direction of $c v$ is either along $\boldsymbol{v}$ (for $c>0$ ) or against $\boldsymbol{v}$ (for $c<0$ ).

\section{Perform operations on matrices and use matrices in applications.}

6. (+) Use matrices to represent and manipulate data, e.g., to represent payoffs or incidence relationships in a network.

7. (+) Multiply matrices by scalars to produce new matrices, e.g., as when all of the payoffs in a game are doubled.

8. (+) Add, subtract, and multiply matrices of appropriate dimensions.

9. (+) Understand that, unlike multiplication of numbers, matrix multiplication for square matrices is not a commutative operation, but still satisfies the associative and distributive properties.

10. (+) Understand that the zero and identity matrices play a role in matrix addition and multiplication similar to the role of 0 and 1 in the real numbers. The determinant of a square matrix is nonzero if and only if the matrix has a multiplicative inverse.

11. (+) Multiply a vector (regarded as a matrix with one column) by a matrix of suitable dimensions to produce another vector. Work with matrices as transformations of vectors.

12. (+) Work with $2 \times 2$ matrices as transformations of the plane, and interpret the absolute value of the determinant in terms of area.

Algebra

Seeing Structure in Expressions A-SSE

Interpret the structure of expressions 
1. Interpret expressions that represent a quantity in terms of its context.

a. Interpret parts of an expression, such as terms, factors, and coefficients.

b. Interpret complicated expressions by viewing one or more of their parts as a single entity. For example, interpret $P(1+r) \mathrm{n}$ as the product of $P$ and $a$ factor not depending on $P$.

2. Use the structure of an expression to identify ways to rewrite it. For example, see $x 4-y 4$ as (x2)2 - (y2)2, thus recognizing it as a difference of squares that can be factored as $(x 2-y 2)(x 2+y 2)$.

Write expressions in equivalent forms to solve problems

3. Choose and produce an equivalent form of an expression to reveal and explain properties of the quantity represented by the expression.

a. Factor a quadratic expression to reveal the zeros of the function it defines.

b. Complete the square in a quadratic expression to reveal the maximum or minimum value of the function it defines.

c. Use the properties of exponents to transform expressions for exponential functions. For example the expression $1.15 \mathrm{t}$ can be rewritten as $(1.151 / 12) 12 t \approx 1.01212 \mathrm{t}$ to reveal the approximate equivalent monthly interest rate if the annual rate is $15 \%$.

4. Derive the formula for the sum of a finite geometric series (when the common ratio is not 1), and use the formula to solve problems. For example, calculate mortgage payments.

Arithmetic with Polynomials and Rational Expressions A -APR

\section{Perform arithmetic operations on polynomials}

1. Understand that polynomials form a system analogous to the integers, namely, they are closed under the operations of addition, subtraction, and multiplication; add, subtract, and multiply polynomials.

\section{Understand the relationship between zeros and factors of polynomials}

2. Know and apply the Remainder Theorem: For a polynomial $p(x)$ and a number $a$, the remainder on division by $x-a$ is $p(a)$, so $p(a)=0$ if and only if $(x-a)$ is a factor of $p(x)$.

3. Identify zeros of polynomials when suitable factorizations are available, and use the zeros to construct a rough graph of the function defined by the polynomial.

\section{Use polynomial identities to solve problems}

4. Prove polynomial identities and use them to describe numerical relationships. For example, the polynomial identity $(x 2+y 2) 2=(x 2-y 2) 2+$ (2xy) 2 can be used to generate Pythagorean triples. 
5. (+) Know and apply the Binomial Theorem for the expansion of $(x+y) n$ in powers of $x$ and $y$ for a positive integer $n$, where $x$ and $y$ are any numbers, with coefficients determined for example by Pascal's Triangle1:The Binomial Theorem can be proved by mathematical induction or by a combinatorial argument.

\section{Rewrite rational expressions}

6. Rewrite simple rational expressions in different forms; write $a(x) / b(x)$ in the form $q(x)+r(x) / b(x)$, where $a(x), b(x), q(x)$, and $r(x)$ are polynomials with the degree of $r(x)$ less than the degree of $b(x)$, using inspection, long division, or, for the more complicated examples, a computer algebra system.

7. (+) Understand that rational expressions form a system analogous to the rational numbers, closed under addition, subtraction, multiplication, and division by a nonzero rational expression; add, subtract, multiply, and divide rational expressions.

\section{Creating Equations A - CED}

\section{Create equations that describe numbers or relationships}

1. Create equations and inequalities in one variable and use them to solve problems. Include equations arising from linear and quadratic functions, and simple rational and exponential functions.

2. Create equations in two or more variables to represent relationships between quantities; graph equations on coordinate axes with labels and scales.

3. Represent constraints by equations or inequalities, and by systems of equations and/or inequalities, and interpret solutions as viable or nonviable options in a modeling context. For example, represent inequalities describing nutritional and cost constraints on combinations of different foods.

4. Rearrange formulas to highlight a quantity of interest, using the same reasoning as in solving equations. For example, rearrange Ohm's law $V=I R$ to highlight resistance $R$.

Reasoning with Equations and Inequalities A -RE I

Understand solving equations as a process of reasoning and explain the reasoning

1. Explain each step in solving a simple equation as following from the equality of numbers asserted at the previous step, starting from the assumption that the original equation has a solution. Construct a viable argument to justify a solution method.

2. Solve simple rational and radical equations in one variable, and give examples showing how extraneous solutions may arise.

Solve equations and inequalities in one variable 
3. Solve linear equations and inequalities in one variable, including equations with coefficients represented by letters.

4. Solve quadratic equations in one variable.

a. Use the method of completing the square to transform any quadratic equation in $x$ into an equation of the form $(x-p) 2=\mathrm{q}$ that has the same solutions. Derive the quadratic formula from this form.

b. Solve quadratic equations by inspection (e.g., for $x 2=49$ ), taking square roots, completing the square, the quadratic formula and factoring, as appropriate to the initial form of the equation.

Recognize when the quadratic formula gives complex solutions and write them as $a \pm b i$ for real numbers $a$ and $b$.

\section{Solve systems of equations}

5. Prove that, given a system of two equations in two variables, replacing one equation by the sum of that equation and a multiple of the other produces a system with the same solutions.

6. Solve systems of linear equations exactly and approximately (e.g., with graphs), focusing on pairs of linear equations in two variables.

7. Solve a simple system consisting of a linear equation and a quadratic equation in two variables algebraically and graphically. For example, find the points of intersection between the line $y=-3 x$ and the circle $x 2+y 2=3$.

8. (+) Represent a system of linear equations as a single matrix equation in a vector variable.

9. (+) Find the inverse of a matrix if it exists and use it to solve systems of linear equations (using technology for matrices of dimension $3 \times 3$ or greater).

\section{Represent and solve equations and inequalities graphically}

10. Understand that the graph of an equation in two variables is the set of all its solutions plotted in the coordinate plane, often forming a curve (which could be a line).

11. Explain why the $x$-coordinates of the points where the graphs of the equations $y=f(x)$ and $y=g(x)$ intersect are the solutions of the equation $f(x)$ $=g(x)$; find the solutions approximately, e.g., using technology to graph the functions, make tables of values, or find successive approximations. Include cases where $f(x)$ and/or $g(x)$ are linear, polynomial, rational, absolute value, exponential, and logarithmic functions. 
12. Graph the solutions to a linear inequality in two variables as a halfplane (excluding the boundary in the case of a strict inequality), and graph the solution set to a system of linear inequalities in two variables as the intersection of the corresponding half-planes.

\section{Functions \\ Interpreting Functions F-IF \\ Understand the concept of a function and use function notation}

1. Understand that a function from one set (called the domain) to another set (called the range) assigns to each element of the domain exactly one element of the range. If $f$ is a function and $x$ is an element of its domain, then $f(x)$ denotes the output of $f$ corresponding to the input $x$. The graph of $f$ is the graph of the equation $y=f(x)$.

2. Use function notation, evaluate functions for inputs in their domains, and interpret statements that use function notation in terms of a context.

3. Recognize that sequences are functions, sometimes defined recursively, whose domain is a subset of the integers. For example, the Fibonacci sequence is defined recursively by $f(0)=f(1)=1, f(n+1)=f(n)+f(n-1)$ for $n \geq \square 1$.

\section{Interpret functions that arise in applications in terms of the context}

4. For a function that models a relationship between two quantities, interpret key features of graphs and tables in terms of the quantities, and sketch graphs showing key features given a verbal description of the relationship. Key features include: intercepts; intervals where the function is increasing, decreasing, positive, or negative; relative maximums and minimums; symmetries; end behavior; and periodicity.

5. Relate the domain of a function to its graph and, where applicable, to the quantitative relationship it describes. For example, if the function $h(n)$ gives the number of person-hours it takes to assemble $n$ engines in a factory, then the positive integers would be an appropriate domain for the function.

6. Calculate and interpret the average rate of change of a function (presented symbolically or as a table) over a specified interval. Estimate the rate of change from a graph.

\section{Analyze functions using different representations}

7. Graph functions expressed symbolically and show key features of the graph, by hand in simple cases and using technology for more complicated cases. 
a. Graph linear and quadratic functions and show intercepts, maxima, and minima.

b. Graph square root, cube root, and piecewise-defined functions, including step functions and absolute value functions.

c. Graph polynomial functions, identifying zeros when suitable factorizations are available, and showing end behavior.

d. (+) Graph rational functions, identifying zeros and asymptotes when suitable factorizations are available, and showing end behavior.

e. Graph exponential and logarithmic functions, showing intercepts and end behavior, and trigonometric functions, showing period, midline, and amplitude.

8. Write a function defined by an expression in different but equivalent forms to reveal and explain different properties of the function.

a. Use the process of factoring and completing the square in a quadratic function to show zeros, extreme values, and symmetry of the graph, and interpret these in terms of a context.

b. Use the properties of exponents to interpret expressions for exponential functions. For example, identify percent rate of change in functions such as $y=(1.02) t, y=(0.97) t, y=(1.01) 12 t, y=(1.2) t / 10$, and classify them as representing exponential growth or decay.

9. Compare properties of two functions each represented in a different way (algebraically, graphically, numerically in tables, or by verbal descriptions). For example, given a graph of one quadratic function and an algebraic expression for another, say which has the larger maximum.

\section{Building Functions F-BF}

Build a function that models a relationship between two quantities

1. Write a function that describes a relationship between two quantities.

a. Determine an explicit expression, a recursive process, or steps for calculation from a context.

b. Combine standard function types using arithmetic operations. For example, build a function that models the temperature of a cooling body by adding a constant function to a decaying exponential, and relate these functions to the model.

c. (+) Compose functions. For example, if $T(y)$ is the temperature in the atmosphere as a function of height, and $h(t)$ is the height of a weather balloon as a function of time, then $T(h(t))$ is the temperature at the location of the weather balloon as a function of time. 
2. Write arithmetic and geometric sequences both recursively and with an explicit formula, use them to model situations, and translate between the two forms.

\section{Build new functions from existing functions}

3. Identify the effect on the graph of replacing $f(x)$ by $f(x)+k, k f(x), f(k x)$, and $f(x+k)$ for specific values of $k$ (both positive and negative); find the value of $k$ given the graphs. Experiment with cases and illustrate an explanation of the effects on the graph using technology. Include recognizing even and odd functions from their graphs andalgebraic expressions for them.

\section{Find inverse functions.}

a. Solve an equation of the form $\mathrm{f}(\mathrm{x})=\mathrm{c}$ for a simple function $\mathrm{f}$ that has an inverse and write an expression for the inverse. For example, $f(x)=2 \times 3$ or $f(x)=(x+1) /(x-1)$ for $x \neq \square 1$.

b. $(+)$ Verify by composition that one function is the inverse of another.

c. (+) Read values of an inverse function from a graph or a table, given that the function has an inverse.

d. (+) Produce an invertible function from a non-invertible function by restricting the domain.

5. (+) Understand the inverse relationship between exponents and logarithms and use this relationship to solve problems involving logarithms and exponents.

\section{Linear, Quadratic, and Exponential Models F -LE}

Construct and compare linear, quadratic, and exponential modelsand solve problems

\section{Distinguish between situations that can be modeled with linear functions and with exponential functions.}

a. Prove that linear functions grow by equal differences over equal intervals, and that exponential functions grow by equal factors over equal intervals.

b. Recognize situations in which one quantity changes at a constant rate per unit interval relative to another.

c. Recognize situations in which a quantity grows or decays by a constant percent rate per unit interval relative to another.

2. Construct linear and exponential functions, including arithmetic and geometric sequences, given a graph, a description of a relationship, or two input-output pairs (include reading these from a table).

3. Observe using graphs and tables that a quantity increasing exponentially eventually exceeds a quantity increasing linearly, quadratically, or (more generally) as a polynomial function. 
4. For exponential models, express as a logarithm the solution to $a b c t=d$ where $a, c$, and $d$ are numbers and the base $b$ is 2,10 , or $e$; evaluate the logarithm using technology.

\section{Interpret expressions for functions in terms of the situation they model}

5. Interpret the parameters in a linear or exponential function in terms of a context.

\section{Trigonometric Functions F-TF}

\section{Extend the domain of trigonometric functions using the unit circle}

1. Understand radian measure of an angle as the length of the arc on the unit circle subtended by the angle.

2. Explain how the unit circle in the coordinate plane enables the extension of trigonometric functions to all real numbers, interpreted as radian measures of angles traversed counterclockwise around the unit circle.

3. (+) Use special triangles to determine geometrically the values of sine, cosine, tangent for $\square / 3, \square / 4$ and $\square / 6$, and use the unit circle to express the values of sine, cosine, and tangent for $\square-x, \square+x$, and $2 \square-x$ in terms of their values for $x$, where $x$ is any real number.

4. (+) Use the unit circle to explain symmetry (odd and even) and periodicity of trigonometric functions.

\section{Model periodic phenomena with trigonometric functions}

5. Choose trigonometric functions to model periodic phenomena with specified amplitude, frequency, and midline.

6. (+) Understand that restricting a trigonometric function to a domain on which it is always increasing or always decreasing allows its inverse to be constructed.

7. (+) Use inverse functions to solve trigonometric equations that arise in modeling contexts; evaluate the solutions using technology, and interpret them in terms of the context.

\section{Prove and apply trigonometric identities}

8. Prove the Pythagorean identity $\sin 2(\theta)+\cos 2(\theta)=1$ and use it to find $\sin (\theta), \cos (\theta)$, or $\tan (\theta)$ given $\sin (\theta), \cos (\theta)$, or $\tan (\theta)$ and the quadrant of the angle.

9. (+) Prove the addition and subtraction formulas for sine, cosine, and tangent and use them to solve problems.

Geometry

Congruence G-CO

Experiment with transformations in the plane 
1. Know precise definitions of angle, circle, perpendicular line, parallel line, and line segment, based on the undefined notions of point, line, distance along a line, and distance around a circular arc.

2. Represent transformations in the plane using, e.g., transparencies and geometry software; describe transformations as functions that take points in the plane as inputs and give other points as outputs. Compare transformations that preserve distance and angle to those that do not (e.g., translation versus horizontal stretch).

3. Given a rectangle, parallelogram, trapezoid, or regular polygon, describe the rotations and reflections that carry it onto itself.

4. Develop definitions of rotations, reflections, and translations in terms of angles, circles, perpendicular lines, parallel lines, and line segments.

5. Given a geometric figure and a rotation, reflection, or translation, draw the transformed figure using, e.g., graph paper, tracing paper, or geometry software. Specify a sequence of transformations that will carry a given figure onto another.

\section{Understand congruence in terms of rigid motions}

6. Use geometric descriptions of rigid motions to transform figures and to predict the effect of a given rigid motion on a given figure; given two figures, use the definition of congruence in terms of rigid motions to decide if they are congruent.

7. Use the definition of congruence in terms of rigid motions to show that two triangles are congruent if and only if corresponding pairs of sides and corresponding pairs of angles are congruent.

8. Explain how the criteria for triangle congruence (ASA, SAS, and SSS) follow from the definition of congruence in terms of rigid motions.

\section{Prove geometric theorems}

9. Prove theorems about lines and angles. Theorems include: vertical angles are congruent; when a transversal crosses parallel lines, alternate interior angles are congruent and corresponding angles are congruent; points on a perpendicular bisector of a line segment are exactly those equidistant from the segment's endpoints.

10. Prove theorems about triangles. Theorems include: measures of interior angles of a triangle sum to $180^{\circ}$; base angles of isosceles triangles are congruent; the segment joining midpoints of two sides of a triangle is parallel to the third side and half the length; the medians of a triangle meet at a point. 
11. Prove theorems about parallelograms. Theorems include: opposite sides are congruent, opposite angles are congruent, the diagonals of a parallelogram bisect each other, and conversely, rectangles are parallelograms with congruent diagonals.

\section{Make geometric constructions}

12. Make formal geometric constructions with a variety of tools and methods (compass and straightedge, string, reflective devices, paper folding, dynamic geometric software, etc.). Copying a segment; copying an angle; bisecting a segment; bisecting an angle; constructing perpendicular lines, including the perpendicular bisector of a line segment; and constructing a line parallel to a given line through a point not on the line.

13. Construct an equilateral triangle, a square, and a regular hexagon inscribed in a circle.

Similarity, Right Triangles, and Trigonometry G-SRT

Understand similarity in terms of similarity transformations

1. Verify experimentally the properties of dilations given by a center and a scale factor:

a. A dilation takes a line not passing through the center of the dilation to a parallel line, and leaves a line passing through the center unchanged.

b. The dilation of a line segment is longer or shorter in the ratio given by the scale factor.

2. Given two figures, use the definition of similarity in terms of similarity transformations to decide if they are similar; explain using similarity transformations the meaning of similarity for triangles as the equality of all corresponding pairs of angles and the proportionality of all corresponding pairs of sides.

3. Use the properties of similarity transformations to establish the AA criterion for two triangles to be similar.

\section{Prove theorems involving similarity}

4. Prove theorems about triangles. Theorems include: a line parallel to one side of a triangle divides the other two proportionally, and conversely; the Pythagorean Theorem proved using triangle similarity.

5. Use congruence and similarity criteria for triangles to solve problems and to prove relationships in geometric figures.

\section{Define trigonometric ratios and solve problems involving right triangles}

6. Understand that by similarity, side ratios in right triangles are properties of the angles in the triangle, leading to definitions of trigonometric ratios for acute angles. 
7. Explain and use the relationship between the sine and cosine of complementary angles.

8. Use trigonometric ratios and the Pythagorean Theorem to solve right triangles in applied problems.

\section{Apply trigonometry to general triangles}

9. (+) Derive the formula $A=1 / 2 a b \sin (\mathrm{C})$ for the area of a triangle by drawing an auxiliary line from a vertex perpendicular to the opposite side.

10. (+) Prove the Laws of Sines and Cosines and use them to solve problems.

11. (+) Understand and apply the Law of Sines and the Law of Cosines to find unknown measurements in right and non-right triangles (e.g., surveying problems, resultant forces).

\section{Circles G-C}

\section{Understand and apply theorems about circles}

1. Prove that all circles are similar.

2. Identify and describe relationships among inscribed angles, radii, and chords. Include the relationship between central, inscribed, and circumscribed angles; inscribed angles on a diameter are right angles; the radius of a circle is perpendicular to the tangent where the radius intersects the circle.

3. Construct the inscribed and circumscribed circles of a triangle, and prove properties of angles for a quadrilateral inscribed in a circle.

4. (+) Construct a tangent line from a point outside a given circle to the circle.

\section{Find arc lengths and areas of sectors of circles}

5. Derive using similarity the fact that the length of the arc intercepted by an angle is proportional to the radius, and define the radian measure of the angle as the constant of proportionality; derive the formula for the area of a sector.

\section{Expressing Geometric Properties with Equations G-GPE}

\section{Translate between the geometric description and the equation for a} conic section

1. Derive the equation of a circle of given center and radius using the Pythagorean Theorem; complete the square to find the center and radius of a circle given by an equation.

2. Derive the equation of a parabola given a focus and directrix.

3. (+) Derive the equations of ellipses and hyperbolas given the foci, using the fact that the sum or difference of distances from the foci is constant.

Use coordinates to prove simple geometric theorems algebraically 
4. Use coordinates to prove simple geometric theorems algebraically. For example, prove or disprove that a figure defined by four given points in the coordinate plane is a rectangle; prove or disprove that the point $(1, \sqrt{ } 3)$ lies on the circle centered at the origin and containing the point $(0,2)$.

5. Prove the slope criteria for parallel and perpendicular lines and use them to solve geometric problems (e.g., find the equation of a line parallel or perpendicular to a given line that passes through a given point).

6 . Find the point on a directed line segment between two given points that partitions the segment in a given ratio.

7. Use coordinates to compute perimeters of polygons and areas of triangles and rectangles, e.g., using the distance formula.

Geometric Measurement and Dimension G-GMD

Explain volume formulas and use them to solve problems

1. Give an informal argument for the formulas for the circumference of a circle, area of a circle, volume of a cylinder, pyramid, and cone. Use dissection arguments, Cavalieri's principle, and informal limit arguments.

2. (+) Give an informal argument using Cavalieri's principle for the formulas for the volume of a sphere and other solid figures.

3. Use volume formulas for cylinders, pyramids, cones, and spheres to solve problems.

Visualize relationships between two-dimensional and three dimensional objects

4. Identify the shapes of two-dimensional cross-sections of three dimensional objects, and identify three-dimensional objects generated by rotations of two-dimensional objects.

Modeling with Geometry G-MG

Apply geometric concepts in modeling situations

1. Use geometric shapes, their measures, and their properties to describe objects (e.g., modeling a tree trunk or a human torso as a cylinder).

2. Apply concepts of density based on area and volume in modeling situations (e.g., persons per square mile, BTUs per cubic foot).

3. Apply geometric methods to solve design problems (e.g., designing an object or structure to satisfy physical constraints or minimize cost; working with typographic grid systems based on ratios).

Statistics

Interpreting Categorical and Quantitative Data S-ID 


\section{Summarize, represent, and interpret data on a single count or measurement variable}

1. Represent data with plots on the real number line (dot plots, histograms, and box plots).

2. Use statistics appropriate to the shape of the data distribution to compare center (median, mean) and spread (interquartile range, standard deviation) of two or more different data sets.

3. Interpret differences in shape, center, and spread in the context of the data sets, accounting for possible effects of extreme data points (outliers).

4. Use the mean and standard deviation of a data set to fit it to a normal distribution and to estimate population percentages. Recognize that there are data sets for which such a procedure is not appropriate. Use calculators, spreadsheets, and tables to estimate areas under the normal curve.

Summarize, represent, and interpret data on two categorical and quantitative variables

5. Summarize categorical data for two categories in two-way frequency tables. Interpret relative frequencies in the context of the data (including joint, marginal, and conditional relative frequencies). Recognize possible associations and trends in the data.

6. Represent data on two quantitative variables on a scatter plot, and describe how the variables are related.

a. Fit a function to the data; use functions fitted to data to solve problems in the context of the data. Use given functions or choose a function suggested by the context. Emphasize linear, quadratic, and exponential models.

b. Informally assess the fit of a function by plotting and analyzing residuals.

c. Fit a linear function for a scatter plot that suggests a linear association.

\section{Interpret linear models}

7. Interpret the slope (rate of change) and the intercept (constant term) of a linear model in the context of the data.

8. Compute (using technology) and interpret the correlation coefficient of a linear fit.

9. Distinguish between correlation and causation.

Making Inferences and Justifying Conclusions S-IC

Understand and evaluate random processes underlying statistical experiments 
1. Understand statistics as a process for making inferences about population parameters based on a random sample from that population.

2. Decide if a specified model is consistent with results from a given datagenerating process, e.g., using simulation. For example, a model says a spinning coin falls heads up with probability 0.5. Would a result of 5 tails in a row cause you to question the model?

Make inferences and justify conclusions from sample surveys, experiments, and observational studies

3. Recognize the purposes of and differences among sample surveys, experiments, and observational studies; explain how randomization relates to each.

4. Use data from a sample survey to estimate a population mean or proportion; develop a margin of error through the use of simulation models for random sampling.

5. Use data from a randomized experiment to compare two treatments; use simulations to decide if differences between parameters are significant.

6. Evaluate reports based on data.

Conditional Probability and the Rules of Probability S-CP

Understand independence and conditional probability and use them to interpret data

1. Describe events as subsets of a sample space (the set of outcomes) using characteristics (or categories) of the outcomes, or as unions, intersections, or complements of other events ("or," "and," "not").

2. Understand that two events $A$ and $B$ are independent if the probability of $A$ and $B$ occurring together is the product of their probabilities, and use this characterization to determine if they are independent.

3. Understand the conditional probability of $A$ given $B$ as $P(A$ and $B) / P(B)$, and interpret independence of $A$ and $B$ as saying that the conditional probability of $A$ given $B$ is the same as the probability of $A$, and the conditional probability of $B$ given $A$ is the same as the probability of $B$.

4. Construct and interpret two-way frequency tables of data when two categories are associated with each object being classified. Use the two-way table as a sample space to decide if events are independent and to approximate conditional probabilities. For example, collect data from a random sample of students in your school on their favorite 
subject among math, science, and English. Estimate the probability that a randomly selected student from your school will favor science given that the student is in tenth grade. Do the same for other subjects and compare the results.

5. Recognize and explain the concepts of conditional probability and independence in everyday language and everyday situations. For example, compare the chance of having lung cancer if you are a smoker with the chance of being a smoker if you have lung cancer.

\section{Use the rules of probability to compute probabilities of compound events in a uniform probability model}

6 . Find the conditional probability of $A$ given $B$ as the fraction of $B$ 's outcomes that also belong to $A$, and interpret the answer in terms of the model.

7. Apply the Addition Rule, $\mathrm{P}(\mathrm{A}$ or $\mathrm{B})=\mathrm{P}(\mathrm{A})+\mathrm{P}(\mathrm{B})-\mathrm{P}(\mathrm{A}$ and $\mathrm{B})$, and interpret the answer in terms of the model.

8. (+) Apply the general Multiplication Rule in a uniform probability model, $\mathrm{P}(\mathrm{A}$ and $\mathrm{B})=\mathrm{P}(\mathrm{A}) \mathrm{P}(\mathrm{B} \mid \mathrm{A})=\mathrm{P}(\mathrm{B}) \mathrm{P}(\mathrm{A} \mid \mathrm{B})$, and interpret the answer in terms of the model.

9. (+) Use permutations and combinations to compute probabilities of compound events and solve problems.

Using Probability to Make Decisions S-MD

Calculate expected values and use them to solve problems

1. (+) Define a random variable for a quantity of interest by assigning a numerical value to each event in a sample space; graph the corresponding probability distribution using the same graphical displays as for data distributions.

2. (+) Calculate the expected value of a random variable; interpret it as the mean of the probability distribution.

3. (+) Develop a probability distribution for a random variable defined for a sample space in which theoretical probabilities can be calculated; find the expected value. For example, find the theoretical probability distribution for the number of correct answers obtained by guessing on all five questions of a multiple-choice test where each question has four choices, and find the expected grade under various grading schemes.

4. (+) Develop a probability distribution for a random variable defined for a sample space in which probabilities are assigned empirically; find the expected value. For example, find a current data distribution on the number of TV sets per household in the United States, and calculate the expected number of sets per household. How many TV sets would you expect to find in 100 randomly selected households?

\section{Use probability to evaluate outcomes of decisions}


5. (+) Weigh the possible outcomes of a decision by assigning probabilities to payoff values and finding expected values.

a. Find the expected payoff for a game of chance. For example, find the expected innings from a state lottery ticket or a game at a fastfood restaurant.

b. Evaluate and compare strategies on the basis of expected values. For example, compare a high-deductible versus a low-deductible automobile insurance policy using various, but reasonable, chances of having a minor or a major accident.

6. (+) Use probabilities to make fair decisions (e.g., drawing by lots, using a random number generator).

7. (+) Analyze decisions and strategies using probability concepts (e.g., product testing, medical testing, pulling a hockey goalie at the end of a game). 
Appendix B

KM-CRE Analysis Matrix with Placement Examinations

KM-CRE is a condensed version of the Common Core State Standards for Middle and High School. The included standards were assessed on 5 universitiy's remediation course finals.

\begin{tabular}{|c|c|c|c|c|}
\hline Ratios and Proportional Relationships & 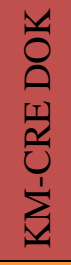 & 光 & 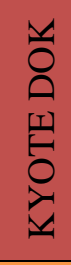 & $\sum_{0}^{\infty} \sum_{0}^{\infty}$ \\
\hline \multicolumn{5}{|l|}{ Ratios and Proportional relationships 6.rP } \\
\hline \multicolumn{5}{|l|}{ Understand ratio concepts and use ratio reasoning to solve problems. } \\
\hline $\begin{array}{l}\text { 1. Understand the concept of a ratio and use ratio language to describe a } \\
\text { ratio relationship between two quantities. For example, "The ratio of } \\
\text { wings to beaks in the bird house at the zoo was } 2: 1 \text {, because for every } 2 \\
\text { wings there was } 1 \text { beak." "For every vote candidate A received, } \\
\text { candidate C received nearly three votes." }\end{array}$ & 2 & 2 & & \\
\hline $\begin{array}{l}\text { 2. Understand the concept of a unit rate a/b associated with a ratio a:b } \\
\text { with } b \neq 0 \text {, and use rate language in the context of a ratio relationship. } \\
\text { For example, "This recipe has a ratio of } 3 \text { cups of flour to } 4 \text { cups of } \\
\text { sugar, so there is } 3 / 4 \text { cup of flour for each cup of sugar." "We paid } \$ 75 \\
\text { for } 15 \text { hamburgers, which is a rate of } \$ 5 \text { per hamburger." }\end{array}$ & 2 & & & \\
\hline \multicolumn{5}{|l|}{$\begin{array}{l}\text { 3.Use ratio and rate reasoning to solve real-world and mathematical } \\
\text { problems, e.g., by reasoning about tables of equivalent ratios, tape } \\
\text { diagrams, double number line diagrams, or equations. }\end{array}$} \\
\hline $\begin{array}{l}\text { c. Find a percent of a quantity as a rate per } 100 \text { (e.g., } 30 \% \text { of a quantity } \\
\text { means } 30 / 100 \text { times the quantity); solve problems involving finding the } \\
\text { whole, given a part and the percent. }\end{array}$ & 2 & 3 & & 3 \\
\hline \multicolumn{5}{|l|}{ Ratios and Proportional Relationships 7.rP } \\
\hline \multicolumn{5}{|l|}{$\begin{array}{l}\text { 2. Recognize and represent proportional relationships between } \\
\text { quantities. }\end{array}$} \\
\hline $\begin{array}{l}\text { c. Represent proportional relationships by equations. For example, if } \\
\text { total cost } t \text { is proportional to the number } n \text { of items purchased at a } \\
\text { constant price } p \text {, the relationship between the total cost and the number } \\
\text { of items can be expressed as } t=\text { pn. }\end{array}$ & 2 & & 2 & 3 \\
\hline $\begin{array}{l}\text { 3. Use proportional relationships to solve multistep ratio and percent } \\
\text { problems. Examples: simple interest, tax, markups and markdowns, } \\
\text { gratuities and commissions, fees, percent increase and decrease, percent } \\
\text { error. }\end{array}$ & 3 & 3 & & \\
\hline
\end{tabular}




\begin{tabular}{|c|c|c|c|c|}
\hline The Number System & & & & \\
\hline The number System 6.nS & & & & \\
\hline $\begin{array}{l}\text { Apply and extend previous understandings of multiplication and } \\
\text { division to divide fractions by fractions. }\end{array}$ & & & & \\
\hline $\begin{array}{l}\text { 1. Interpret and compute quotients of fractions, and solve word problems } \\
\text { involving division of fractions by fractions, e.g., by using visual fraction } \\
\text { models and equations to represent the problem. For example, create a } \\
\text { story context for }(2 / 3) \div(3 / 4) \text { and use a visual fraction model to show the } \\
\text { quotient; use the relationship between multiplication and division to } \\
\text { explain that }(2 / 3) \div(3 / 4)=8 / 9 \text { because } 3 / 4 \text { of } 8 / 9 \text { is } 2 / 3 \text {. (In general, }(\mathrm{a} / \mathrm{b}) \\
\div(\mathrm{c} / \mathrm{d})=\mathrm{ad} / \mathrm{bc} \text {.) How much chocolate will each person get if } 3 \text { people } \\
\text { share } 1 / 2 \mathrm{lb} \text { of chocolate equally? How many } 3 / 4 \text {-cup servings are in } 2 / 3 \\
\text { of a cup of yogurt? How wide is a rectangular strip of land with length } \\
3 / 4 \text { mi and area } 1 / 2 \text { square mi? }\end{array}$ & 2 & & 2 & \\
\hline $\begin{array}{l}\text { Compute fluently with multi-digit numbers and find common factors } \\
\text { and multiples. }\end{array}$ & & & & \\
\hline $\begin{array}{l}\text { 4. Find the greatest common factor of two whole numbers less than or } \\
\text { equal to } 100 \text { and the least common multiple of two whole numbers less } \\
\text { than or equal to } 12 \text {. Use the distributive property to express a sum of two } \\
\text { whole numbers } 1-100 \text { with a common factor as a multiple of a sum of } \\
\text { two whole numbers with no common factor. For example, express } 36+8 \\
\text { as } 4(9+2) \text {. Expectations for unit rates in this grade are limited to non- } \\
\text { complex fractions. }\end{array}$ & 2 & 2 & & \\
\hline $\begin{array}{l}\text { Apply and extend previous understandings of numbers to the system } \\
\text { of rational numbers. }\end{array}$ & & & & \\
\hline $\begin{array}{l}\text { 5. Understand that positive and negative numbers are used together to } \\
\text { describe quantities having opposite directions or values (e.g., temperature } \\
\text { above/below zero, elevation above/below sea level, credits/debits, } \\
\text { positive/negative electric charge); use positive and negative numbers to } \\
\text { represent quantities in real-world contexts, explaining the meaning of } 0 \\
\text { in each situation. }\end{array}$ & 2 & 2 & & \\
\hline $\begin{array}{l}\text { 6. Understand a rational number as a point on the number line. } \\
\text { Extend number line diagrams and coordinate axes familiar from } \\
\text { previous grades to represent points on the line and in the plane with } \\
\text { negative number coordinates. }\end{array}$ & & & & \\
\hline $\begin{array}{l}\text { b. Understand signs of numbers in ordered pairs as indicating locations in } \\
\text { quadrants of the coordinate plane; recognize that when two ordered pairs } \\
\text { differ only by signs, the locations of the points are related by reflections } \\
\text { across one or both axes. }\end{array}$ & 2 & & 2 & 2 \\
\hline 7.Understand ordering and absolute value of rational numbers. & & & & \\
\hline
\end{tabular}


c. Understand the absolute value of a rational number as its distance from 0 on the number line; interpret absolute value as magnitude for a positive or negative quantity in a real-world situation. For example, for an account balance of -30 dollars, write $|-30|=30$ to describe the size of the debt in dollars.

\section{The Number System 7.nS}

Apply and extend previous understandings of operations with fractions to add, subtract, multiply, and divide rational numbers.

1. Apply and extend previous understandings of addition and subtraction to add and subtract rational numbers; represent addition and subtraction on a horizontal or vertical number line diagram.

c. Understand subtraction of rational numbers as adding the additive inverse, $p-q=p+(-q)$. Show that the distance between two rational numbers on the number line is the absolute value of their difference, and apply this principle in real-world contexts.

d. Apply properties of operations as strategies to add and subtract rational numbers.

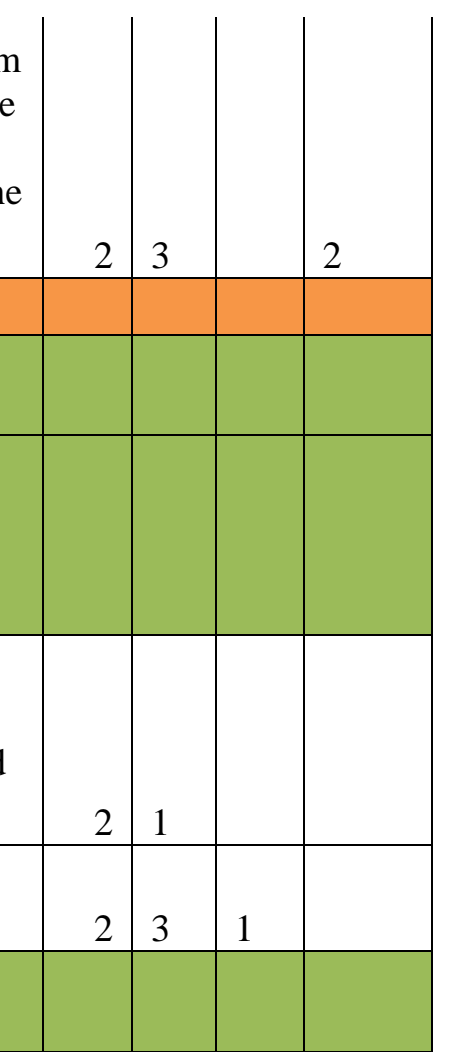

\section{Apply and extend previous understandings of multiplication and division and of fractions to multiply and divide rational numbers.}

a. Understand that multiplication is extended from fractions to rational numbers by requiring that operations continue to satisfy the properties of operations, particularly the distributive property, leading to products such as $(-1)(-1)=1$ and the rules for multiplying signed numbers. Interpret products of rational numbers by describing real-world contexts.

c. Apply properties of operations as strategies to multiply and divide rational numbers.

3. Solve real-world and mathematical problems involving the four operations with rational numbers.

The Number System 8.nS

Know that there are numbers that are not rational, and approximate them by rational numbers.

2. Use rational approximations of irrational numbers to compare the size of irrational numbers, locate them approximately on a number line diagram, and estimate the value of expressions (e.g., $\pi$ ). For example, by truncating the decimal expansion of $\sqrt{2}$, show that $\sqrt{2}$ is between 1 and 2 , then between 1.4 and 1.5, and explain how to continue on to get better approximations.

\section{Expressions and Equations}

\section{Expressions and Equations 6.ee}

Apply and extend previous understandings of arithmetic to algebraic expressions. 
1. Write and evaluate numerical expressions involving whole-number exponents.

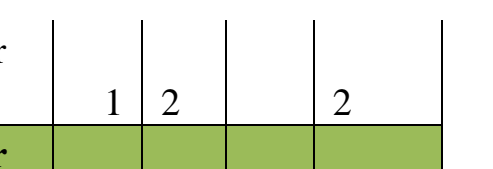

\section{Write, read, and evaluate expressions in which letters stand for numbers.}

a. Write expressions that record operations with numbers and with letters standing for numbers. For example, express the calculation "Subtract y from 5" as $5-\mathrm{y}$.

b. Identify parts of an expression using mathematical terms (sum, term, product, factor, quotient, coefficient); view one or more parts of an expression as a single entity. For example, describe the expression $2(8+7)$ as a product of two factors; view $(8+7)$ as both a single entity and a sum of two terms.

c. Evaluate expressions at specific values of their variables. Include expressions that arise from formulas used in real-world problems. Perform arithmetic operations, including those involving whole number exponents, in the conventional order when there are no parentheses to specify a particular order (Order of Operations). For example, use the formulas $\mathrm{V}=\mathrm{s} 3$ and $\mathrm{A}=6 \mathrm{~s} 2$ to find the volume and surface area of a cube with sides of length $\mathrm{s}=1 / 2$.

3. Apply the properties of operations to generate equivalent expressions. For example, apply the distributive property to the expression $3(2+x)$ to produce the equivalent expression $6+3 x$; apply the distributive property to the expression $24 x+18 y$ to produce the equivalent expression $6(4 x+3 y)$; apply properties of operations to $y+y$ $+\mathrm{y}$ to produce the equivalent expression $3 \mathrm{y}$.

\section{Reason about and solve one-variable equations and inequalities.}

5. Understand solving an equation or inequality as a process of answering a question: which values from a specified set, if any, make the equation or inequality true? Use substitution to determine whether a given number in a specified set makes an equation or inequality true.

7. Solve real-world and mathematical problems by writing and solving equations of the form $\mathrm{x}+\mathrm{p}=\mathrm{q}$ and $\mathrm{px}=\mathrm{q}$ for cases in which $\mathrm{p}, \mathrm{q}$ and $\mathrm{x}$ are all nonnegative rational numbers.

\section{Expressions and Equations 7.ee} Use properties of operations to generate equivalent expressions.

1. Apply properties of operations as strategies to add, subtract, factor, and expand linear expressions with rational coefficients.

\begin{tabular}{l|l|l|l}
2 & 3 & 2 & 2 \\
\hline
\end{tabular}


3. Solve multi-step real-life and mathematical problems posed with positive and negative rational numbers in any form (whole numbers, fractions, and decimals), using tools strategically. Apply properties of operations to calculate with numbers in any form; convert between forms as appropriate; and assess the reasonableness of answers using mental computation and estimation strategies. For example: If a woman making $\$ 25$ an hour gets a $10 \%$ raise, she will make an additional 1/10 of her salary an hour, or $\$ 2.50$, for a new salary of $\$ 27.50$. If you want to place a towel bar $93 / 4$ inches long in the center of a door that is $271 / 2$ inches wide, you will need to place the bar about 9 inches from each edge; this estimate can be used as a check on the exact computation.

\section{Use variables to represent quantities in a real-world or} mathematical problem, and construct simple equations and inequalities to solve problems by reasoning about the quantities.

a. Solve word problems leading to equations of the form $p x+q=r$ and $p(x+q)=r$, where $p, q$, and $r$ are specific rational numbers. Solve equations of these forms fluently. Compare an algebraic solution to an arithmetic solution, identifying the sequence of the operations used in each approach. For example, the perimeter of a rectangle is $54 \mathrm{~cm}$. Its length is $6 \mathrm{~cm}$. What is its width?

b. Solve word problems leading to inequalities of the form $p x+q>r$ or $\mathrm{px}+\mathrm{q}<\mathrm{r}$, where $\mathrm{p}, \mathrm{q}$, and $\mathrm{r}$ are specific rational numbers. Graph the solution set of the inequality and interpret it in the context of the problem. For example: As a salesperson, you are paid $\$ 50$ per week plus $\$ 3$ per sale. This week you want your pay to be at least $\$ 100$. Write an inequality for the number of sales you need to make, and describe the solutions.

\section{Expressions and Equations 8.ee}

Work with radicals and integer exponents.

1. Know and apply the properties of integer exponents to generate equivalent numerical expressions.

2. Use square root and cube root symbols to represent solutions to equations of the form $\mathrm{x}=\mathrm{p}$ and $\mathrm{x}=\mathrm{p}$, where $\mathrm{p}$ is a positive rational number. Evaluate square roots of small perfect squares and cube roots of small perfect cubes. Know that $\sqrt{2}$ is irrational.

4. Perform operations with numbers expressed in scientific notation, including problems where both decimal and scientific notation are used. Use scientific notation and choose units of appropriate size for measurements of very large or very small quantities (e.g., use millimeters per year for seafloor preading). Interpret scientific notation that has been generated by technology.

\section{Solve linear equations in one variable.}


b. Solve linear equations with rational number coefficients, including equations whose solutions require expanding expressions using the distributive property and collecting like terms.

\section{Analyze and solve pairs of simultaneous linear equations.}

b. Solve systems of two linear equations in two variables algebraically, and estimate solutions by graphing the equations. Solve simple cases by inspection. For example, $3 x+2 y=5$ and $3 x+2 y=6$ have no solution because $3 x+2 y$ cannot simultaneously be 5 and 6 .

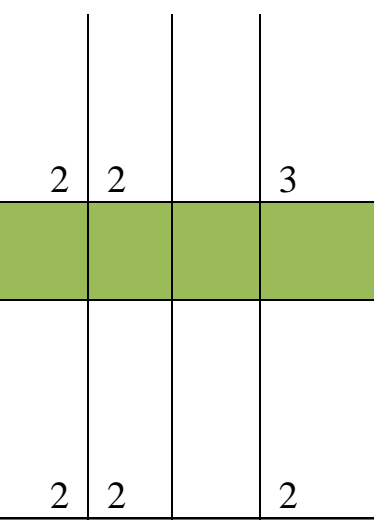

\section{Geometry \\ Geometry 7.G \\ Draw, construct, and describe geometrical figures and describe the relationships between them.}

4. Know the formulas for the area and circumference of a circle and use them to solve problems; give an informal derivation of the relationship between the circumference and area of a circle.

\section{Geometry 8.G}

\section{Understand and apply the Pythagorean Theorem.}

7.Apply the Pythagorean Theorem to determine unknown side lengths in right triangles in real-world and mathematical problems in two and three dimensions.

8. Apply the Pythagorean Theorem to find the distance between two points in a coordinate system.

\section{HS-Geometry}

Congruence G-CO

\section{Experiment with transformations in the plane}

5. Given a geometric figure and a rotation, reflection, or translation, draw the transformed figure using, e.g., graph paper, tracing paper, or geometry software. Specify a sequence of transformations that will carry a given figure onto another.

\section{Geometric Measurement and Dimension G-GMD}

\section{Explain volume formulas and use them to solve problems}

3. Use volume formulas for cylinders, pyramids, cones, and spheres to solve problems.

Expressing Geometric Properties with Equations G-GPE

\section{Use coordinates to prove simple geometric theorems} algebraically 
5. Prove the slope criteria for parallel and perpendicular lines and use them to solve geometric problems (e.g., find the equation of a line parallel or perpendicular to a given line that passes through a given point).

6 . Find the point on a directed line segment between two given points that partitions the segment in a given ratio.

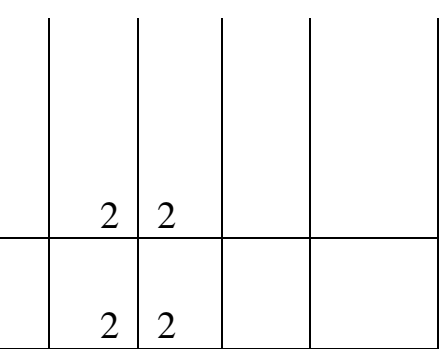

\section{Functions}

\section{8th gradeFunctions $8 . f$}

Define, evaluate, and compare functions.

1.Understand that a function is a rule that assigns to each input exactly one output. The graph of a function is the set of ordered pairs consisting of an input and the corresponding output.

3. Interpret the equation $y=m x+b$ as defining a linear function, whose graph is a straight line; give examples of functions that are not linear. For example, the function $\mathrm{A}=\mathrm{s}$ giving the area of a square as a function of its side length is not linear because its graph contains the points $(1,1)$, $(2,4)$ and $(3,9)$, which are not on a straight line.

Use functions to model relationships between quantities.

4. Construct a function to model a linear relationship between two quantities. Determine the rate of change and initial value of the function from a description of a relationship or from two $(x, y)$ values, including reading these from a table or from a graph. Interpret the rate of change and initial value of a linear function in terms of the situation it models, and in terms of its graph or a table of values.

\section{HS-Functions}

\section{Interpreting Functions F-IF}

\section{Understand the concept of a function and use function notation}

1. Understand that a function from one set (called the domain) to another set (called the range) assigns to each element of the domain exactly one element of the range. If $f$ is a function and $x$ is an element of its domain, then $f(x)$ denotes the output of $f$ corresponding to the input $x$. The graph of $f$ is the graph of the equation $y=f(x)$.

2. Use function notation, evaluate functions for inputs in their domains, and interpret statements that use function notation in terms of a context.

\section{Interpret functions that arise in applications in terms of the} context 


\begin{tabular}{|c|c|c|c|}
\hline $\begin{array}{l}\text { 4. For a function that models a relationship between two quantities, } \\
\text { interpret key features of graphs and tables in terms of the } \\
\text { quantities, and sketch graphs showing key features given a verbal } \\
\text { description of the relationship. Key features include: intercepts; } \\
\text { intervals where the function is increasing, decreasing, positive, or } \\
\text { negative; relative maximums and minimums; symmetries; end } \\
\text { behavior; and periodicity. }\end{array}$ & 2 & & 2 \\
\hline $\begin{array}{l}\text { 5. Relate the domain of a function to its graph and, where } \\
\text { applicable, to the quantitative relationship it describes. For } \\
\text { example, if the function } h(n) \text { gives the number of person-hours it } \\
\text { takes to assemble n engines in a factory, then the positive integers } \\
\text { would be an appropriate domain for the function. } \star\end{array}$ & 3 & & \\
\hline Analyze functions using different representations & & & \\
\hline $\begin{array}{l}\text { 7. Graph functions expressed symbolically and show key features } \\
\text { of the graph, by hand in simple cases and using technology for } \\
\text { more complicated cases. } \star\end{array}$ & & & \\
\hline $\begin{array}{l}\text { a. Graph linear and quadratic functions and show intercepts, } \\
\text { maxima, and minima. }\end{array}$ & 3 & & 2 \\
\hline $\begin{array}{l}\text { 8. Write a function defined by an expression in different but } \\
\text { equivalent forms to reveal and explain different properties of the } \\
\text { function. }\end{array}$ & & & \\
\hline $\begin{array}{l}\text { a. Use the process of factoring and completing the square in a } \\
\text { quadratic function to show zeros, extreme values, and symmetry of } \\
\text { the graph, and interpret these in terms of a context. }\end{array}$ & 2 & 3 & 2 \\
\hline Building Functions F-BF & & & \\
\hline $\begin{array}{l}\text { Build a function that models a relationship between two } \\
\text { quantities }\end{array}$ & & & \\
\hline $\begin{array}{l}\text { 1. Write a function that describes a relationship between two } \\
\text { quantities. } \star\end{array}$ & & & \\
\hline $\begin{array}{l}\text { a. Determine an explicit expression, a recursive process, or steps } \\
\text { for calculation from a context. }\end{array}$ & 3 & 3 & 3 \\
\hline $\begin{array}{l}\text { b. Combine standard function types using arithmetic operations. } \\
\text { For example, build a function that models the temperature of a } \\
\text { cooling body by adding a constant function to a decaying } \\
\text { exponential, and relate these functions to the model. }\end{array}$ & 2 & & 2 \\
\hline $\begin{array}{l}\text { Interpret expressions for functions in terms of the situation } \\
\text { they model }\end{array}$ & & & \\
\hline $\begin{array}{l}\text { 5. Interpret the parameters in a linear or exponential function in } \\
\text { terms of a context. }\end{array}$ & 3 & 3 & \\
\hline
\end{tabular}




\begin{tabular}{|c|c|c|c|c|}
\hline \multicolumn{5}{|l|}{ Linear, Quadratic, and Exponential Models $\star F-\mathrm{LE}$} \\
\hline \multicolumn{5}{|l|}{$\begin{array}{l}\text { Construct and compare linear, quadratic, and exponential } \\
\text { modelsand solve problems }\end{array}$} \\
\hline \multicolumn{5}{|l|}{$\begin{array}{l}\text { 1. Distinguish between situations that can be modeled with linear } \\
\text { functions and with exponential functions. }\end{array}$} \\
\hline $\begin{array}{l}\text { c. Recognize situations in which a quantity grows or decays by a } \\
\text { constant percent rate per unit interval relative to another. }\end{array}$ & 3 & 3 & & 3 \\
\hline $\begin{array}{l}\text { 2. Construct linear and exponential functions, including arithmetic } \\
\text { and geometric sequences, given a graph, a description of a } \\
\text { relationship, or two input-output pairs (include reading these from } \\
\text { a table). }\end{array}$ & 3 & 3 & & 3 \\
\hline \multicolumn{5}{|l|}{ Number and Quantity } \\
\hline \multicolumn{5}{|l|}{ The Real Number System N -RN } \\
\hline \multicolumn{5}{|l|}{ Extend the properties of exponents to rational exponents. } \\
\hline $\begin{array}{l}\text { 1. Explain how the definition of the meaning of rational exponents } \\
\text { follows from extending the properties of integer exponents to those } \\
\text { values, allowing for a notation for radicals in terms of rational } \\
\text { exponents. For example, we define } 51 / 3 \text { to be the cube root of } 5 \\
\text { because we want }(51 / 3) 3=5(1 / 3) 3 \text { to hold, so }(51 / 3) 3 \text { must equal } \\
5 \text {. }\end{array}$ & 2 & & 2 & \\
\hline $\begin{array}{l}\text { 2. Rewrite expressions involving radicals and rational exponents } \\
\text { using the properties of exponents. }\end{array}$ & 2 & & & 2 \\
\hline \multicolumn{5}{|l|}{ Use properties of rational and irrational numbers. } \\
\hline $\begin{array}{l}\text { 3. Explain why the sum or product of two rational numbers is } \\
\text { rational; that the sum of a rational number and an irrational number } \\
\text { is irrational; and that the product of a nonzero rational number and } \\
\text { an irrational number is irrational. }\end{array}$ & 2 & & & \\
\hline \multicolumn{5}{|l|}{ Quantities N-Q } \\
\hline \multicolumn{5}{|l|}{ Reason quantitatively and use units to solve problems. } \\
\hline $\begin{array}{l}\text { 1. Use units as a way to understand problems and to guide the } \\
\text { solution of multi-step problems; choose and interpret units } \\
\text { consistently in formulas; choose and interpret the scale and the } \\
\text { origin in graphs and data displays. }\end{array}$ & 3 & 2 & & \\
\hline $\begin{array}{l}\text { 2. Define appropriate quantities for the purpose of descriptive } \\
\text { modeling. }\end{array}$ & 3 & & & \\
\hline $\begin{array}{l}\text { 3. Choose a level of accuracy appropriate to limitations on } \\
\text { measurement when reporting quantities. }\end{array}$ & 2 & & & \\
\hline
\end{tabular}




\begin{tabular}{|c|c|c|c|c|}
\hline The Complex Number System N -CN & & & & \\
\hline Perform arithmetic operations with complex numbers. & & & & \\
\hline $\begin{array}{l}\text { 2. Use the relation } i 2=-1 \text { and the commutative, associative, and } \\
\text { distributive properties to add, subtract, and multiply complex } \\
\text { numbers. }\end{array}$ & 2 & & & \\
\hline HS -Algebra & & & & \\
\hline Seeing Structure in Expressions A-SSE & & & & \\
\hline Interpret the structure of expressions & & & & \\
\hline $\begin{array}{l}\text { 1. Interpret expressions that represent a quantity in terms of its } \\
\text { context. } \star\end{array}$ & & & & \\
\hline $\begin{array}{l}\text { a. Interpret parts of an expression, such as terms, factors, and } \\
\text { coefficients. }\end{array}$ & 2 & & & \\
\hline $\begin{array}{l}\text { 2. Use the structure of an expression to identify ways to rewrite it. } \\
\text { For example, see } x 4-y 4 \text { as }(x 2) 2-(y 2) 2 \text {, thus recognizing it as a } \\
\text { difference of squares that can be factored as }(x 2-y 2)(x 2+y 2) \text {. }\end{array}$ & 2 & 2 & & 2 \\
\hline Write expressions in equivalent forms to solve problems & & & & \\
\hline $\begin{array}{l}\text { 3. Choose and produce an equivalent form of an expression to } \\
\text { reveal and explain properties of the quantity represented by the } \\
\text { expression. } \star\end{array}$ & & & & \\
\hline $\begin{array}{l}\text { a. Factor a quadratic expression to reveal the zeros of the function } \\
\text { it defines. }\end{array}$ & 2 & & & 2 \\
\hline $\begin{array}{l}\text { b. Complete the square in a quadratic expression to reveal the } \\
\text { maximum or minimum value of the function it defines. }\end{array}$ & 3 & & & \\
\hline $\begin{array}{l}\text { c. Use the properties of exponents to transform expressions for } \\
\text { exponential functions. For example the expression } 1.15 \mathrm{t} \text { can be } \\
\text { rewritten as }(1.151 / 12) 12 t \approx 1.01212 \mathrm{t} \text { to reveal the approximate } \\
\text { equivalent monthly interest rate if the annual rate is } 15 \% \text {. }\end{array}$ & 2 & & & 2 \\
\hline Arithmetic with Polynomials and Rational Expressions A -APR & & & & \\
\hline Perform arithmetic operations on polynomials & & & & \\
\hline $\begin{array}{l}\text { 1. Understand that polynomials form a system analogous to the } \\
\text { integers, namely, they are closed under the operations of addition, } \\
\text { subtraction, and multiplication; add, subtract, and multiply } \\
\text { polynomials. }\end{array}$ & 2 & 2 & 2 & 2 \\
\hline $\begin{array}{l}\text { Understand the relationship between zeros and factors of } \\
\text { polynomials }\end{array}$ & & & & \\
\hline $\begin{array}{l}\text { 3. Identify zeros of polynomials when suitable factorizations are } \\
\text { available, and use the zeros to construct a rough graph of the } \\
\text { function defined by the polynomial. }\end{array}$ & 3 & & & \\
\hline Rewrite rational expressions & & & & \\
\hline
\end{tabular}


6. Rewrite simple rational expressions in different forms; write $a(x) / b(x)$ in the form $q(x)+r(x) / b(x)$, where $a(x), b(x), q(x)$, and $r(x)$ are polynomials with the degree of $r(x)$ less than the degree of $b(x)$, using inspection, long division, or, for the more complicated examples, a computer algebra system.

\section{Creating Equations $\star$ A - CED}

\section{Create equations that describe numbers or relationships}

1. Create equations and inequalities in one variable and use them to solve problems. Include equations arising from linear and quadratic functions, and simple rational and exponential functions.

2. Create equations in two or more variables to represent relationships between quantities; graph equations on coordinate axes with labels and scales.

3. Represent constraints by equations or inequalities, and by systems of equations and/or inequalities, and interpret solutions as viable or nonviable options in a modeling context. For example, represent inequalities describing nutritional and cost constraints on combinations of different foods.

4. Rearrange formulas to highlight a quantity of interest, using the same reasoning as in solving equations. For example, rearrange Ohm's law $V=I R$ to highlight resistance $R$.

Reasoning with Equations and Inequalities A -RE I

Understand solving equations as a process of reasoning and explain the reasoning

2. Solve simple rational and radical equations in one variable, and give examples showing how extraneous solutions may arise.

\section{Solve equations and inequalities in one variable}

3. Solve linear equations and inequalities in one variable, including equations with coefficients represented by letters.

4. Solve quadratic equations in one variable.

a. Use the method of completing the square to transform any quadratic equation in $x$ into an equation of the form $(x-p) 2=\mathrm{q}$ that has the same solutions. Derive the quadratic formula from this form.

b. Solve quadratic equations by inspection (e.g., for $x 2=49$ ), taking square roots, completing the square, the quadratic formula and factoring, as appropriate to the initial form of the equation.

Recognize when the quadratic formula gives complex solutions and write them as $a \pm b i$ for real numbers $a$ and $b$.

Solve systems of equations 
5. Prove that, given a system of two equations in two variables, replacing one equation by the sum of that equation and a multiple of the other produces a system with the same solutions.

6. Solve systems of linear equations exactly and approximately (e.g., with graphs), focusing on pairs of linear equations in two variables.

Represent and solve equations and inequalities graphically

10. Understand that the graph of an equation in two variables is the set of all its solutions plotted in the coordinate plane, often forming a curve (which could be a line).

12. Graph the solutions to a linear inequality in two variables as a halfplane (excluding the boundary in the case of a strict inequality), and graph the solution set to a system of linear inequalities in two variables as the intersection of the corresponding half-planes.

\begin{tabular}{|l|l|l|l|l|} 
& & & & \\
& 2 & & & \\
\hline & 2 & & 2 & 2 \\
\hline ming & & & & \\
\hline a the & 2 & 2 & & \\
\hline & & & & \\
& & & & \\
\end{tabular}




\section{CURRICULUM VITAE}

Lisa Conn

122 Bluestone Road

Morehead, KY 40351
606-474-3269 (W)

606-776-6638 (C)

lconn@kcu.edu

\section{Education:}

Graduate College/University:

_Morehead State University

Degree/s: Master of Arts in Education

Date: August 1, 1998
Undergraduate College/University: Morehead State University

Degree: Bachelor of Business

Administration

Date: May 15, 1993

Graduate College/University:

University of Louisville

Degree/s: Currently pursuing a PHD in Curriculum and Instruction

\section{Work History:}

University

Position

Date

Kentucky Christian University Assistant Professor

2009-Present

- Education professor 2009 - Present

- Equity Committee Co-Chair

- Library Committee Member

- Faculty Advisor to KCU's teacher organization- Pi Chi Delta

- KTIP Teacher Educator

- National Council of Teachers of Mathematics member

- Association of Mathematics Teacher Educators member

- Teaching assignments include: Math for Teachers I and II, Math Methods p-8, Educational Technology, Computer Programming, Introduction to Education, Sophomore and Junior Practicum, History of Mathematics, Learning Theories and Assessment. 


\section{University}

Morehead State University/

Northern Kentucky University

- Liaison between NKU and MSU

- Report development on College Readiness Initiatives

- Research of College Readiness Assessments

- Sharing of organization meeting minutes between universities

- Survey development of College Readiness Initiatives in regional service area
Date

$2011-2012$

\section{University}

Morehead State University

- Classroom Management online course Instructor

\section{Position}

Position

Adjunct Professor

Maysville Community and

Technical College

055 Remedial Math Instructor

065 Remedial Math Instructor
Date

2011

\section{Date}

\section{Position Date}

Mathematics Teacher

2009-2011

Lakeside Christian Academy

High School math teacher

Taught Algebra II and Pre-Calculus

\section{School District}

Rowan County Senior High School

\section{Position}

Mathematics Teacher
Date

2001-2009

- High School math teacher from 2001 to present

- Teach Algebra, Calculus, and Cisco classes

- STLP Coordinator at RCSHS

- Guided STLP students in implementation of a community service Internet Safety Course for elementary students in Rowan County

- Wrote and received two $\$ 500$ academic / attendance Sealmaster grants

- Wrote and received two $\$ 1000$ Community Service Grant

Rowan County Middle School

Math Teacher
$2001-1995$ 
- Goals 2000 Math Resource Teacher from 1999 to 2001

- Seventh Grade Math Teacher from 1995 until 1999.

- Provided technology based In-services for the math and science departments.

- Guided the Student Technology Leadership Program group through the development of RCMS' first Web Site.

- Provided ongoing support for RCMS math teachers by modeling lessons and/or preparing activities.

- Wrote and received a \$15,000 GTE Math/Science Professional Growth Grant.

- Wrote and received a \$2000 Rowan Entrepreneur Venture Grant.

- Wrote and received money from the Kentucky Department of Education Professional Growth Fund.

\section{Nicholas County High School}

High School Math Teacher

1993-1995

- Taught Pre-Algebra, Technical Math, Consumer Math and Algebra I in the 1993-1994 school year.

- Taught Algebra II, Pre-Calculus, Calculus, and Computer Math during the 1994-1995 school year.

\section{Professional Experiences:}

\section{Experience \\ Date}

Attended National Council for Teachers of Mathematics

International Conference

Member of Association of Mathematics Teacher Educators

(AMTE)

Attended AMTE National Conference

Developed Secondary Mathematics Program at KCU

EPSB approved (2011)

Attended KTIP Resource Teacher Certification Class

Presented at Kentucky Council for Teachers of Mathematics

Attended Kentucky Technology Conference

Completed National Board Certification Mentoring Class

Presented at the International T3 Conference

Received National Board Certification

Completed Cisco Certification Course

Attended the AP Calculus Summer Workshop

Presented at the International Teachers Teaching with Technology Conference
2011

2007

2001-2007

2005

2003

2003

2003-2004

2002

2011 and 2006

2011-2008

2011-2008

2001 


\section{Leadership Roles:}

Kentucky Christian Athletic Association (KCAA)

Kentucky Christian Athletic Association Regional Director

- Represent Region 4 of the KCAA at administrative meetings

- Develop plans for league growth

- Schedule regional/state tournaments

- Sanctioning of new sports

- Served on Mr./Mrs. Basketball/Softball selection committee

Lakeside Christian Academy

2003- 2011

Athletic Director

- Charged with the hiring of coaches and developing new athletic programs

Johnson First Church of God

Youth Counselor

- Prepare and present youth lessons for youth group on Sunday and Wednesday nights

- Sunday School Teacher

Lakeside Christian Academy

2003- 2007

School Board Member

- Help make decisions concerning the financial, academic and athletic well-being and growth of Lakeside Christian Academy 